\title{
LA PRATIQUE DE L'ÉCRITURE DANS LES TUILERIES GALLO-ROMAINES
}

\author{
Fabrice CHARLIER
}

Mots-clés. Gaule, Occident romain, tuilerie, tuilier, tuile, brique, graffite, incision de comptage, contrat de louage, contrat de vente, production, historiographie.

Résumé. À l'époque romaine, des matériaux de construction en terre cuite (tuile, brique, tubulure, etc.) ont servi de supports d'écriture. Les textes ont été inscrits avant ou après la cuisson. Dans le premier cas, les graffites ont été réalisés à l'intérieur des tuileries et sont donc pour la plupart l'euvre de tuiliers. Les recherches portant sur ces documents sont plus ou moins développées selon les pay's européens : ce sont les provinces situées sur le limes rhéno-danubien qui ont livré le plus grand nombre de ces inscriptions, mais c'est en (irandeBretagne qu'a été réalisé le seul corpus national. Les grandes catégories de graffites découverts en France sont proches de celles qui ont été observées ailleurs. L'une de celles-ci, les graffites relatifs au travail des tuiliers, fait l'objet d'une étude approfondie. Cies documents et ceux du même type provenant de tout l'Occident romain ont été classés en fonction de leur rôle dans la chaîne opératoire et analysés selon les conditions matérielles, sociales et juridiques de la production. Les graffites on tété réalisés à différents stades de la production :

¿n de l'engagement d'un mouleur à la vente de matériaux. Si l'on excepte les incisions de comptage, la majorité d'entre eux servaient à identifier le travail de mouleurs auvrant dans des ateliers légionnaires. En annexe, l'inventaire des graffites découverts en France et publiés fait connaître 98 documents provenant de 49 communes.

Key-words. Gaul, Roman Western provinces, tilery, tile, tile producer, brick, graffite, count mark, hiring, sale contract, production, istoriography.

Abstract. Roman earthen building materials (tiles, bricks, tubuli...) bore writings. Texts were written before or after firing. In the first case, graffites were scratched in tileries and were consequently made for the most part by tile-makers. Studies on these documents are more or less developed in European countries. Rhineland and Danubian provinces along the Limes have yielded the largest amount of inscriptions but only one general corpus have been so far published, in Great Britain. The categories of graffites discovered in France are close to those known elsewhere. The graffites related to tile production are being here thoroughly studied. This type of document, from the western provinces, has been classified according to their function in the production line and analyzed in accordance with the material, social and juridical conditions of production. Graffites were traced all along the steps of production: from the appointment of a moulder up to the sale. Apart from the count incisions, most of them were used to identify the work of the moulder in legionary workshops. In an appendix, the catalogue of the graffites from France already published includes 98 documents found in 49 localities.

Translation: Isabelle FACDCET

Schlagwörter. Gallien, Westen des Römischen Reiches, Ziegeleien, Ziegler, Dachziegel, Mauerziegel, Graffites, Zählmarken, Dienstleistungsvertrag, Kaufvertrag, Produktion, Geschichtsschreibung.

Zusammenfassung. Verschiedene keramische Baustoffe wie Dach-und Mauerziegel oder Bestandteile der Tubulatur dienen in römischer Zeit als Schriftriüger. Die Texte werden entweder vor oder nach dem Brand angebracht. Ersteres impliziert, daß die Graffites in den Ziegeleibetrieben entstanden, weshalb ein Großteil von der Hand der Ziegler stammen muß. In den verschiedenen europäischen Ländern herrscht zu solchen Funden ein recht unterschiedlicher Forschungsstand. Die Rhein- und Donauprovinzen lieferten zwar die größte Anzahl derartiger Inschriften. Ein landesweites Korpus wurde dagegen bisher nur in Großbritannien erarbeitet. Die Hauptkategorien der in Frankreich entdeckten Graffites entsprechen den anderswo bekannt gewordenen. Eine davon, nämlich die der Graffites aus dem Arbeitsbereich der Ziegler, wird hier näher untersucht. Diese Funde und gleichartige Belege aus dem gesamten Westen des Römischen Reiches werden entsprechend ihrer Rolle innerhalb des Herstellungsvorgangs geordnet und hinsichtlich der materiellen, sozialen und juristischen Rahmenbedingungen der Produktion analysiert. Die Graffites entstanden zu verschiedenen Phasen der Produktion, vom Vertrag mit dem Ziegeleiarbeiter bis zum Verkauf der Ware. Wenn man die Zählmarken ausnimmt, diente der Großteil dazu, die Geverke der in den Legionsziegeleien tätigen Arbeiter zu identifizieren. Der Anhang dieses Beitrags verzeichnet die bislang 98 veröffentlichten Funde aus 49 französischen Gemeinden.

Übersetzung : Stefan WIRTH 
Les matériaux produits dans les tuileries d'époque romaine sont les supports de deux formes épigraphiques : les estampilles et les graffites. Cette étude ne traite que des seconds puisqu'ils témoignent seuls de la pratique individuelle de l'écriture.

Il faut entendre ici par graffites des inscriptions manuscrites tracées dans l'argile. Je ne les définis donc que par leurs seules caractéristiques techniques ${ }^{79}$.

Les graffites portés sur tout objet céramique doivent être distingués selon qu'ils ont ćté inscrits avant ou après la cuisson.

S'il y a postériorité, l'écriture se situc dans un contexte d'usage et incite à identifier le scripteur comme l'utilisateur de l'objet, si ce n'est son possesseur ${ }^{80}$. Les noms inscrits après cuisson, notamment quand ils sont au génitif, sont ainsi interprétés comme des marques de propriété.

Dans le cas de l'antériorité, puisque l'inscription a été portée sur des objets en cours de fabrication, il est certain qu'elle a été réalisée dans le cadre strictement matériel d'un atelier, par un artisan ou par une personne autorisée à pénétrer dans l'atelier et à manipuler les objets durant leur phase de séchage.

Parmi ces documents, les plus connus sont certainement les comptes de potiers portés avant cuisson sur des assiettes ou des plats découverts dans l'atelier de La Graufesenque. La plupart sont interprétés comme des bordereaux d'enfournement (Marichal, 1988). Les graffites aveyronnais et les quelques pièces comparables provenant d'autres ateliers sont des documents capitaux quand il s'agit de restituer l'organisation de la production de poteries et plus particulièrement de céramiques sigillées. D’autres graffites, inscrits également avant cuisson sur des poteries, ne se rapportent pas au travail des potiers et sont de nature plus anecdotique.

De la même façon, les matériaux de construction en terre cuite, c'est-à-dire essentiellement les tuiles - tuiles plates à rebords (tegulae) et tuiles courbes (imbrices) - et les briques, ont reçu des inscriptions avant ou après leur cuisson.

Quand un graffite a été porté après cuisson, il y a dans la majorité des cas détournement d'usage définitif : le matériau de construction n'est plus qu'un support d'écriture. C'est pourquoi les graffites ont généralement été inscrits sur des fragments de matériaux et non sur des pièces entières, plus difficilement manipulables. On peut ainsi appeler ostraka les 18 fragments de tuiles porteurs de graffites cultuels découverts dans le sanctuaire gallo-romain de Châteauneuf en Savoie (Mermet, 1993, p. 126-134). Il en est de même pour les diraines de fragments de matériaux porteurs de chiffres ou de lettres retrouvés à Paris en 1903, lors de la fouille d'une nécropole à incinération de la rue du Hameau (Duval, 1960, p. 155-157, n” 59, et pl. XXIX.C). D'autres graffites fournissent une énumération chiffrée (Lambert, 2002, p. 241-242, *L-94) ou simplement un nom (Desaye, Blanc, 1969, p. 220-221, n" 5b, fig. 11 ; Brun dir., 1989, p. 138, fig. 33, n” 4 et p. 139, tabl. IV). Dans ces cas, il est possible que les matériaux porteurs aient été employés dans la construction.

79. On trouvera dans Pietri, 1983, différentes définitions des graffites antiques.

80. Il n'est évidemment pas question ici des ostraka, ces tessons de poterie remployés comme support d'écriture.
Un détournement de leur fonction initiale est en revanche manifeste dans le cas de matériaux qui ont reçu des inscriptions funéraires. La brique pedalis entière découverte à Angoulême en 1882 en est un bel exemple. Porteuse d'une épitaphe chrétienne datéc de 405, clle était disposée verticalement dans une tombe derrière le crâne du défunt (I c. Blant, 1892, p. 294-295). On pcut la rapprocher d'une pièce trouvée à Worms (Allemagne) : une brique carrée bessalis, dont l'usage habituel cst de former avec ses semblables des pilettes d'hypocauste, porte un formulaire funéraire chrétien (L.e Blant, 1856, p. 462$463, n^{\circ} 348$ et pl. $\left.37, n^{\circ} 224\right)$.

Les circonstances d'écriture, les scripteurs et leurs motivations sont extrêmement variés dans le cas des graffites sur matériaux cuits ${ }^{81}$.

Quant aux graffites portés avant cuisson, ils n'ont pu être inscrits sur les matériaux que dans le cadre même de la production. On peut raisonnablement croire que la plupart sont l'œuvre des artisans eux-mêmes.

Archéologues et historiens se plaignent souvent, et à juste titre, du caractère particl et partial des sources disponibles sur les " humbles " des sociétés antiques. Parmi eux, les céramistes (potiers et tuiliers) sont les artisans qui ont certainement fait l'objet du plus grand nombre de recherches. Mais si les aspects matériels de leur production sont aujourd'hui bien connus, en revanche les cadres sociaux et juridiques qui régissaient leur travail, ainsi que leur statut, leur mentalité, ou simplement l'organisation des ateliers sont sujets à bien des conjectures.

Pourtant, cette source directe que constituent les graffites sur tuiles et briques n'a pratiquement pas été exploitée, sinon épisodiquement pour illustrer des études consacrées aux seuls potiers, et elle est souvent complètement ignoréc par beaucoup de chercheurs français.

Le dédain longtemps de mise chez la majorité des archéologues à l'égard des matériaux de construction en terre cuite est certainement une des raisons principales de cette sousexploitation, confortée durant tout le $\mathrm{xx}^{\mathrm{c}} \mathrm{s}$. par l'absence de curiosité des épigraphistes français à leur égard (voir p. 70-71).

81. Fn outre, on doit signaler que cette écriture sur tuiles romaines peut être beaucoup plus réconte que les matériaux eux-mêmes. De nombreux faux ont en effet été réalisés aux XVII" et XIX"s. Ainsi le site qui aurait été découvert en 1854 à Fontaine-la-Soret (Eure), à proximité de la chapelle Saint-Ëloi, est une supercherie et les quelque 70 graffites sur de grands fragments de tegulae qui sont censés en provenir sont des faux (I.e Blant, 1856, p. 197-217 et pl. 16-19; (iquet, 1993, p. 78, n² 70). Citons quelques autres séries de faux : les dizaines de fragments de tuiles et de briques inscrits provenant du sanctuaire bien réel de Neurysur-Barangeon dans le Cher (Provost et al., 1992, p. 330-331), auxquels on peut rattacher peut-être des pièces qui proviendraient des environs de Vierzon (Bulletin de la Société nationale des Antiquaires de France, 1884, p. 303) ; les huit inscriptions funéraires sur briques associées à d'autres inscriptions sur pierres qui auraient été découvertes à Agen, présentées dans le manuscrit de P. de Beaumesnil en 1772-1773, doivent également être considérées comme fausses (Bladé, 1885, p. 182-185, n" XXVIXXXIV; Fages, 1995, p. 123, n"101 et p. 133, fig. 62). Autres faux : le graflite de Soings-en-Sologne (Loir-et-Cher) qui associc texte et dessin (Dondin-Payre, 1994) et l'inscription sur une brique qui aurait été trouvée au Xvi" s. à Savanac (Lot) dans la maçonnerie du canal de l'aqueduc de Cahors (I abbrousse, Mercadier, 1990, p. 45-47). 
La seconde partie de cette étude, consacrée aux sculs graffites relatifs au travail des tuiliers, propose une classification des documents en fonction de leur rôle dans la production. Mais puisqu'il était indispensable, pour comprendre les excmplaires français, de les rapprocher du plus grand nombre possible de pièces recueillies dans le monde romain, j’ai souhaité dans une première partie proposer un survol des recherches antérieures et une évaluation des ressources documentaires européennes avant de commenter succinctement l'inventaire des graffites découverts en France.

\section{HISTOIRE DE LA RECHERCHE ET RESSOURCES}

L'étude des graffites, quel que soit leur support, a longtemps été négligée par rapport aux autres types d'inscriptions (Pietri, 1983, col. 637).

Pour les graffites sur tuiles et briques, comme bien d'autres probablement, l'humilité du support et les graffites eux-mêmes, souvent courts et, qui plus est, presque toujours incomplets, expliquent certainement ce déficit d'intérêt. À ces raisons subjectives s'ajoute une difficulté bien réelle: lire l'écriture cursive dans laquelle ils ont souvent été rédigés.

L'histoire de la recherche et l'inventaire des ressources actuellement disponibles révèlent des disparités nationales qui tiennent autant à la personnalité des chercheurs qu'à la qualité des pièces et à la chronologie de leur découverte.

\section{EN EUROPE (LA FRANCE EXCEPTÉE)}

Les historiens allemands ont èté les premiers à prendre conscience de l'intérêt de ce type de document épigraphique. Quelques années après avoir publié les graffites pariétaux de Pompéi et d'Herculanum (CII, IV), Karl Zangemeister consacre un article à ces graffites en 1879 , où il compare deux pièces inédites à une série de graffites au formulaire très proche issus de publications récentes de ses collègues allemands. Parmi ces documents figurent certains des fameux graffites de Siscia/Sisak en Pannonie (Croatie), publiés par Theodor Mommsen dans l'Ephemeris Epigraphica en 1875 et 1881 (CIL, III, 11378-11386). K. Zangemeister a également tiré parti du corpus des inscriptions de Rhénanie de Wilhelm Brambach de 1867 et des volumes du CII, publiés à cette époque. Quelques années plus tard, Emil Hübner énumère, dans le volume d'Exempla du $C I L$, les types d'inscriptions sur les différentes catégories de mobilier et consacre à cette occasion un paragraphe aux graffites avant cuisson sur tuiles et briques (Hübner, 1885, p. XLIV-XLV). La rapide classification qu'il propose s'appuie sur des exemples tirés des volumes du CII déjà publiés et des quelques publications citées ci-dessus. La publication du CIL, qui s'est effectućc presque cntièrement entre 1863 et 1907 , a permis de disposer de l'ensemble des graffites inscrits sur les matériaux de construction en terre cuite dans le monde romain $s 2$.

82. Outre la dispersion inévitable de ces documents dans les différents volumes, la rédaction du $(I I$, entraine des difficultés pour qui veut
Les découvertes ultérieures réalisées en Allemagne ont été publiées soit dans des recueils épigraphiques (Riese, 1914, p. 449-450) ; Vollmer, 1915), soit dans des publications archéologiques (Flügel, Schmidts, 2000-2001) ${ }^{8: 3}$. En 1947, dans son étude des estampilles sur les tuiles et les briques, Herbert Bloch a proposé une courte synthèse des graffites contenant une date. Il a rassemblé des exemplaires recueillis en Allemagne et à Siscia (Bloch, 1947, p. 329-330).

L'intérêt des historiens pour les estampilles légionnaires a favorisé les découvertes et l'étude de graffites portés sur les mêmes matériaux. Toutefois, les recherches menées sur les estampilles ne suffisent pas à expliquer le très grand nombre de graffites connus aujourd'hui dans toutes les provinces frontières de l'Europe romaine.

Les publications successives des foulles ou du seul mobilier des camps du limes ont ainsi révélé des séries parfois très importantes de graffites: le camp de Saalbourg dès 1897 (Jacobi, 1897, p. 312-313 et pl. 74), ceux du limes autrichien (Ruzicka, 1919, col. 105-116), parmi lesquels Vindobona/Vienne (Neumann, 1973, p. 50 et 130 et pl. 73-76).

Pour l'ensemble des provinces danubiennes, les nombreux exemplaires fournis par le CIL III ont été enrichis au fur et à mesure de l'ćdition de corpus nationaux. Une étude paléographique rassemble les plus longs graffites retrouvés en Mésie supérieure (Petrovic, 1975, p. 23-42 et 154-155), tandis que les travaux de Nicolac Gudea ont fait comnâtre les plus beaux documents de Dacie (Gudea, 1983, 1988, 1996) et permis une très succincte synthèse pour cette province (id., 1991). Signalons encore une série de graffites en grec inscrits sur des briques découvertes en Thrace, à Serdica/Sofia (Bescvliev, 1952, p. 31-32 et pl. 20-21).

En ce qui concerne l'Europe occidentale la situation est contrastée.

En Grande-Bretagne, Gerald Brodribb, dans ses publications consacrées aux matériaux de construction en terre cuite d'époque romaine, a fait le point sur un type discret de graffites, les tally-marks, ou incisions de comptage (Brodribb, 1979a et b ; 1987, p. 131-135). Les autres graffites découverts dans ce pays ont fait l'objet d'un article de synthèse de Roger Tomlin, qui s'est appuyé sur un premier inventaire national comptant 111 pièces (Tomlin, 1979). Aujourd'hui nous disposons d'un corpus exhaustif des graffites inscrits avant et après cuisson, édité avec les estampilles sur tuiles et briques dans un des volumes de The Roman Inscriptions of Britain (RJB, II-5, n' 2491 ; Frere, Tomlin, 1993), corpus mis à jour ammuellement dans la revue Britannia.

La documentation est beaucoup plus disperséc dans les autres pays.

Les graffites recueillis en Italie ne semblent pas avoir suscité le même intérêt que les estampilles, il est vrai incompara-

travailler sur les graffites des tuiles et des briques. Aucune information n'est domnée sur les matériaux, qu’il n’est pas toujours possible de déterminer avec certitude - le mot tegula étant employé pour désigner autant une tuile qu'une brique - et, plus grave, la précision de l'antériorité ou non de l'inscription sur la cuisson manque souvent.

83. D’autres références bibliographiques sont fournies dans les pages suivantes pour quelques pièces étudiées. 
blement plus nombreuses. Depuis la parution du CIL, ils ont souvent été édités avec les estampilles, parfois placés en annexe (Steinby, 1977-1978, p. 368-369 et pl. 222-224 ; Bodel, 1983, p. $71 \mathrm{et} \mathrm{pl.} \mathrm{28).} \mathrm{Les} \mathrm{plus} \mathrm{belles} \mathrm{pièces} \mathrm{ont} \mathrm{fait} \mathrm{l'objet} \mathrm{d'articles}$ indépendants, notamment la tegula de Sant'Angelo in Formis publiée par K. Zangemeister (Zangemeister, 1894; AE, 1894, $\left.\mathrm{n}^{\circ} 159\right)$, la brique de San Quirino $\left(A E, 1939, \mathrm{n}^{\circ} 141\right)$, la brique de Cesena ( $\left.A E, 1978, \mathrm{n}^{\circ} 334\right)$, la brique de Pietrabbondante et la tegula de Pellaro (Morel, 1991).

La situation est comparable en Espagne pour laquelle le paléographe français Jean Mallon a consacré une série d'études à quelques documents remarquables : les briques d'Aceuchal en 1948 et d'Italica en 1952, la tegula de Villafranca de los Barros en 1973 et 1977 (études rassemblées dans Mallon, 1986). Il a également fourni un inventaire de 67 graffites avant cuisson sur des briques découvertes dans l'ensemble du monde romain (Mallon, 1952, p. 63-65). Cet auteur n'a cessé de souligner et de démontrer l'intérêt de ce type de documents dans l'étude de l'évolution de l'écriture latine. Enfin, toujours dans la péninsule Ibérique, un lot exceptionnel de graffites sur tuiles et briques a été mis au jour sur le site de Conimbriga/Coimbra au Portugal (Étienne et al., 1976) ; une nouvelle étude de ce lot, enrichie d'autres pièces de Lusitanie occidentale, a été publiée récemment (Correia et al., 2001).

\section{EN FRANCE}

Le premier graffite découvert en France et publié semble être le celui de Vendémian en 1832 (34.1) ${ }^{84}$. Du milieu du $\mathrm{XIX}^{\mathrm{e}}$ s. à la publication complète du CIL XIII (Gaules et Germanies) en 1907, des inscriptions de ce type ont été régulièrement publiées (dans l'ordre chronologique : 38.2, 27.2, 27.1, 86.1, 88.1, 86.2, 21.3, 83.4, 83.2, 13.1, 38.1), dont, dès 1858 , les premières découvertes effectuées à Châteaubleau en Seine-et-Marne (77.1-77.3). Si certaines ne sont que signalées, d'autres sont intégrées à des corpus épigraphiques dont quelques-uns retiennent même les lettres isolées tracées au doigt (06.1, 74.1). Le corpus établi par Auguste Allmer comporte ainsi tous les graffites sur tuiles ou briques de la cité de Vienne ${ }^{85}$. Notre connaissance de ces pièces doit beaucoup à l'activité des membres épigraphistes de la Société impériale, puis nationale, des Antiquaires de France, qui en ont publié presque la moitié dans leur bulletin.

Ensuite, jusqu'aux années 1930, ces graffites se font plus rares dans les publications archéologiques et, si l'on excepte les découvertes effectuées à Strasbourg, seules les pièces remarquables sont éditées. Que ce soit les tegulae de Rennes (35.1), de Montenach (57.1) ou d'Auzéville-en-Argonne (55.2), il s'agit toujours de matériaux entiers ou presque, porteurs de graffites

84. Les numéros en gras dans le texte renvoient, dans l'inventaire placé en annexe, à ceux des graffites.

85. Ces graffites sont les $n^{\circ \times} \mathbf{3 8 . 2}$ et 74.1, deux autres découverts à Genève et un dernier probablement réalisé après cuisson (Allmer, Terrebasse, 1875-1876). de plusieurs lignes. Le cas est différent pour Argentorate/ Strasbourg. Dans les publications des fouilles qu'il a réalisées dans la ville, Robert Forrer fait connaître, en 1913 et 1919, sept graffites épigraphiques, la plupart très courts et incomplets (67.1-67.7). Il s'agit alors du plus grand nombre de documents de ce type retrouvé en France sur un même site. La plupart sont issus de tuileries légionnaires qui dépendaient du camp romain de Strasbourg. Leur origine, leur nombre et leur formulaire les rapprochent des exemplaires découverts dans les régions rhénanes et danubiennes. Il est d'ailleurs significatif que l'un des graffites strasbourgeois, composé d'un formulaire très fréquent sur le limes, ait été mal lu par R. Forrer et parfaitement compris par un archéologue allemand, Emil Ritterling (67.6).

Dans la période troublée de l'avant-guerre à l'après-guerre, une seule pièce est publiée (83.3).

À partir des années 1950, les graffites, même modestes, apparaissent plus régulièrement dans les publications. Le Bulletin de la Société nationale des Antiquaires de France en accueille à nouveau quelques-uns (26.1, 38.1-38.2) et édite les contributions de J. Mallon sur la tuile espagnole de Villafranca de los Barros en 1973 et 1974. Mais la plupart de ces documents sont édités dans une multitude de publications (ouvrages, monographies, comptes rendus de fouilles, revues nationales et locales) et, rarement repris dans des publications synthétiques ou spécialisées, ils ne bénéficient pratiquement jamais d'une véritable étude épigraphique ${ }^{86}$.

Si au XIX s. en France, ce type de graffites est publié et étudié par les épigraphistes, ces derniers semblent s'en désintéresser au siècle suivant, alors que de nouveaux graffites, parfois remarquables, sont publiés par les archéologues. Ce désintérêt, ou plus probablement une méconnaissance de ces pièces, est clairement exprimé par René Cagnat en 1914. Dans la $4^{r}$ édition de son fameux traité d'épigraphie, après avoir consacré six pages aux estampilles sur les briques et les tuiles, il fait un sort aux graffites en quelques lignes : " Il ne peut être question qu'en passant des graffites qu'on traçait sur des briques ou autres poteries. Il en est de très intéressants comme d'insignifiants ; c'est ce qu'on peut dire, du reste, de tous les graffites, où qu'ils aient été gravés; mais il serait difficile de les classer en des catégories bien tranchées. " (Cagnat, 1914, p. 343), et il ne fournit aucun exemple de ces pièces. Les travaux des épigraphistes allemands avaient pourtant déjà révélé l'existence de quelques " catégories bien tranchées " et parfaitement illustrées par des exemples du CIL. À la décharge de R. Cagnat, il faut reconnaitre que les graffites recueillis en France à l'époque étaient non seulement beaucoup moins nombreux que dans les régions du limes, mais présentaient une plus grande diversité de formulaires.

Les nouvelles découvertes de graffites à partir des années 1950, liées au développement de l'archéologie, ne vont pas susciter davantage l'intérêt des épigraphistes. En 1982, J. Mallon regrettait l'absence de recherche sur ces pièces dans une note parue dans un catalogue consacré notamment aux fouilles de

86. Il est révélateur que les pièces intégrées dans les catalogues épigraphiques soient très rares (05.1; 55.2 dans Wuilleumier, 1963. p. $\left.210-211, \mathrm{n}^{\circ} 533\right)$. 
Châteaubleau. Cette publication lui donna l'occasion d'attirer une nouvelle fois l'attention de ses collègues épigraphistes et paléographes sur ces documents : "Il faut se pénétrer de cette idée qu'un méchant morceau de tuile cassée portant quelques lettres, oublié dans une vitrine poussiéreuse d'un petit musée archéologique, mérite le même respect et la même attention que tel misérable débris de papyrus [...]. Tout, ou presque tout, est à faire dans l'ordre des monuments ainsi écrits sur terre ultérieurement cuite dans toute l'étendue du monde romain où ils ont pu se conserver, dans tous les sols et sous tous les climats " (in Burin dir., 1982, p. 29).

Si certains documents écrits avant ou après cuisson découverts en France ont été soumis à des paléographes et des linguistes, dont Michel Lejeune, Robert Marichal et Charles Perrat (Lambert, 2002, p. 241-242, *L-94 ; 26.1 ; 63.1 ; Lambert, 1998, p. 666 pour les graffites $\mathbf{7 7 . 5 , 4 6 . 1}$ et $\mathbf{4 6 . 5}$ ), leur intérêt s'est surtout porté sur les graffites inscrits sur les poteries ${ }^{87}$. On pourrait en dire autant des chercheurs allemands qui, durant la même période, ont publié des corpus de graffites sur des poteries (Bakker, Galsterer-Kröll, 1975), tandis que les graffites sur les tuiles et les briques sont restés dispersés dans la bibliographie.

L'absence d'étude spécifique menée sur ces documents explique que plusieurs graffites découverts en France n'ont plus été publiés depuis leur première édition au $\mathrm{XIX}^{\mathrm{e}} \mathrm{s}$. ou à peine signalés, et que d'autres, simplement signalés au siècle suivant, ne sont connus par aucune illustration (35.1, 55.1-55.2).

En outre, on constate que la multiplication des fouilles de sauvetage de ces vingt dernières années en France n'a pas provoqué une multiplication des découvertes, ou plus exactement une multiplication de signalements de ces documents. Le temps accordé aux responsables des opérations de fouilles pour publier leurs résultats et les compétences particulières nécessaires à l'étude de ces pièces suffisent en grande partie à expliquer ce fait.

À partir des années 1980, la collection de la Carte archéologique de la Gaule, sous la direction de Michel Provost, a permis de rassembler ces pièces au fur et à mesure de la publication des volumes départementaux. Rares sont les graffites publiés antérieurement qui n'y figurent pas et certains volumes en fournissent une précieuse illustration, en particulier pour le département du Var (Brun, Borréani, 1999).

Plusieurs publications, au tournant des $\mathrm{Xx}^{\mathrm{e}}$ et $\mathrm{XXI}^{\mathrm{e}} \mathrm{s}$., semblent amorcer une nouvelle période. En quelques années, plus de pages ont été consacrées aux graffites que durant les cent cinquante années précédentes. Ces derniers travaux suivent deux voies de recherches complémentaires. Certains exploitent ces documents pour tenter de restituer les modalités de la production dans les tuileries gallo-romaines. Outre cette présente étude, un article précédent abordait les modalités socio-juridiques du travail à l'aide de trois sources : les graffites, les marques digitées et les estampilles (Charlier, 1999).

L'autre voie de recherche est de nature paléographique et linguistique, et trouve son origine dans la découverte à

87. R. Marichal dans Les graffites de La Graufesenque utilise comme documents de comparaison quelques graffites sur briques et tuiles (1988, p. 17-19).
Châteaubleau en 1997 d'un graffite entier de 11 lignes, en gaulois, sur une tegula. Le paléographe celtisant Pierre-Yves Lambert publie non seulement ce document mais également, et de manière exhaustive, le lot exceptionnel de graffites épigraphiques inscrits avant cuisson sur les tuiles et les briques trouvées depuis le $\mathrm{XIX}^{\mathrm{e}} \mathrm{s}$. sur la même commune (77.1-77.17) et à proximité (77.18). Tous les documents, en latin et en gaulois, sont édités avec un riche commentaire (Lambert, 1998, 19982000a et b ; 2002). Dans le Recueil des inscriptions gauloises: textes gallo-latins sur instrumentum, P.-Y. Lambert publie et commente, outre les documents en gaulois de Châteaubleau, sept autres graffites avant cuisson trouvés en France (21.3, 46.1, 46.5, 63.2, 71.1) et en Autriche (Lambert, 2002). Le même chercheur édite également en 2001 un autre graffite provenant de fouilles effectuées à Sains-du-Nord (59.2).

\section{LES GRAFFITES DÉCOUVERTS EN FRANCE}

L'inventaire des graffites épigraphiques gallo-romains et mérovingiens placé en annexe compte 98 pièces découvertes en France et publiées. Il ne recense que les graffites portés avant cuisson sur les matériaux de construction en terre cuite ${ }^{88}$.

Les graffites anépigraphes (dessins, marelles) ont été écartés, ainsi que tous ceux qui ont été inscrits sur les pesons ${ }^{89}$ et sur les matériaux destinés à l'agencement interne des fours à sigillées (tubulures, pseudo-tournettes, supports) ${ }^{9}$.

J'ai retenu comme cadre chronologique la Gaule romaine et mérovingienne pour plusieurs raisons. Ne présenter que les graffites gallo-romains m'aurait obligé à conserver ou à écarter arbitrairement des exemplaires découverts dans des contextes " tardifs ». En outre, il est logique de présenter avec les graffites gallo-romains les quelques exemplaires qui sont (peut-être) mérovingiens, car ceux-ci constituent les derniers témoignages en Gaule de cette écriture antique sur les briques et les tuiles. Cette pratique est en effet tombée complètement en désuétude durant le Moyen Âge en France. Cette disparition va de pair avec le déclin de la production de ces matériaux durant le haut Moyen Âge. Cependant la reprise de cette production au bas Moyen Âge semble n'avoir suscité aucune pratique scripturale. Il faut attendre la Renaissance pour voir des graffites réapparaître sur les tuiles et les briques.

88. L'inventaire a été clos le 30/09/2003. À cette date, je n'ai retenu que les graffites pour lesquels $j$ 'avais la certitude qu'ils avaient été écrits avant cuisson.

89. Les pesons faisaient partie de la gamme de production de certaines tuileries, par exemple à Conimbriga (voir p. 81) ou à Salles-la-Source dans l'Aveyron (Llech, 1990, p. 107 et 110, fig. 31). Ce dernicr atelier a livré des pesons sur lesquels a été incisée une lettre. Six lettres différentes ont été dénombrées. Le marquage des pesons demanderait une étude à part entière, c'est pourquoi j’ai préféré ne pas les inclure dans ce travail.

90. Ces matériaux inscrits se rencontrent dans plusieurs ateliers de sigillées: Lezoux (Bet, Delage, 1993), Gueugnon (information de J.-C. Notet) ou l'Argonne (Chenet, 1941, p. 52-54 ; Chenet, Gaudron, 1955 , p. 89, 92 et 96 ; Feller, Brulet, 1998, p. 310-313). 


\section{NATURE DU SUPPORT}

On peut restituer ainsi le " parcours " d'une tuile ou d'une brique avant sa cuisson.

Le matériau, une fois moulé, passe de la table de moulage au sol sablé d'une aire de séchage. I.orsqu'il a acquis une certaine fermeté, on le dresse sur un côté pour parfaire son séchage. Une fois sec, il est entreposé sous une halle jusqu'à ce que le tuilier dispose d'une quantité suffisante de matériaux à cuire.

À chacune de ces phases, un matériau peut recevoir un graffite dont l'aspect va dépendre de la maîtrise scripturale de son auteur et surtout du degré de séchage du support.

Juste après le moulage, l'argile qui compose le matériau est si molle que tout objet posé sur lui suffit à le marquer. Le scripteur peut utiliser son doigt, un bâton, ou un véritable instrument d'écriture (calame ou stylet) ${ }^{91}$. Le déplacement de l'instrument laisse généralement des traits profonds, ourlés par le refoulement de l'argile et parfois refermés par la pression subie lors de l'exécution de traits voisins. La largeur et la profondeur des traits dépendent de l'instrument utilisé. Au fur et à mesure du séchage, le scripteur est obligé d'exercer une pression de plus en plus forte. Une fois qu'il est sec, seule une pointe permet de tracer des lettres en entamant superficiellement le matériau.

Les graffites réalisés avant cuisson présentent donc des aspects très différents sclon la dureté du support. Le séchage est un processus continu, mais, par souci de simplification, on ne distingue généralement que deux catégories de graffites, les uns réalisés sur argile molle et les autres sur argile dure. Si les premiers sont très caractéristiques, il convient de ne pas confondre les seconds avec des graffites réalisés après cuisson ${ }^{92}$.

Des graffites ont été inscrits sur tous les types de matériaux en proportion variable, que ce soit des tuiles, des briques ou des matériaux plus particuliers. Il est impossible de connaître les parts respectives de ces matériaux dans la production globale de la Gaule, mais elles pourraient assez. bien correspondre aux pourcentages de graffites que l'on y trouve inscrits (tabl. III). Les scripteurs n'ont donc pas, semble-t-il, choisi un matériau plutôt qu'un autre, ils ont fort logiquement écrit plus souvent sur les matériaux les plus nombreux. L'imbrex est la seule exception à cette correspondance. La forme courbe de cette tuile, qui en faisait un support d'écriture peu pratique ${ }^{93}$, suffit certainement à expliquer le faible pourcentage de graffites qui y ont été inscrits.

91. R. Étienne et G. Fabre ont pu identifier les instruments utilisés à Conimbriga (Portugal) : un style végétal (calame), une pointe métallique (stylet) ou le doigt (Étienne et al., 1976). Rares sont les publications de graffites qui fournissent des renseignements aussi précis à ce sujet.

92. Ces observations ont déjà été fort bien formulées par R. Marichal (1974, p. 88-89) pour les graffites de La Graufesenque et à nouveau par P. Bet et R. Delage (1993, p. 306) pour ceux qui figurent sur les diverses productions et le matériel d'enfournement des ateliers de Ic\%oux.

93. En outre, en début de séchage, à moins que l'imbrex ne soit encore sur la forme courbe en bois qui permet te la cintrer, il est probable qu'y inscrire un graffite risque de la déformer.

\section{TYPES DE GRAFFITES}

La majorité des graffites présente des textes amputés qui sont, de ce fait, le plus souvent incompréhensibles.

Les textes enticrs ou facilement restituables, que nous comprenons, peuvent être classés en quelques grandes catégories.

Une catégorie comprend tous les graffites relatifs au travail des tuiliers. Ces documents très divers dans leur contenu comme dans leur forme sont l'objet de la seconde partie de cette étude.

Les abécédaires, et par extension les exercices d'écriture plus développés, forment un groupe bien défini. Quatre abécédaires ont été découverts en France (12.1, 77.4, 77.17 et 16.1).

Les textes à caractère littéraire sont suffisamment nombreux pour être distingués. Ils se composent notamment de graffites métriques découverts dans tout l'Occident romain, dont plusieurs citations de Virgile ( $R I B$, II-5, $\mathrm{n}^{\text {os }}$ 2491.146-2491.148; Mallon, 1986, p. 132-166). Le graffite de Grand est incomplet mais doit probablement être rattaché à cette catégorie $\mathbf{( 8 8 . 1 )}$. Elle compte aussi le verset 1 du Psaume I inscrit sur une brique découverte dans le monastère de Pental à Saint-Samson-de-laRoque (27.2). Ce dernier exemplaire est comparable à deux autres extraits bibliques présents sur des briques trouvées en Espagne (Mallon, 1986, p. 146-147 et p. 222-225) ${ }^{9-4}$.

On peut probablement établir une catégorie "épitaphes ", dans laquelle se place la tegula de Droussas avec un graffite mixte, texte-dessin (26.1) ${ }^{9}$. Si l'inventaire ne s'était pas limité aux seuls graffites épigraphiques, cette catégorie compterait plusieurs autres tuiles sur lesquelles sont figurées des scènes de chasse, représentations auxquelles on attribue un symbolisme funéraire (Combier, Conry, 1995, p. 160-161).

Une catégorie est composée de noms, seuls ou sous forme de liste (38.2). Certains ont pu servir à identifier des lots de matériaux (voir p. 80-81), mais d'autres, qu'ils appartiennent ou non à des tuiliers, n'ont certainement joué aucun rôle dans la production.

On comptc enfin quelques graffites plus longs, très divers.

Certains ne sont qu'anecdotiques : un nommé Achille nous apprend sur l'un qu'il a donné une amphore de vin aux céramistes, et sur un autre c'est un certain Atcuritus qui déclare son désir pour Heutica par des termes et une image que l'on qualifiera d'explicites (34.1 et 86.1) (fig. 49). Enfin, un compte de boucher a été porté sur une brique (59.2). Ce dernier document prouve que des personnes étrangères à la production ont écrit sur des matériaux.

Deux graffites découverts à Châteaubleau sont d'une autre nature. Écrits en gaulois, ils ne sont que très partiellement compris : l'un fait référence à un sanctuaire (77.5), et l'autre pourrait être une composition littéraire produite à l'occasion d'un mariage (77.16). I eur inscription sur des tuiles aurait servi

94. J. Mallon précise que l'une d'elles peut être datce du $\aleph^{\circ}$ au vi"s. d'après la paléegraphice. Le contexte de découverte et la paléographie du graffite de Saint-Samson-de-lat-Roque le placent à une date encore plus basse : vi"-vitr"s.

95. Outre cette piece, trois autres en Fance associent texte et dessin, les n" 16.1, 77.14 el 86.1 (fig. 49). 
Tabl. III - Types de matériaux porteurs de graffites découverts en France.

\begin{tabular}{|c|c|c|c|}
\hline Matériaux & Nombre & $\%$ & $N^{0}$ d'inventaire des graffites \\
\hline Tegula & 49 & 50,0 & $\begin{array}{l}04.1-04.5 ; 05.1 ; 15.1 ; 16.1 ; 24.1 ; 26.1 ; 27.1 ; 34.1 ; 35.1 \\
38.1 ; 46.1-46.5 ; 55.1,55.2 ; 57.1 ; 63.1,63.4,63.5 ; 67.1 \\
67.5,67.7,67.9 ; 70.2 ; 74.1 ; 77.2,77.4,77.5,77.9,77.10 \\
77.13-77.18 ; 83.1-83,4 ; 85.1 ; 88.2,88.3\end{array}$ \\
\hline Imbrex & 8 & 8,2 & $11.1 ; 21.1,21.3 ; 63.3 ; 71.1 ; 72.1 ; 77.6,77.8$ \\
\hline Tegula ou imbrex & 4 & 4,1 & $67.3,67.10 ; 77.1,77.12$ \\
\hline Antéfixe & 1 & 1,0 & 63.2 \\
\hline Brique carrée & 5 & 5,1 & $\begin{array}{l}\text { - bessalis : } 21.2 ; 67.2,67.4 \\
\text { - sesquipedalis : } 67.6 \\
\text { - indéterminé : } 70.1\end{array}$ \\
\hline Brique rectangulaire & 2 & 2,0 & $27.2 ; 59.2$ \\
\hline Brique carrée ou rectangulaire & 19 & 19,4 & $\begin{array}{l}31.1-31.7,31.9-31.12 ; 38.2 ; 67.8 ; 74.2 ; 77.3,77.11 ; 86.1, \\
86.2 ; 88.1\end{array}$ \\
\hline Brique quart-de-rond & 1 & 1,0 & 87.1 \\
\hline Tuyau & 1 & 1,0 & 12.1 \\
\hline Matériau indéterminé & 8 & 8,2 & $\begin{array}{l}\text { - tegula ou brique }: 06.1 ; 31.8 ; 35.2 ; 59.1 ; 81.1 \\
\text { - non précisé : } 13.1 ; 66.1 ; 77.7\end{array}$ \\
\hline Total & 98 & 100 & \\
\hline
\end{tabular}

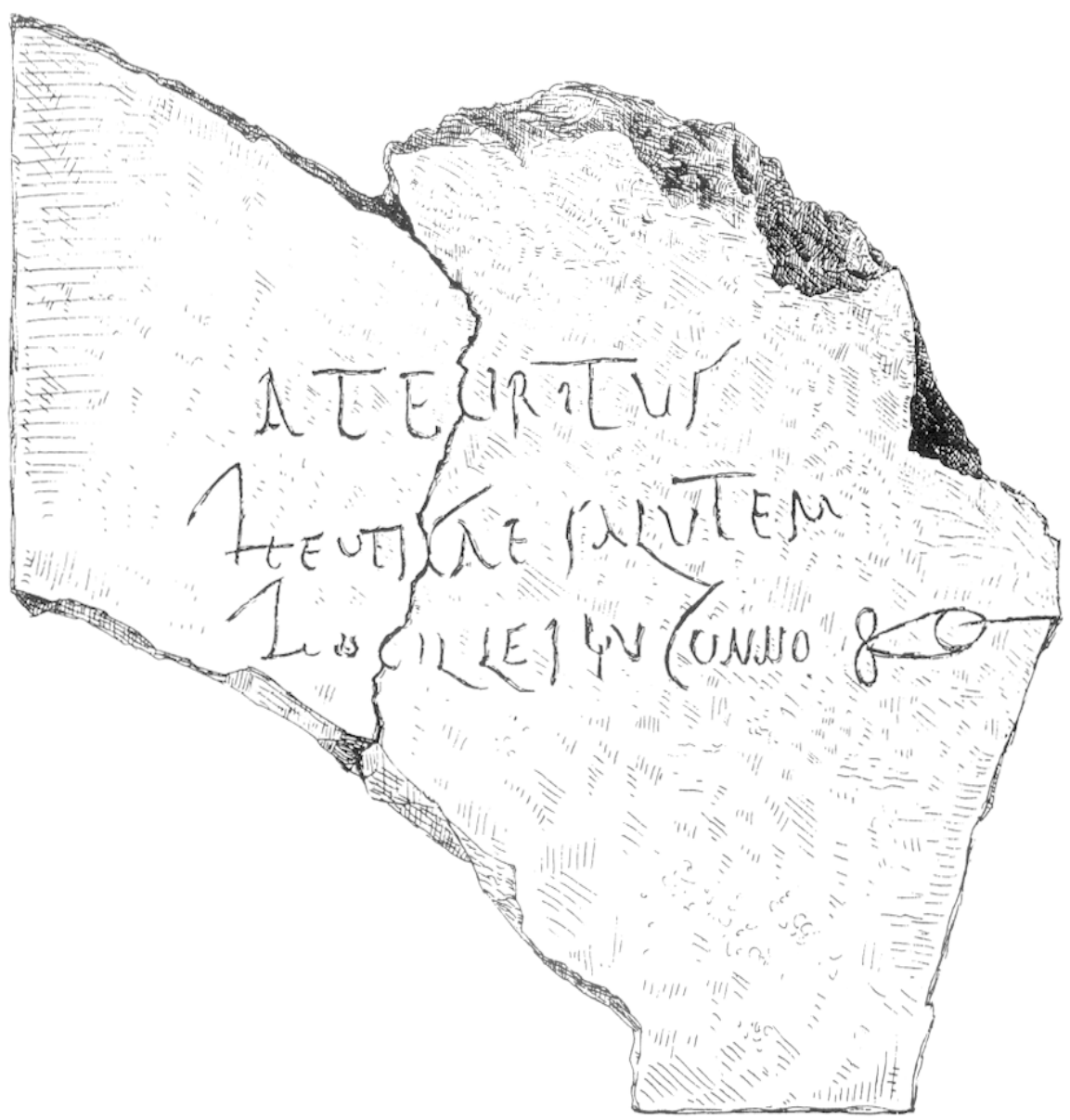

Fig. 49 - (iraffite sur une brique découverte à Poitiers : 86.1 (d'après Mowat, 1873, p. 82 ins). Sans échelle. 


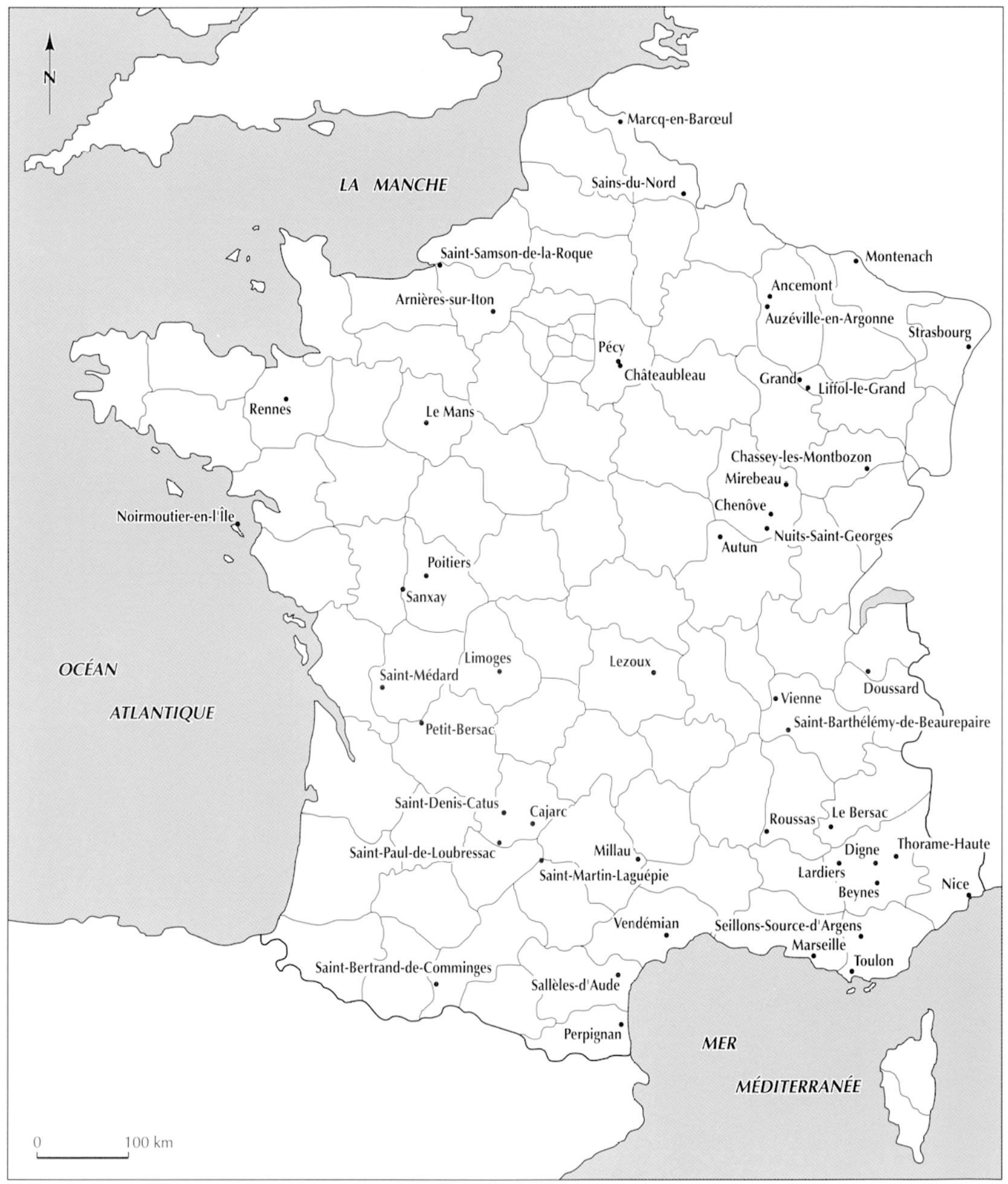

Fig. 50 - Carte de localisation des graffites (DAO F. Charlier).

à les conserver, voire à les afficher, de façon temporaire toutefois puisque les deux matériaux ont terminé leur existence sur un toit ${ }^{96}$.

96. La seule pièce comparable est la tegula de Villafranca de los Barros (Espagne), porteuse d'un graffite relatif à la condamnation d'un
Avec ces deux derniers graffites, P.-Y. Lambert recense cinq graffites gaulois, parfois mêlé de latin $(\mathbf{4 6 . 2}, \mathbf{7 7 . 5}, \mathbf{7 7 . 6}, \mathbf{7 7 . 1 6}$, 77.18), et trois autres qui comportent peut-être des éléments celtiques $(21.3,46.5,71.1)$ (Lambert, 2002).

esclave. J. Mallon y voit un écritcau placé sur le licu où un condamné a subi un châtiment public (Mallon, 1986, p. 322-325 et 330). 


\section{GÉOGRAPHIE DES GRAFFITES}

L'inventairc ne répertorie qu'une partie des graffites découverts en France; il est sûr que quelques-uns ont échappé au dépouillement bibliographique tandis que d'autres n'ont pas (encore) été publiés. Toutefois le nombre d'exemplaires inventoriés me semble suffisamment élevé pour nous renseigner sur la géographie de cette écriture tégulaire.

La répartition géographique des graffites pourrait faire l'objet d'une analyse détaillée qui prendrait en compte les types et la chronologie des documents. Je me contenterai ici d'un commentaire succinct de leur localisation sur le territoire français (fig. 50). La Narbonnaise est particulièrement riche en graffites, puisque sur les 49 communes françaises qui en ont livré un tiers sont situées dans cette province.

La carte montre surtout une nette concentration de graffites sur toute la frange est du pays, axe de grande circulation entre l'Italic et le limes rhénan.

À l'échelle de la Gaule, la correspondance est remarquable entre la localisation des graffites et les voies principales les plus anciennes aménagées par les Romains. Les lieux de découverte jalonnent ces voies directement ou à une distance de quelques kilomètres seulement. Le long de la côte méditerranéenne, l'axe Italic-Espagne était composé à l'est du Rhône par la via Aurelia (Nice, Toulon et Marseille) et à l'ouest par la via Domitia (Vendémian, Sallèles-d'Aude et Perpignan). L'axe rhodanien permettait de joindre la Méditerranée à Lyon (Roussas et Vienne). De là se poursuivait le réseau routier d'Agrippa. À l'ouest, une voie conduisait vers les Santons et l'Aquitaine (Lezoux et Limoges) et au nord-ouest une autre menait vers l'Océan (Autun et Châteaubleau/Pécy). Enfin une voic se dirigeait vers le Rhin, reliant Lyon à Mayence (Nuits-SaintGeorges, Grand/Liffol-le-Grand et Montenach).

Dans le nord-est de la Gaule encore, l'implantation de la VIII" légion est à l'origine de nombreux graffites trouvés sur les sites de Strasbourg et Mirebeau/Chenôve.

En ce qui concerne les productions militaires, on doit citer le cas de graffites présents sur des matériaux de la Classis Britannica découverts à Boulogne ${ }^{97}$, ville d'arrivée de la voie de l'Océan. Aucune relation en revanche ne peut être établie à Saint-Bertrand-de-Comminges entre les graffites sur briques et l'occupation militaire du III' $^{\circ}$ s. attestée par un camp.

\section{GRAFFITES RELATIFS AU TRAVAIL DES TUILIERS}

Le classement adopté repose sur un principe différent de celui qui a été retenu par $\mathrm{S}$. Frere et $\mathrm{R}$. Tomlin pour présenter les documents retrouvés en Grande-Bretagne. Cette différence ne tient pas à la nature des graffites eux-mêmes mais aux objectifs visés. Le RIB est un corpus épigraphique qui rassemble toutes les pièces, inscrites avant et après cuisson, classées en catégories qui sont fondées sur la nature des mots utilisés plus

97. Boulogne ne figure pas sur la carte puisque les lieux de découverte des incisions de comptage n’y sont pas portés (voir p. 83-85). que sur le sens du texte entier. Ainsi, par exemple, la première catégorie de la partie "Tile-making " regroupe tous les graffites qui comportent le nom d'un matériau, tegula, tubus... ou le terme fecit, même si c'est là leur seul point commun. Ce critère de distinction épigraphique est de nature objective, il est donc très pratique dans l'établissement d'un corpus, mais, utilisé seul, il est trop limitatif pour que les groupes obtenus rendent compte des raisons d'être des graffites et des motivations des scripteurs.

Pour comprendre ces graffites, il est indispensable de les étudier non pour ce qu'ils sont aujourd'hui, des documents épigraphiques isolés, mais pour ce qu'ils étaient, des " outils" épigraphiques utilisés par les tuiliers pour réaliser leur travail. J'ai tenté, en établissant le classement ci-dessous, de replacer les différents graffites dans la chaîne opératoire. Les pièces ont été distribuées en sept catégories principales désignées par : "Un instrumentum de louage d'ouvrage ", "Lettres digitées ", " Identification de production de mouleurs ", "Pièces diverses ", "Incisions de comptage ", "Documents de nature commerciale " et "Relations entre tuiliers ». À la lecture de ces titres on devinera aisément que les différents types de graffites ont été inégalement compris.

Ce travail, fondé sur l'examen de plusicurs centaines de graffites découverts dans toute l'Europe romaine, ne mentionne que quelques dizaines d'exemplaires. Seuls les graffites intégralement conservés ont été retenus. Dans les faits, cette intégrité n'est certaine que si les matériaux sont entiers, ce qui est rare, j’ai donc dû enrichir cette sélection par des graffites, apparemment entiers, présents sur quelques grands fragments ${ }^{98}$. Des graffites incomplets ont été aussi exploités mais seulement de manière ponctuelle.

\section{UN INSTRUMENTUM ${ }^{99}$ DE LOUAGE D'OUVRAGE}

Le texte inscrit sur une brique bipedalis découverte en Italie à Sant'Angelo in Formis (près de Capoue) constitue, à ma connaissance, un document unique sur ce type de support (Zangemeister, 1894 ; $A E, 1894, \mathrm{n}^{\circ} 159$ ).

Le graffite est centré et orné à ses angles de courtes lignes foliacées. Sa transcription est la suivante :

$$
\begin{aligned}
& \mathrm{N} \cdot \mathrm{D} \cdot \overparen{\mathrm{ET}} \cdot \mathrm{C} \\
& \text { Idibus Iul(i)is Celer finget } \\
& \text { bipedas VXXXI } \\
& \text { Actum Casilino } \\
& \text { Modesto II et Probo co(n)s(ulibus) } \\
& \text {-. - }
\end{aligned}
$$

98. Il est souvent difficile d'évaluer l'intégrité d'un texte inscrit sur un fragment et les publications ne sont pas toujours d'une grande aide. Les signes conventionnels utilisés dans l'édition de documents épigraphiques sont rarement suffisants pour nous renseigner avec la précision nécessaire, d'autant plus que l'ordonnance des graffites tégulaires n'atteint jamais la régularité des inscriptions lapidaires. I a publication de ces documents devait donc toujours comporter au moins unc reproduction qui montre la totalité du matériau conservé et non pas sculement des rues du graffite lui-même.

99. Instrumentum est employé ici dans un sens juridique. En droit romain, le terme instrumentum désigne l'écrit qui établit l'existence et le contenu d'un acte juridique. 
On peut le traduire ainsi :

$\mathrm{N} \cdot \mathrm{D} \cdot \widehat{\mathrm{ET}} \cdot \mathrm{C}$;

"Pour les ides de juillet, Celer façonnera

5031 briques bipedales.

Fait à Casilinum.

Sous le deuxième consulat de Modestus et sous celui de Probus."

$$
\text { -.. }
$$

Les abréviations de la première ligne ne sont pas comprises. Le reste du texte est clair : un nommé Celer s'engage à façonner 5031 briques bipedales pour le compte d'un patron de tuilerie. Celle-ci ne peut être située qu'à Casilinum, où le texte a été écrit. La date mentionnée en deuxième ligne (les ides de juillet, soit le 15 juillet) constitue probablement le terme de ce contrat. La mention des consuls éponymes indique l'année, soit 228 apr. J.-C. Une brisure du matériau ne permet pas de lire la dernière ligne ; je suppose qu'elle comportait la souscription des intéressés.

Le caractère formel de ce graffite et son ordonnance attestent indéniablement une volonté de lui donner la solennité propre à un acte juridique. La forme juridique qui, dans le droit romain, correspond le mieux à la situation contractuelle à laquelle semble se référer le texte est le louage, plus précisément le louage d'ouvrage.

On distingue, en droit romain, trois types de louages : la locatio rei (le louage de chose, dit aussi contrat de bail), la locatio operarum (le louage de service, dit aussi contrat de travail) et la locatio operis faciendi (le louage d'ouvrage, dit aussi louage d'entreprise). Ces contrats ont pour éléments communs un bailleur (locator), un preneur (conductor) et une rémunération.

Seuls nous intéressent les deux louages qui concernent le travail. Dans la locatio operarum, un ouvrier (locator) met son activité, c'est-à-dire ses journées de travail (operae), à la disposition d'un employeur (conductor) qui s'engage à lui verser en contrepartic un salaire. Dans la locatio operis faciendi, les rôles de locator et de conductor sont inversés puisqu'une personne (locator) confie une chose (en général une matière première) qui doit faire l'objet d'un travail à accomplir (opus) par un artisan, un entrepreneur (conductor), et cela pour un prix convenu d'avance ${ }^{100}$.

Dans le cas du graffite de Sant'Angelo in Formis, l'objet du contrat est un travail parfaitement déterminé : fingere bipedas VXXXI, opus que doit réaliser le conductor, un mouleur nommé Celer, au profit d'un locator, le patron d'une tuilerie. L'acte ne précise pas que la terre était fournie au mouleur par le patron, cela allait de soi ${ }^{101}$. Ce graffite correspond bien à une locatio operis faciendi, un contrat de louage d'ouvrage ${ }^{102}$.

100. Le louage n'ćtait pas la scule manière d'employer temporairement un ourrier, la stipulation était également très utilisée. Comme le louage, elle portait soit sur des operae soit sur un opus. (Ces questions juridiques ont été remarquablement traitées par J. Macqueron (1964 et 1971). Dans sa thèse consacrée au monde des potiers gallo-romains, J.P. Jacob a tenté de définir les formes juridiques d'engagement qui étaient employées par les potiers romains (Jacob, 1981, p. 188-198).

101. Il n'est pas dit non plus quel serait le salaire du mouleur: son montant devait correspondre au tarif en vigueur dans la profession à cette époque. L.'́́dit du Maximum, en 301 apr. J.-C., indique que le salaire des mouleurs était calculé par lot de quatre ou de huit briques (Giacchero, 1974, p. 150, 7.1.15 et 16).

102. R. Marichal analyse ce graffite de manière ambiguë : " [c’] est un
Bien que le louage fasse partie des obligations dont Gaius dit dans ses Institutes qu'elles " se contractent par consentement mutuel, parce qu'elles n'exigent ni paroles, ni écrits spéciaux, et qu'il suffit que ceux qui font affaire soient d'accord " (III, 136), les deux parties pouvaient néanmoins décider de porter par écrit les termes de leur accord. Un tel document, un instrumentum, n'avait d'autre utilité que de servir de moyen de preuve. Le graffite de Sant'Angelo in Formis constitue sans doute un instrumentum du contrat de louage d'ouvrage passé entre un patron et le mouleur Celer.

Le support choisi est inhabituel pour ce type de document, mais on conviendra qu'il ne présentait aucune étrangeté dans le contexte qui était le sien. De plus, ce document de poids (!) ${ }^{103}$ n'était pas destiné à être conservé au-delà de la réalisation du travail demandé.

\section{LETTRES DIGITÉES}

Parmi les inscriptions qui ont été inscrites sur la surface supérieure des matériaux, un groupe se distingue par l'emplacement, la composition et le mode de réalisation. J'ai dénommé ces graffites " lettres digitées ", par analogie avec l'expression de " marques digitées ", marques avec lesquelles elles ont été jusqu'à présent confondues.

Dans l'étude qu'ils avaient consacrée aux marques digitées sur les tuiles et les briques gallo-romaines, L. Goulpeau et F. Le Ny en proposaient une typologie qui distinguait plusieurs "familles" selon la forme. Leur famille K présente la particularité de regrouper des marques en forme de lettres, mais seuls des exemplaires représentant la lettre $\mathrm{R}$ sont cités et illustrés (Goulpeau, Le Ny, 1989, p. 118 et 120, fig. 5a). Rappelons que les marques digitées sont des marques réalisées essentiellement sur les tegulae et les briques, presque toujours au doigt, et presque toujours à partir de la tranche avant des matériaux, c'est-à-dire le côté tourné vers le mouleur. Ces marques sont généralement interprétées comme des marques de tâcheron - chaque mouleur ou groupe de travail aurait eu sa marque propre pour identifier ses matériaux - mais d'autres interprétations ont été avancées (Goulpeau, Le Ny, 1989, p. 115 et 117 ; Charlier, 1999, p. 164-172).

Les auteurs du RIB ont également considéré que ces lettres n'étaient qu'un type de marques digitées, tandis que

véritable contrat : (eler s'engage, le 15 juillet, à façonner 5031 briques de deux pieds, grosse commande : un mois de travail pour un mouleur, plus le temps de séchage et la cuisson; naturellement le contrat doit être conservé jusqu'à la livaraison des briques " (Marichal, 1988, p. 18-19). En effet, les termes de "commande " et de "livraison" correspondent plutôt à une vente qu'à un louage (voir p. 86-88), et croire que (celer doit non seulement façonner les briques mais aussi les cuire est une interprétation abusive du texte. Ia cuisson n'y est pas mentionnée, fingere signifiant simplement façonner fautre occurrence de ce verbe pour des matériaux, des briques crues, dans Plinc, Histoire naturelle, 35, 170). Il est à noter que l'Édit du Maximum najoute pas la cuisson des briques au travail des moulcurs, contrairement à ce que laissent croire toutes les traductions françaises antérieures à la version que j'en ai donnée (Charlier, 1999, p. $167-168)$.

103. (e graffite est inscrit sur une brique carrée de 2 pieds de côté, soit près de $60 \mathrm{~cm}$, et qui pèse donc plusieurs dizaines de kilos. 


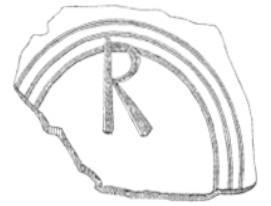

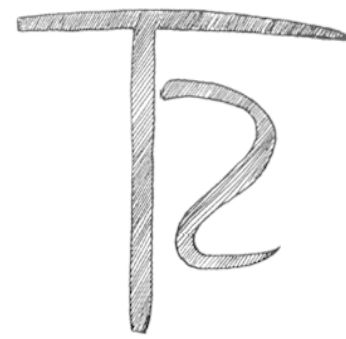

2
Fig. 51 - Lettres digitées sur des matériaux découverts : 1, à Cimiez, Nice (06.1) (d'après Bourquelot, 1850) ; 2, à Toulon (83.3) (d'après Benoit, 1943). Sans échelle.

" the majority of 'Signatures' are non-epigraphic marks of various shapes" (Frere, Tomlin, 1993, p. 92), Signature étant le terme utilisé par les archéologues anglais pour désigner les marques digitées.

Les Signatures épigraphiques recensées dans le RIB sont presque toujours constituées d'une lettre unique : A, C, M, N, P, $\mathrm{R}, \mathrm{S}$ ou $\mathrm{V}$, les lettres $\mathrm{A}, \mathrm{C}, \mathrm{R}$ et $\mathrm{S}$ étant les mieux représentées. De cet inventaire, il faut éliminer la lettre A, car aucune des marques anglaises ne représente cette lettre. Il s'agit en fait de marques digitées en forme de boucle, un type asse $z$ fréquent. La boucle est plus ou moins ample et les " jambes " plus ou moins longues selon les exemplaircs. Assimiler cette marque à un $\mathrm{A}$ semble impossible tant son tracé est radicalement différent du ductus de la lettre ${ }^{104}$.

En France, les lettres représentées sont les suivantes: $\mathrm{P}$ (46.3), R (06.1, 35.2, 81.1, 88.2-88.3), S (74.1) et T (46.4). On peut ajouter à ces exemples publiés deux inédits : un $\mathrm{R}$ et une série de $S$ trouvés dans le Jura ${ }^{105}$. Le $P$ et le $T$, connus chacun par un unique exemplaire sur un seul et même site, semblent tout à fait anecdotiques par rapport aux $\mathrm{R}$ et $\mathrm{S}$, lettres qui sont aussi les mieux représentées en Grande-Bretagne. Si ces lettres ne sont qu'une catégorie de marques digitées, il est bien difficile de comprendre pourquoi si peu de lettres ont été employées sur un territoire aussi étendu. Aucune des interprétations proposées actuellement ne permet d'expliquer pourquoi les tuiliers ne traçaient pratiquement que des $\mathrm{R}$ et des $\mathrm{S}$. Comme pour le A du RIB, peut-être faut-il écarter le $\mathrm{S}$ des signes épigraphiques et n'y voir qu'un simple trait ondulé. Je n'en suis pas convaincu, mais faute d'une meilleurc explication je retiendrai cette hypothèse pour le moment.

Reste la lettre R. Sur le fragment de matériau de Cimiez à Nice (06.1), un $\mathrm{R}$ a été tracé en partie sur une marque digitée

104. Certains autcurs ont décrit ces boucles en se référant aux lettres grecques $\alpha$ ou $\gamma$ selon l'orientation choisic, quand ils ne les ont pas interprétées directement comme telles. Dans tous ces cas, c'est le sens de lecture des marques qui interdit ces comparaisons et, à plus forte raison, ces interprétations. I a comparaison d'une telle boucle avec la représentation d'un poisson est tout aussi erronée et source de confusion.

105. Je n'ai pu retenir un autre $R$, faute de renscignements suffisamment précis. Cette lettre figurait sur une tuile ou une brique romaine trouvée à Garros, près d'Auch. Il s'agit d'une "initiale de grande dimension, et marquée dans le coin du haut à gauche " (Bladé, 1885. p. 62 et $\left.69, n^{\circ} 35\right)$. composéc de trois demi-cercles emboîtés (fig. 5l, $n^{\circ} 1$ ). La présence sur un même matériau d'un $\mathrm{R}$ et d'une marque digitée prouve que ces deux signes ne remplissaient pas la même fonction. I.cur présence conjointe s'observe également sur des tuiles mises au jour par Nino Lamboglia sur la côte italienne, à quelques dizaines de kilomètres de Nice. Sur deux tegulae trouvées à Bordighera un $\mathrm{R}$ a été tracé dans le demicercle inférieur d'unc marque digitée, composéc pour l'une de quatre demi-cercles et pour l'autre de trois, comme sur l'exemplaire de (imiez (Lamboglia, 1958, p. 128, fig. 7). De même, les lettres RT ont été inscrites sur une tegula découverte à Vintimille (Lamboglia, 1938, p. 208). On peut comparer ce lot au graffite d'une tegula découverte à Toulon (83.3), que Fernand Benoit lisait TS, avec un $\mathrm{S}$ rétrograde, et qui est plus probablement un T et un R ligaturés. Les exemples précédents m incitent à les lire RT.

Que signifient donc ces lettres toujours écrites au doigt près de la tranche des matériaux ${ }^{106}$ - la tranche avant pour les tegulae-comme pour les marques digitées? La combinaison RT ne semble pas être répertoriéc dans les listes d'abréviations latines. Sans connaître la fonction de cette marque, il est difficile de la restituer avec assurance. N. Lamboglia, qui voyait dans ces lettres " un' indicazione di fabbrica ", les développait en Recognitum (Lamboglia, 1958, p. 128), que l'on traduirait ici par "Vu " ${ }^{107}$, on peut aussi penser à Recte (ou bien Recta) dans le sens de "Bien " ou "Bon ". Ce ne sont là que des hypothèses ${ }^{108}$.

\section{IDENTIFICATION DE PRODUCTION DE MOULEURS}

\section{IDENTIFICATION PAR UNE DATE}

Ces graffites sont très standardisés : leur formulaire débute systématiquement par une date qui peut être suivie de noms et/ou de chiffies. Il est possible de les classer en trois groupes selon leur longueur.

Les graffites à formulaire long sont composés de tous les éléments : date, nom(s) et chiffre(s). La nature des matériaux fabriqués est parfois précisée (tabl. IV). Dans les graffites à formulaire moyen la date n'est suivie que par un nom ou que par un chiffre (tabl. V), et scule la date est mentionnée pour le dernier groupe, les graffites à formulaire court (tabl. VI).

106. Pour les exemplaires français, seul le graffite de Toulon (83.3) n'est pas réalisé au doigt, ainsi que le $\mathrm{P}$ et le $\mathrm{T}$ de Saint-Denis-Cautus (46.3 et 46.4).

107. Bien que N. Lamboglia ne le précise pas, je suppose qu'il songeait à la lettre $\mathrm{R}$, lue R(ecognitum), présente sur de nombreux blocs de marbre et interprétée comme la marque du probator, un fonctionnaire des carrières impériales chargé de contrôler la qualité des filons à exploiter et des blocs extraits (Dubois, 1908, p. XXXIII, et par exemple les inscriptions $11^{\circ "} 175,257,283,491$ ou 535).

108. Il faut souligner que, si l'on excepte le petit lot de miles niçoises et italiennes, tous les matériaux porteurs d'un $\mathrm{R}$ découverts sur le territoire français sont vierges de toute marque digitée. Même si ce marquage n était pas strstématique, l'absence de marques digitées est assez surprenante, surtout dans le cas des dizaines de tuiles porteuses d'un $R$ trowées dans la tuilerie de Liffol-le-Grand (88.3). 
Tabl. IV - Graffites à formulaire long d'identification par une date : 1-5, Siscia ; 6, Mariazeiller; 7, Holdeurn.

\begin{tabular}{|c|c|c|c|}
\hline No & Lecture & Traduction & Référence \\
\hline 1 & $\begin{array}{l}\text { Pr(idie) Idus lunials } \\
\text { Felicio CCXX }\end{array}$ & $\begin{array}{l}\text { La veille du jour des ides de juin } \\
\text { Felicio : } 220\end{array}$ & CIL, III, 11379 \\
\hline 2 & $\begin{array}{l}\text { Kal(endis) lulis } \\
\text { Seuerus } C C X X \\
\text { Fortis } C C X X \\
\text { Candidus } C C X X \\
\text { Felicio } C C X X \\
\text { in uno DCCCLXXX }\end{array}$ & $\begin{array}{l}\text { Le jour des calendes de juillet } \\
\text { Severus : } 220 \\
\text { Fortis : } 220 \\
\text { Candidus : } 220 \\
\text { Felicio : } 220 \\
\text { en tout : } 880\end{array}$ & CIL, III, 11381 \\
\hline 3 & $\begin{array}{l}\text { Pri(die) non(a)s lul(i)a(s) } \\
\text { Seuerus } \\
\text { et Fortis } \\
\text { et Candidus } \\
\quad C C X X \\
\end{array}$ & $\begin{array}{l}\text { La veille du jour des nones de juillet } \\
\text { Severus } \\
\text { et Fortis } \\
\text { et Candidus } \\
220 \text { (chacun) }\end{array}$ & CIL, III, 11380 \\
\hline 4 & $\begin{array}{l}\text { (ante diem) XIII K(alendas) Octobr(es) } \\
\text { Fortis CCXXII } \\
\text { Candidus CCXXV } \\
\text { lustinus CXXXVII } \\
\text { Artemas CLXXXXVIIII } \\
\text { min(us) XXI }\end{array}$ & $\begin{array}{l}\text { Le } 13 \text { e jour avant les calendes d'octobre } \\
\text { Fortis : } 222 \\
\text { Candidus : } 225 \\
\text { Justinus : } 137 \\
\text { Artemas : } 199 \\
\text { en moins : } 21\end{array}$ & CIL, III, 11385 \\
\hline 5 & $\begin{array}{l}\text { (ante diem) V Kal(endas) Aug(ustas) } \\
\text { Seuerus et } \\
\text { Fortunatlus } \\
\text { later(es) CCCCXXXX }\end{array}$ & $\begin{array}{l}\text { Le } 5 \text { e jour avant les calendes d'août } \\
\text { Severus et } \\
\text { Fortunatus } \\
\text { briques : } 440\end{array}$ & CIL, III, 11383 \\
\hline 6 & $\begin{array}{l}\text { (ante diem) XVI K(alendas) lunias } \\
\text { Hristo n(umero) LXI }\end{array}$ & $\begin{array}{l}\text { Le } 16 \text { e jour avant les calendes de juin } \\
\text { Hristo, nombre : } 61\end{array}$ & Zangemeister, 1879 \\
\hline 7 & $\begin{array}{l}\text { Kal(endis) lun(i)is } \\
\text { Quartus } \\
\text { laterclos } \\
\text { n(umero) CCXIIII }\end{array}$ & $\begin{array}{l}\text { Le jour des calendes de juin } \\
\text { Quartus } \\
\text { briques } \\
\text { nombre: } 214\end{array}$ & Brambach, 1867, p. $28, n^{\circ} 114$ \\
\hline
\end{tabular}

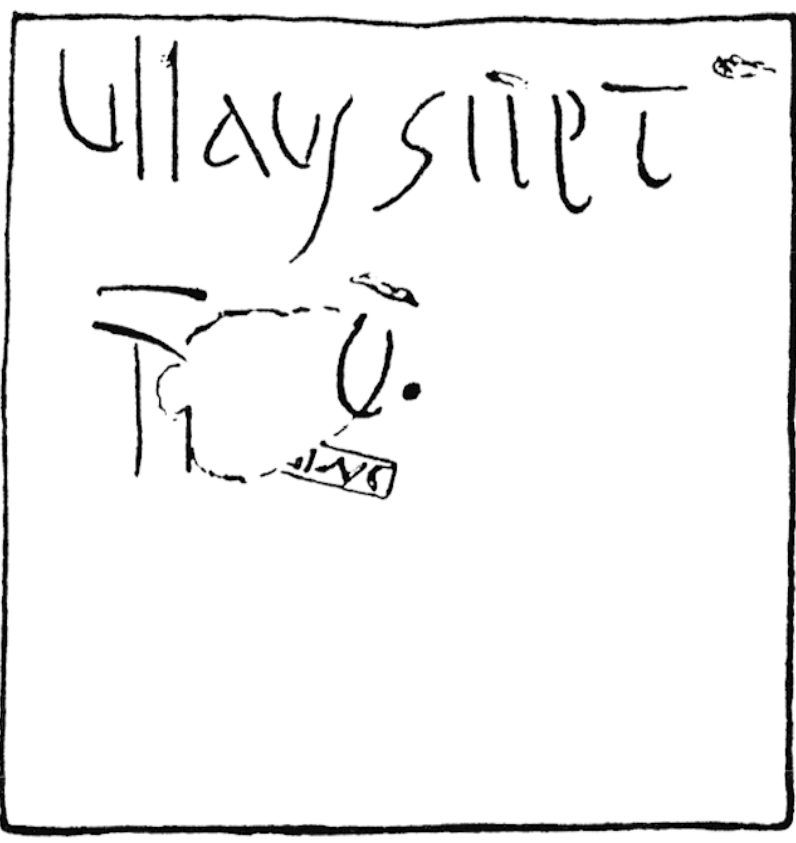

Fig. 52 - Graffite sur une brique sesquipedalis découverte à Strasbourg : 67.6 (d'après Forrer, 1927, p. 469, fig. 344).
Les graffites les plus longs sont les plus rares. Je n'ai pu en recenser qu'une dizaine découverts sur trois sites seulement (tabl. IV), dont huit à Siscia. Les exemplaires des autres groupes sont plus fréquents et plus largement distribués : de la province de Bretagne à celle de Thrace (tabl. V et VI). Un seul a été découvert sur le territoire français, à Strasbourg (67.6) (fig. 52).

L'état fragmentaire de nombreux graffites qui commencent par une date ne permet pas d'en connaître la longueur initiale. Nous ignorons par exemple si la date portée sur une tegula de Strasbourg (67.9) était suivie par d'autres éléments ${ }^{109}$. C'est pourquoi je n'ai exploité que les textes dont l'intégrité est quasiment assurée.

Quelle que soit leur longueur, beaucoup de ces graffites ont été inscrits sur des matériaux produits par les légions, comme l'attestent la présence d'une estampille militaire ou le lieu de découverte (la tuilerie légionnaire de Holdeurn par exemple). Presque tous les autres graffites ont été trouvés dans les régions du limes, la probabilité qu'ils soient également issus d'ateliers légionnaires est donc forte ${ }^{110}$.

109. En revanche, deux autres matériaux inédits découverts dans cette même ville ne portent qu'une date. L'ensemble des graffites strasbourgeois fera l'objet d'une publication ultérieure.

110. Cependant les briques découvertes à Sofia (tabl. V, nos 1-4) pourraient provenir d'un atelier civil, c'est ce que laisse entendre V. Velkow (1977, p. 158-161). 
Tabl. V - Graffites à formulaire moyen d'identification par une date : 1-4, Sofia ; 5, Mainz; 6-7, Holdeurn; 8, Londres ; 9, Baden-Baden ; 10-13, limes autrichien ; 14, Vienne; 15, Meschenich; *, les éditeurs de ce document croient voir un M sur une ligne supérieure, lettre pour laquelle ils proposent l'hypothèse de $\mathrm{m}(\mathrm{anu})$ soit : " de la main de... ". Compte tenu de l'état de conservation du fragment, cette interprétation est hasardeuse. On peut aussi interpréter cette première ligne comme un simple trait ondulé que l'on observe à la surface de certaines tegulae.

\begin{tabular}{|c|c|c|c|}
\hline No & Lecture & Traduction & Référence \\
\hline 1 & 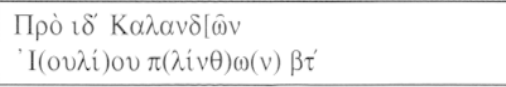 & $\begin{array}{l}\text { Le } 14 \text { e jour avant les calendes } \\
\text { de juillet, briques : } 302\end{array}$ & Besevliev, 1952, p. 31, no 49 \\
\hline 2 & 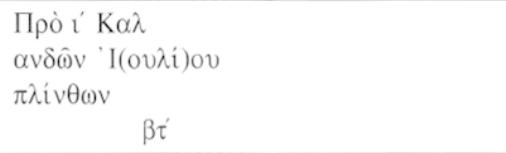 & $\begin{array}{l}\text { Le } 10 \text { e jour avant les calendes } \\
\text { de juillet } \\
\text { briques } \\
\qquad 302\end{array}$ & Id., p. 31, no 47 \\
\hline 3 & 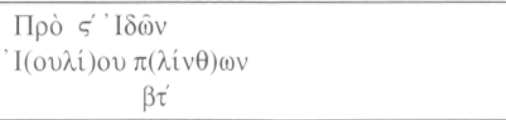 & $\begin{array}{l}\text { Le } 6 \text { e jour avant les ides } \\
\text { de juillet, briques } \\
302\end{array}$ & Id., p. 31, no 50 \\
\hline 4 & $\begin{array}{l}\text { Про̀ } \zeta^{\prime} \mathrm{K} \alpha \lambda \alpha v \\
\delta \hat{\omega} v^{\prime} \mathrm{A} \gamma(\mathrm{ov} \sigma \tau) \mathrm{v} \tau \\
(\lambda \dot{i v} \theta) \omega(v) \beta \tau\end{array}$ & $\begin{array}{l}\text { Le } 7 \text { e jour avant les calendes } \\
\text { d'août, briques } \\
\quad 302\end{array}$ & Id., p. 31, no 48 \\
\hline 5 & $\begin{array}{l}\text { (ante diem) IIII Id(us) Mai(ias) } \\
\text { IIIL (ou ML) }\end{array}$ & $\begin{array}{l}\text { Le } 4 \text { e jour avant les ides de mai } \\
47 \text { (ou 1050) }\end{array}$ & Körber, 1905 , p. 56, no 78 \\
\hline 6 & $\begin{array}{l}\text { (ante diem) XVII K(alendas) Iun(ias) } \\
D C L X X I I\end{array}$ & $\begin{array}{l}\text { Le } 17 \text { e jour avant les calendes de juin } \\
672\end{array}$ & Brambach, 1867, p. 28, no 111 \\
\hline 7 & $\begin{array}{l}\text { (ante diem) XV K(alendas) Iul(ias) } \\
\text { DXVI }\end{array}$ & $\begin{array}{l}\text { le } 15^{\mathrm{e}} \text { jour avant les calendes de juillet } \\
516\end{array}$ & Id., p. 28, no 113 \\
\hline 8 & $\begin{array}{l}\text {...nlonas Aug(ustas) } \\
\text { IXXV }\end{array}$ & $\begin{array}{l}\text {...nones d'août } \\
\ldots 25 \text { (ou plus) }\end{array}$ & RIB, II-5, no 2491.10* \\
\hline 9 & $\begin{array}{l}\text { (ante diem) XV K(alendas) Sept(embres) } \\
\text { n(umero) D }\end{array}$ & $\begin{array}{l}\text { Le } 15 \text { e jour avant les calendes de septembre } \\
\text { nombre : } 500\end{array}$ & Weigels, 1977 \\
\hline 10 & $\begin{array}{l}\text { (ante diem) XII Kal(endas) Iul(ias) } \\
\text { Eraclides }\end{array}$ & $\begin{array}{l}\text { Le } 12 \mathrm{e} \text { jour avant les calendes de juillet } \\
\text { Éraclides }\end{array}$ & Ruzicka, 1919, col. 109 \\
\hline 11 & $\begin{array}{l}\text { (ante diem) IIII Nonas August(as) } \\
\text { Isauricus }\end{array}$ & $\begin{array}{l}\text { Le } 4 \text { e jour avant les nones d'août } \\
\text { Isauricus }\end{array}$ & Id., col. 113 \\
\hline 12 & $\begin{array}{l}\text { (ante diem) III Idus Aug(ustas) } \\
\text {...nus }\end{array}$ & $\begin{array}{l}\text { Le } 4 \text { e jour avant les ides d'août } \\
\text {...nus }\end{array}$ & Id., col, 114-116 \\
\hline 13 & $\begin{array}{l}\text { Nonis } \\
\text { Sept(embris) } \\
\text { Annamus }\end{array}$ & $\begin{array}{l}\text { Le jour des nones } \\
\text { de septembre } \\
\text { Annamus } \\
\end{array}$ & CIL, III, p. 963, no 14 \\
\hline 14 & $\begin{array}{l}\text { VI Nonas lul(ias) } \\
\text { FI Kindini }\end{array}$ & $\begin{array}{l}\text { Le } 4 \text { e jour avant les nones de juillet } \\
\text { FI. (fils ou esclave) de Kindinus }\end{array}$ & Neumann, 1973, p. 50 \\
\hline 15 & $\begin{array}{l}\text { Seuerus ex } \\
\text { pridie Nonas }\end{array}$ & $\begin{array}{l}\text { Severus, depuis } \\
\text { la veille des nones }\end{array}$ & Lehner, 1901, p. 234 \\
\hline
\end{tabular}

La composition des graffites à formulaire long permet de les identifier comme des totaux de production journalière de mouleurs (tabl. IV). On apprend que tel jour, tel et tel mouleur ont réalisé tant et tant de matériaux. La production enregistrée correspond au travail de un à quatre mouleurs. Ces graffites ne présentent que des différences minimes qui portent sur la manière dont les quantités de matériaux sont notées.

La date est le seul renseignement que l'on retrouve systématiquement dans les autres types de graffites.

L'analogie de forme de tous les graffites datés 111 et l'origine militaire de la plupart laissent supposer qu'ils rem-

111. Ln seul graffite se distingue quelque peu. Le $n^{\circ} 15$ du tableau $V$ commence par un nom et livre une date sous une forme originale. Le matériau ainsi inscrit permettait d'identifier les briques moulées par Severus depuis la veille des nones du mois courant. Le lot devait correspondre à plusieurs journées de travail. plissaient tous la même fonction dans la production. Si les graffites à formulaire long peuvent être interprétés comme des relevés de production, les autres ne contiennent pas suffisamment d'informations pour que l'on puisse leur attribuer une telle fonction. Compte tenu de leur nombre et de leur répartition, les premiers ne sont qu'une forme exceptionnellement longue des seconds. Tels quels, ces graffites à formulaire moyen et court devaient permettre de connaitre l'identité du mouleur et le nombre de matériaux moulés. Je suppose donc que chacun des matériaux inscrits restait associé à son lot journalier tant qu'un véritable relevé de production n'avait pas été dressé.

Le graffite était inscrit par le mouleur ou par un responsable de la tuilerie sur le dernier matériau moulé de la journée. Certains graffites laissent penser que le travail de plusieurs mouleurs était, dès ce stade, regroupé et identifié par un seul matériau inscrit. 
Tabl. VI - (iraffites à formulaire court d'identification par une date: 1, Saalburg; 2, Holdeurn; 3, Caerlon ; 4, Vienne ; 5, Köln-Marienlnurg; *, ce graffite a été lu à l'envers et sa reproduction publiée ainsi; sa transcription était "[Ka/]lendis Se[pt(embris)] ". La qualité du dessin publié permet de rendre à ce graffite sa véritable orientation et d'en corriger la lecture.

\begin{tabular}{|c|l|l|l|}
\hline No & \multicolumn{1}{|c|}{ Lecture } & \multicolumn{1}{|c|}{ Traduction } & \multicolumn{1}{c|}{ Référence } \\
\hline $\mathbf{1}$ & (ante diem) III Idus lunias & Le $\left(2^{\mathrm{e}}\right.$ ?) jour avant les ides de juin & Baatz, 1970, p. 50* \\
\hline $\mathbf{2}$ & (ante diem) XII K(alendas) lul(ias) & Le $12^{\mathrm{e}}$ jour avant les calendes de juillet & Holwerda, Braat, 1946, pl. XXXIV.2 \\
\hline $\mathbf{3}$ & pri(die) Idus Aug(ustas) & La veille des ides d'août & RIB, II-5, no 2491.11 \\
\hline $\mathbf{4}$ & (ante diem) V Idus Aug(ustas) & Le 5 e jour avant les ides d'août & Neumann, 1973, pl. LXXIV, no 1157 \\
\hline $\mathbf{5}$ & (ante diem) V K(alendas) Nou(embres) & Le 5 e jour avant les calendes de novembre & Hanel, 1988, p. 408 \\
\hline
\end{tabular}

Tabl. VII - Craffites d'identification par un nom: 1, Conimbriga ; 2, Leicester; 3, Sofia ; 4, 5, Silchester; 6, Cadder ; 7, région du mur d'Hadrien, Grande-Bretagne ; 8, Kösching ; 9, Leicester ; 10, Dover ; 11-15, Conimbriga ; 16, Aachen ; 17, Holl; *, les parties supérieure et droite du graffite manquent; néanmoins il est peu probable qu'une date précède le nom, car aucun des nombreux graffites de Conimbriga ne comporte de date.

\begin{tabular}{|c|c|c|c|}
\hline No & Lecture & Traduction & Référence \\
\hline 1 & $\begin{array}{l}\text { A]gilio } \\
\text { ICl lateres }\end{array}$ & $\begin{array}{l}\text { A]gilio } \\
\text { ]101 briques (ou plus)* }\end{array}$ & Étienne et al., 1976, p. 160, no 359 \\
\hline 2 & $\begin{array}{l}\text { Primus } \\
\text { fecit } L X\end{array}$ & $\begin{array}{l}\text { Primus } \\
\text { en a fait } 60\end{array}$ & RIB, II-5, no 2491.3 \\
\hline 3 & Maximo CCC & Maximo : 300 & Velkov, 1977, p. 160, n. 638 \\
\hline 4 & $\begin{array}{l}\text { Fecit tubu(m) } \\
\text { Clementi } \\
\text { nus }\end{array}$ & Clementinus a fait cette tubulure & RIB, II-5, no 2491.1 \\
\hline 5 & $\begin{array}{l}\text { Birgin } \\
\text { us }\end{array}$ & Birginus (pour Briginus) & RIB, II-5, no 2491.81 \\
\hline 6 & JTargarus & Targarus (?) & RIB, II-5, no 2491.123 \\
\hline 7 & Ti(berius ?) Primus & Ti(berius ?) Primus & RIB, II-5, no 2491.127 \\
\hline 8 & \begin{tabular}{|l} 
Ge \\
mell \\
us Ge \\
mell \\
e filius \\
\end{tabular} & $\begin{array}{l}\text { Gemellus, fils de Gemellus } \\
\text { (ou de Gemella) }\end{array}$ & Vollmer, 1915, no 260 \\
\hline 9 & Minic(i)i & De Minicius & RIB, II-5, no 2491.109 \\
\hline 10 & Tauri & De Taurus & RIB, II-5, no 2491.124 \\
\hline 11 & Nigellionis & De Nigellio & Étienne et al., 1976, p. 164, no 365 \\
\hline 12 & Gale(ti) & De Galetus & Id., p. 161-162, no 361 \\
\hline 13 & APR(i ?) & D'Aper (?) & Id., p. 161, no 360 \\
\hline 14 & Tan(geni ?) & De Tangenus (?) & Id., p. 164-165, no 367 \\
\hline 15 & Arc(onis) & D'Arco & Id., p. 172, no 376 \\
\hline 16 & $\begin{array}{l}\text { Victorinus } \\
\text { ductor }\end{array}$ & $\begin{array}{l}\text { Victorinus, } \\
\text { mouleur }\end{array}$ & Rüger, 1987 \\
\hline 17 & $\begin{array}{l}\text { Iulius Auentinus milis } \\
\text { co(ho)rtis prima(e) Sunicor(um) }\end{array}$ & $\begin{array}{l}\text { Iulius Aventinus, soldat } \\
\text { de la première cohorte des Sunici }\end{array}$ & RIB, II-5, no 2491.96 \\
\hline
\end{tabular}

\section{IDENTIFICATION PAR UN NOM}

Cette catégorie regroupe des graffites composés d'un anthroponyme seul (cntier ou abrégé) et d'autres où un anthroponyme est l'élément essentiel. Ces graffites sont moins nombreux que les précédents mais paraissent plus largement répartis géographiquement et non réservés aux productions légiomnaires.

Comme pour les graffites datés, les documents qui livrent le plus grand nombre d'informations sont aussi les phus rares : je n'ai recensé que trois exemples de nom suivi d'un nombre de matériaux (tabl. VII, n $1-3)$. 
Le graffite de Mircbeau-sur-Bèze appartient peut-être à cette catégorie (21.2). Six anthroponymes - cinq au nominatif $\mathrm{et}$ un au génitif - sont disposés sur une colonne ${ }^{112}$, mais seul le premier est suivi d'un chiffre : 326 . Ce nombre paraît trop faible pour être le total des matériaux produits par tous les individus mentionnés. Mais ce graffite comptabilise peut-être autre chose que des matériaux moulés, à moins qu'il ne soit resté inachevé.

Un autre document nous informe que "Clementinus a fait cctte tubulure" (tabl. VII, n"4). Si ce texte joue un rôle dans la production, il faut croire que le singulier de tubus avait valeur de générique et que Clementinus indiquait ainsi qu'il avait fabriqué toutes les tubulures auxquelles appartenait l'exemplaire inscrit.

En ce qui concerne les graffites composés d'un seul nom au nominatif, il est délicat d'affirmer qu'ils jouaient un rôle dans la production, ni même qu'ils désignaient des tuiliers. L'exemple de la brique bessalis retrouvée à León (Espagne) sur laquelle est inscrite uniquement la titulature d'Antonin le Picux (Bellido, 1970, p. 577 et fig. 20) : IMP. CAES. I T. AELIO HA., justific pleinement la prudence qu'il convient d'adopter dans l'interprétation de ces noms. Mais prudence ne signifie pas rejet systématique. Une brique pedalis provenant de Caerwent (GrandeBretagne) porte quatre fois le même nom : Bellicianus. Il peut s'agir d'un jeu d'écriture totalement anecdotique, mais on ne peut cependant écarter l'hypothèse qu'un tuilier ait voulu identifier un lot de matériaux en inscrivant sur l'un d'eux son nom, qu'il a répété ensuite par jeu.

Si des graffites qui ne comportent qu'un nom au nominatif (tabl. VII, n $n^{\circ 5} 5-8$ et en France : 77.11 et 86.2) se rattachent effectivement à la production, alors la forme verbale fecit est implicite. Je ne connais pas d'exemple de graffites composés uniquement d'un anthroponyme et de fecit. Lne tegula de Strasbourg porte Jandio fe (67.7), qui pourrait être restitué en Amandio, ou Seruandio fe(cit) en se référant aux noms contenus dans le CII. XIII, mais la taille du fragment ne permet pas de savoir si ce graffite ne se composait que de ces deux mots ${ }^{113}$. L'équivalent en gaulois de cette seule formule nous est donné par une inscription portée sur la partie inférieure d'une antéfixe découverte à Lczoux (63.2). Seul subsiste le terme auo(t) qui devait être précédé d'un anthroponyme au nominatif. Cet exemple, unique sur ce type de matériau, est singulier; dans ce cas, en effet, le graffite semble prendre la place d'une estampille ou, plus exactement, occupe la place où apparaît sur certaines de ces pièces un nom qui était moulé avec le décor de l’antéfixc.

D'autres noms apparaissent seuls, mais au génitif (tabl. VI, n"s-11). L'emploi de ce cas révèle clairement une relation entre le matériau et l'individu nommé, et permet d'identifier ce dernicr comme un producteur. Dans l'exemple d'Atiliani à L.czoux (63.4 ct 63.5), le rapport entre cet Atilianus et une tuilerie est d'autant plus sûr que son nom est présent seul sur deux tegulae.

112. Les quatre derniers noms sont incomplets mais présentent incontestablement des terminaisons en -us (s pour la l. 6) ; seuls les $e$ des 1.3 et 4 sont douteux.

113. Un graffite trouvé à Pécy indique sur ses deux premières lignes que "Sat]urninos a fait 310 tegulae" (77.18). Faute de comprendre les trois lignes suivantes, il est difficile d'interpréter précisément ce document.
Au Portugal, à Conimbriga, parmi les graffites qui ne sont composés, semble-t-il, que d'un anthroponyme (tabl. VII, n"s 11 15), on trouve un nom entier au génitif : Nigellionis, et plusieurs noms abrégés : Arc, Tan, (iale et APR. Robert Étienne et Georges Fabre les développent d'autant plus aisément au génitif que trois d'entre eux apparaissent sur plusieurs matériaux, répétition qui s'explique plus facilement si les personnes nommées sont impliquées dans la production ${ }^{114}$. On peut aussi interpréter la lettre A, qui apparaît seule sur quatre matériaux de Conimbriga, comme l'initiale d'un nom, d'autant plus que les autres graffites livrent au moins trois noms qui commencent par cette lettre (Étienne et al., 1976, p. 174-175, n”385 et pl. XXIX).

Pour mieux saisir le rôle des individus nommés dans la production et comprendre pourquoi ils apparaissent sur les matériaux, continuons d'exploiter le si riche lot de Conimbriga. Des graffites et des estampilles sur les tuiles et les briques de ce site, et des découvertes réalisćes sur d'autres sites de I usitanic occidentale, nous font connaitre l'identité de quatre responsables et/ou propriétaires de tuilerie, à savoir les Allii Auiti, Duatius, Maelo et Primus. Il faut noter qu'aucun de ces noms n'apparaît seul sous forme de graffite. Trois briques laissent bien apparaître un $\mathrm{M}$, interprété comme l'initiale de Maelo, mais il s'agit d'estampilles en relief. On ne trouve les noms de ces individus sous forme de graffites que sur des pesons. Sur plus de 80 pesons marqués, moins d'un tiers présentent un graffite incisé sur la face supérieure, alors que sur tous les autres ces noms sont estampillés. Pour Maelo, graffites et estampilles se réduisent souvent à la seule initiale (Correia et al., 2001, p. 153-154 et p. 165-166). Il semble donc qu'à Conimbriga, seuls les ouvriers écrivaient leurs noms sur les tuiles et les briques encore crues. Cette pratique était-elle identique ailleurs? S’il est vrai qu'aucun site d'époque romaine n'a livré autant de graffites relatifs au travail que la cité lusitanienne, un même nom n'a jamais été retrouvé, à ma connaissance, à la fois sur une estampille et seul sur un graffite. Si ces noms ne désignent pas les responsables ou/et les propriétaires des ateliers, l'emploi du génitif ne peut s'expliquer que s'ils sont des noms de mouleurs.

Comme pour les graffites précédents, les documents qui commencent par un nom devaient servir à identifier les matériaux fabriqués par les différents mouleurs pour faciliter le relevé de leur production. Il est possible que les très rares documents où un nom est suivi d’informations complémentaires sur l'individu nommé remplissaient la même fonction (tabl. VII, $\left.\mathrm{n}^{\mathrm{s}} 16-17\right)$. Cela est même très vraisemblable dans le cas de la tegula de Aachen (Aix-la-Chapelle, Allemagne), sur laquelle le nommé Victorinus nous précise, rien de moins, qu'il était ductor, c'est-à-dire mouleur ${ }^{115}$ ! Peut-être faut-il y voir la manifestation d'une certaine fierté professionnelle?

114. On peut citer en France deux exemples de noms abrégés retrouvés sur le site de Chassey-lès-Montbozon (70.1 et 70.2).

115. Dans le seul ouvrage en français qui mentionne ce graffite. F. Le Ny propose de traduire ductor par a matre-fournier (conducteur du feu)" (I.e Ny, 1992, vol. IA, p. 241). Cette traduction est inexacte. L'expression lateres ducere employée à huit reprises par Vitruve dans le chap. III de son live II (consacré à la fabrication des briques crues) ne laisse aucun doute sur la signification de ductor, même s'il s’agit ici de 


\section{IDENTIFICATION PAR UN NOMBRE}

Certains graffites, relativement rares, ne sont composés que d'un nombre. Aux exemplaires rassemblés dans le tableau VIII, qui comprend à la fois des productions civiles et militaires, s'ajoutent quelques inscriptions trouvées en France. Une brique de Strasbourg (67.4 et fig. 53) et une imbrex de Sallèles-d'Aude (11.1) portent respectivement les nombres de 240 et 124 . Le graffite numérique sur une imbrex découverte au Mans est peutêtre incomplet (72.1).

Ces graffites pouvaient servir comme les précédents à identifier des lots de matériaux, avec en outre la précision de leur nombre. Dans la plupart des cas, chacun des lots devait correspondre au travail d'un mouleur. Dans l'exemplaire 5 du tableau VIII, le premier nombre, 215 (ou 220), a été tracé au doigt tandis qu'un outil pointu a été utilisé pour écrire le second, 214. Le chercheur qui a publié cette pièce se demande avec pertinence si les nombres correspondent à la production de deux ouvriers différents ou si l'un des deux nombres, plutôt le second, ne serait pas une correction du premier : un patron recomptant et corrigeant le nombre de matériaux revendiqués par son ouvrier (Foster, 1986, p. 211-212). Le graffite 4 est légèrement différent des autres car il enregistre clairement deux travaux distincts: le moulage et l'ébarbage. Si la plupart des nombres seuls font référence sans aucun doute au moulage, on peut supposer que certains enregistrent d'autres totaux, des matériaux ébarbés ou des matériaux achetés par exemple, comme cela est attesté sur des graffites plus développés (tabl. IX).

Avant d'aborder l'emploi de ces graffites, j'aimerais faire quelques remarques sur deux aspects essentiels de la production mis en évidence par ces documents : son caractère saisonnier et les quotas de production journalière de mouleurs.

Les dates indiquées attestent du caractère saisonnier de la production puisqu'elles s'échelonnent des nones d'avril (Ruprechtsberger, 1982, p. 81, $\mathrm{n}^{\circ}$ 103) au $3^{\mathrm{c}}$ jour avant les ides de novembre ${ }^{116}$ (Neumann, 1973, p. 50 et pl. 66.1958), soit du 5 avril au 11 novembre. Ces dates sont les dates extrêmes, la majorité d'entre elles se répartissent de mai à septembre. Pour assurer une bonne cuisson des matériaux, ces derniers devaient être parfaitement secs avant d'être enfournés, ce qui explique que l'on ne moulait que durant les mois les plus chauds ${ }^{117}$.

L'existence d'un quota de production journalière de mouleurs a été envisagée dès la première publication des

la seule occurrence du terme dans ce sens. Il est dommage que la dernière édition française de Vitruve (Callebat et al., 1999) ne rende pas simplement et précisément le sens de ducere par mouler, comme Choisy l'avait fait auparavant (1909).

116. Cette date est particulièrement tardive mais je ne vois pas pour ce graflite d'autre développement possible que " (ante diem) III Id(us) $N$ (ouembres)". La date la plus tardive ensuite est celle du $55^{\circ}$ jour avant les calendes de novembre, soit le 28 octobre (tabl. VI, n"5). Je ne retiens pas les hypothèses de lecture en "Pridie...Decemb. " d'un graffite découvert à Xanten (Steiner, 1911, p. 73 et pl. 25.296), et en «XF- Jl(ante) Kal(endas)] / D[ec(embres)] " d'un exemplaire trowé à Farningham (RIB, II-5, n²491.15).

117. À titre de comparaison, les graffites de La Graufesenque révèlent que les cuissons de céramiques sigillées se déroulaient de mars à octobre.
Fig. 53 - Craffite sur une brique bessalis découverte à Strasbourg: 67.4 (d'après Forrer, 1927, p. 27, pl. IV.65a).

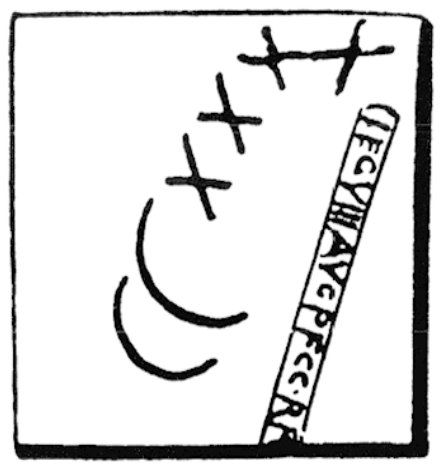

graffites de Siscia pour justifier la répétition du nombre 220 (tabl. IV, $n^{\circ \mathrm{ss}} 1-5^{118}$ ). Des nombres entre 200 et 240 , ou leurs multiples, se rencontrent également sur d'autres pièces 119 (tabl. IV, n" 7 ; tabl. V, $\mathrm{n}^{\circ} 6$ et tabl. VIII, $\mathrm{n}^{\text {os }} 5-8$ ). Toutefois, d'autres ne correspondent pas à cet ordre de grandeur. Dans l'hypothèse où tous correspondent à des totaux de productions journalières, des écarts peuvent être expliqués par des raisons anecdotiques, mais il est probable aussi que l'on se référait à des quotas différents selon la taille et la forme des matériaux à mouler. Cela semble confirmé par les graffites de Sofia qui enregistrent tous une quantité de 300-302 (tabl. V, n*s 1-4 et tabl. VIII, $\mathrm{n}^{\circ} 3$ ). On peut donc bien parler de quotas journaliers pour expliquer la répétition de certains nombres, d'autant plus qu'un mouleur fait clairement référence à un tel quota dans un graffite qu'il a inscrit sur une brique de Conimbriga (voir infra, p. 89).

Que l'élément essentiel soit une date, un nom ou un nombre, et quelle que soit leur longueur, ces graffites remplissaient certainement tous la même fonction : identifier les différents lots de matériaux en train de sécher afin de faciliter les opérations comptables (et de contrôle ?). L'interprétation des graffites datés (voir supra, p. 79) peut être étendue aux autres documents : il est probable que tous les lots identifiés par des graffites, même si ceux-ci ne comportaient pas de date, correspondaient à des matériaux réalisés dans une même journée de travail par un ou plusieurs mouleurs.

Le dernier matériau était inscrit soit sur la table de moulage, soit à terre. Les différents matériaux inscrits constituaient sur l'aire de séchage des repères qui facilitaient l'enregistrement du travail de chacun. Ce relevé, réalisé périodiquement lorsque les pièces étaient encore sur l'aire de séchage, devait permettre, en outre, de contrôler la qualité du travail des mouleurs et, selon leur statut, de les rétribuer en fonction du nombre de pièces fabriquées ${ }^{120}$.

118. Seul Justimus, mentionné dans le graffite n" 4 du tableau IV, en a moulé nettement moins : 137 , mais le scripteur arait en tête 220 comme référence, car il a précisé pour le dernier mouleur cité. Artemas, le nombre de materiaux manquants dans sa production pour atteindre ce total : "Artemas : 199, en moins : 21 ".

119. Ie centre de production de Rheinzabern (Allemagne) a livré un graffite très incomplet, composé d'au moins trois chiffres l'un aut-dessus de l'autre, l'un d'eux pourrait être 220 (Wiegels, 1989, p. 16 et 66, fig. 66).

120. Pour une approche des relations contractuelles qui pouvaient exister entre un ouvrier tuilier et son patron, voir Charlier, 1999. 


\begin{tabular}{|c|c|c|c|}
\hline No & Lecture & Traduction & Référence \\
\hline 1 & $X X X V I$ & 36 & RIB, II-5, no 2491.35 \\
\hline 2 & $\begin{array}{l}\text { XXXXIIIII } \\
\text { XXXXVI }\end{array}$ & $\begin{array}{l}44 \\
46\end{array}$ & RIB, II-5, no 2491.36 \\
\hline 3 & $\begin{array}{l}\sum \varepsilon \lambda \mathrm{i} \delta(\varepsilon \varsigma \mathrm{ou}-(\omega v) \\
\rho \mathrm{K}^{\prime}\end{array}$ & $\begin{array}{l}\text { Matériaux (« traverses } * \text { ?) } \\
120\end{array}$ & Besevliev, 1952, p. 32, no 53 \\
\hline 4 & $\begin{array}{l}\text { CXX } \\
\text { et rasi } X X\end{array}$ & $\begin{array}{l}\text { (moulés :) } 120 \\
\text { et ébarbés : } 20^{*}\end{array}$ & CIL, V, 8110.450 \\
\hline 5 & $\begin{array}{l}\text { CCXV (ou CCXX) } \\
\text { CCXIIII }\end{array}$ & $\begin{array}{l}215 \text { (ou 220) } \\
214\end{array}$ & RIB, II-5, no 2491.43 \\
\hline 6 & CCXXIII & 223 & Étienne et al., 1976, p. 166, no 369 \\
\hline 7 & CCXXXVI & $236^{* *}$ & Bodel, 1983, p. 71 \\
\hline 8 & CCCC & 400 & RIB, II-5, no 2491.47 \\
\hline
\end{tabular}

Tabl. VIII - Graffites d'identification par un nombre: 1, Bath; 2, Woodchester ; 3, Sofia ; 4, Taggia ;

5, Hartfield ; 6, Conimbriga ; 7, Pouzzoles ;

8 , Chester; *, pour une justification de cette traduction voir $p .88 ; * *$, linterprétation des derniers signes (VI) est incertaine, mais la lecture de J. Bodel (240) me semble encore plus douteuse.

Le formulaire des graffites différait selon les scripteurs et plus probablement selon les usages en vigueur dans les différents ateliers. Quand le nom ou la date n'était pas inscrit, il ne devait pas être difficile de savoir par qui ou quand, même à quelques jours de distance, avait été moulé tel ou tel lot de matériaux. On peut supposer que les mouleurs plaçaient leur production sur l'aire de séchage de manière à ce qu'il n'y ait aucune confusion possible. Si c'était le nombre de matériaux qui manquait, le calcul pouvait être effectué lors du relevé, et surtout l'existence d'un quota journalier rendait sans doute superflue cette indication dans beaucoup de cas. À quoi bon fournir un total, si le mouleur avait effectivement moulé la quantité habituelle de briques ou de tuiles.

La standardisation des graffites datés fait penser que leur forme est calquée sur celle de l'enregistrement ultérieur. Celuici devait probablement toujours comporter au moins ces trois rubriques, et dans cet ordre : date du jour, nom du mouleur et nombre de matériaux.

Une fois le relevé effectué, ces graffites n'avaient plus aucune utilité. Leur signification était de toute façon perdue dès qu'ils étaient dissociés de leur lot de matériaux. Ces textes sur tuiles et briques, quelle que soit leur longueur, n'étaient donc absolument pas destinés à être conservés ${ }^{121}$. Seule la cuisson de leur support nous permet de les connaître aujourd'hui, tandis que les documents comptables des tuileries, portés sur des supports plus habituels et beaucoup plus périssables (tablette, papyrus), ont disparu depuis bien des siècles.

Le rapprochement de ces graffites révèle des pratiques d'identification très différentes entre les ateliers civils et les ateliers militaires. Ces différences se manifestent à la fois par le nombre et par la qualité des graffites. Ils sont en effet incomparablement plus nombreux sur les productions militaires que sur les productions civiles, et leurs différents formulaires sont très inégalement répartis entre les deux. Les graffites datés, quelle

121. Mon interprétation s'oppose à celle de R. Marichal qui, en prenant comme exemple des graffites de Siscia et de Holdeurn, ainsi que celui de Thorame-Haute (voir p. 86), affirme que si beaucoup de graffites ont été écrits par amusement, " il en est d'autres, très proches de nos bordereaux et autres notices [de La Graufesenque], où les aroir fait cuire semble bien indiquer l'intention d’en assurer l'authenticité et la durée. "(Marichal, 1988, p. 17-18). que soit leur longueur, semblent n'avoir été en usage que dans des tuileries légionnaires, ou du moins localisées dans des régions qui connaissaient une présence militaire importante.

\section{INCISIONS DE COMPTAGE}

L'expression " incisions de comptage ", proposée par L. Goulpeau et F. Le Ny (1989), désigne un type de marque très précis que les archéologues anglais nomment tally-marks.

Ces marques sont, selon toute vraisemblance, de nature épigraphique. Cependant, et contrairement au choix des auteurs du $R I B$, je ne les ai pas incluses dans l'inventaire (annexe) en raison de leur fréquence et de l'état actuel des recherches. Ces graffites sont beaucoup plus nombreux que tous les autres, mais ils sont aujourd'hui, en proportion, très rares à avoir été publiés. C'est pourquoi la représentativité des exemplaires connus est difficile à èvaluer.

Ces graffites sont très précisément caractérisés par leur forme et leur emplacement. Ils sont constitués de traits rectilignes qui entaillent légèrement les briques carrées et rectangulaires sur les côtés et les tegulae sur la tranche avant. Ces marques semblent n'avoir été portées que sur ces matériaux ${ }^{122}$. Leur tracé rectiligne, leur finesse et leur profil, le plus souvent en $V$, indiquent qu'ils ont été réalisés à l'aide d'une lame, mais certains traits plus larges et à fond plat ont été obtenus avec un autre outil. Les graffites se composent d'un ou de plusieurs traits perpendiculaires ou inclinés par rapport au plateau des matériaux. Ces traits peuvent se suivre et s'associer pour former des V et des X, voire un L (RIB, II-5, p. 110, n²491.66). La combinaison de ces traits forme donc des chiffres romains, de là l'appellation d'incisions de comptage.

Les exemplaires découverts en Grande-Bretagne montrent des chiffres de I à XII ; le IV et le V sont les plus représentés tandis que les VII, VIII et IX sont absents. Des chiffres plus élevés ne sont illustrés que par trois exemples : XXV, XXX et LXVIII ( $R I B$, II-5, p. 106-110).

En France, quelques-unes de ces marques ont été intégrées dans des corpus épigraphiques dès le xIX“s. (Fontenay, 1874,

122. Une seule exception est connue : une imbrex ou une tuile faittière en Angleterre (Brodribb, 1987, p. 133). 


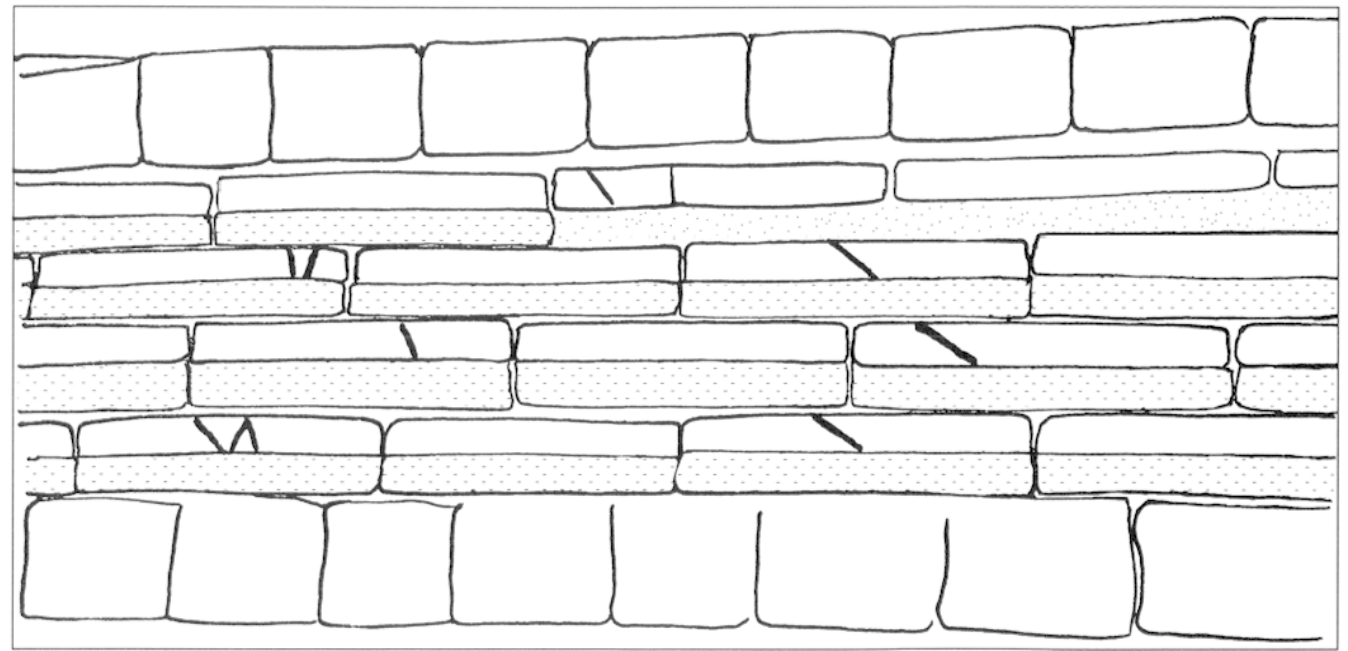

Fig. 54 - Incisions de comptage sur la tranche des briques d'un mur des thermes de Cluny à Paris (d'après Duval, 1960, I, p. 157, fig. 69). Sans échelle.

p. 434), mais la plupart ne sont que succinctement signalées dans des publications de fouilles. Sans prétendre à l'exhaustivité, on peut dresser une première liste de découvertes: Rennes (Goulpeau, Le Ny, 1989, p. 108, fig. 2c), Évreux (Aupert dir., 1997, p. 106), Paris (fig. 54) et l'île-de-France (Duval, 1960, p. 157-158, et pl. XXXII.A ; Barat, 1999, p. 65-66 et 2002, p. 234235), Boulogne (Brodribb, 1979b, p. 154 et 1987, p. 134), Liffolle-Grand (musée de Liffol-le-Grand, Vosges), Langres (fig. 55, n”3), la Bourgogne (Fontenay, 1874, p. 434, n"616; Bernardin, 1954 ; Kapps, 1983 ; Rebourg, 1998, p. 205), la Drôme (Chauffin, 1956, p. 85 ; Desaye, Blanc, 1969, p. 217, 218, n 23 , 24 ; Blanc, Desaye, 1975, p. 251, n6) et le Lot (Pauc, 1982, p. 83). Des exemplaires sont fréquemment découverts en Franche-Comté (fig. 55, no: 1 et 2). Cette liste est évidemment très partielle puisque ces incisions, très modestes, passent souvent inaperçues. Il est frappant cependant de constater que les sites où se rencontrent des incisions de comptage sont tous localisés dans des aires géographiques qui ont livré d'autres types de graffites (fig. 50).

I.es exemplaires découverts en France présentent les formes suivantes : I, II, IV, V, VV, IX et IXI.

On explique souvent ces marques en se référant à un comptage de tuiles stockées sous forme de piles, ces incisions restant ainsi toujours visibles ${ }^{123}$. Les piles pouvaient ctre verticales ou horizontales. 1)ans ce dernier cas, les matériaux étaient posés sur un de leurs longs côtés et serrés les uns contre les autres; une autre rangée pouvait être disposće de la même façon sur la première et ainsi de suite ${ }^{124}$.

123. Une interprétation de repères pour la construction a été parfois croqué (Aupert dir., 1997, p. 106; Rebourg, 1998, p. 205). Elle me semble irrecevable pour des marques faites arant cuisson sur des matériaux standardisés.

124. Contrairement à un empilement vertical, le rangement horizontal oblige à caler les tuiles contre un support quelconque.
Une hypothèse originale a été émise récemment sur la lecture de ces signes. Yvan Barat propose de lire ces marques dans l'autre sens, les I et X ne changent pas, mais le $\mathrm{V}$ devient $\Lambda$, c'est-à-dire un A. Remarquant que A et X sont les deux lettres extrêmes de l'alphabet latin composé de 21 lettres, il suppose que ces marques servaient de repère à des lots de 21 tuiles dans les lieux de stockage. Il justifie ce chiffre par la dimension des tuiles produites à Meudon (Hauts-de-Seine) : 21 tuiles correspondent exactement à une toiture de 3 pieds de large sur 7 de long (Barat, 2002, p. 234-235). Si la formation d'un lot de tuiles en fonction d'une surface de toiture est une hypothèse défendable, il me paraît plus hasardeux de croire que des tuiliers, pour des besoins aussi simples, aient eu recours à une écriture numérique différente du système commun.

Il est vrai que dans certains cas, le $\mathrm{V}$ est à l'envers par rapport à l'orientation normale du matériau ${ }^{125}$ (Desaye, Blanc, 1969, p. 217 , n`23 ; Blanc, Desaye, 1975, p. 251, n6), celui-ci était sans doute retourné quand il a été marqué.

À partir des chiffres rencontrés et des observations techniques, je proposerai de restituer les modalités matérielles de ce comptage de la façon suivante : les matériaux suffisamment secs pour être empilés sont comptés par pile ou par lot de piles, en marquant successivement une pièce toutes les cinq, d'un $\mathrm{V}$ puis d'un X. Au sommet d'une pile, si les matériaux restants sont inférieurs à j, leur nombre est indiqué sur la tranche du dernier par autant de I. Cette hypothèse permet d'expliquer l'absence quasi totale de chiffre entre $\mathrm{V}$ et $\mathrm{X}$.

On peut noter que les I sont très souvent inclinés et que les $\mathrm{V}$ et les $\mathrm{X}$ sont généralement déséquilibrés. L'inclinaison observée, presque toujours sur la gauche si le matériau est orienté normalement, ne doit pas faire croire que les piles penchaient (!), mais indique tout simplement que les scripteurs ćtaient majoritairement droitiers.

125. C'est-à-dire la face supérieure lissée, dirigée vers le haut et la face inférieure irrégulière, souvent sabléce, vers le bas. 

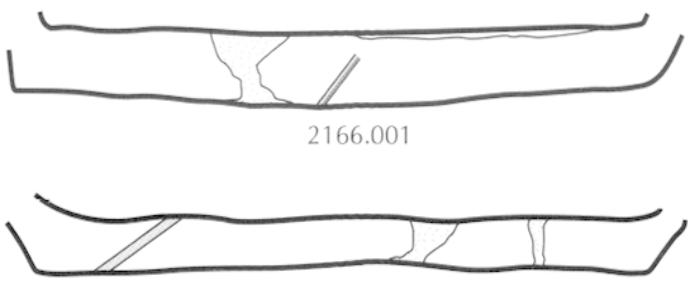

2152.011

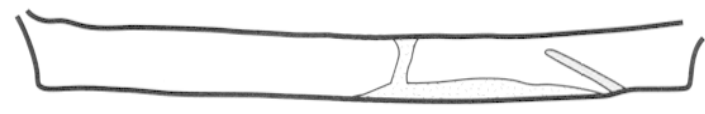

2433.024

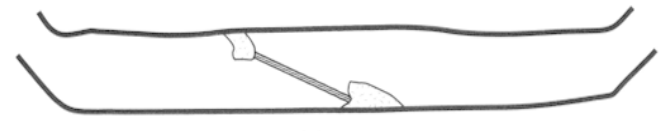

2152.008

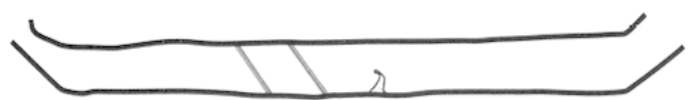

2152.012

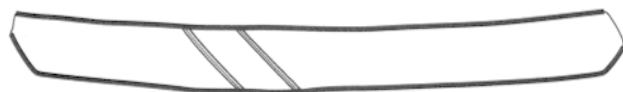

2152.035

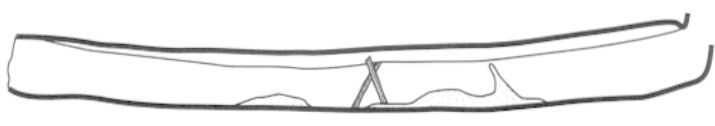

3001.097

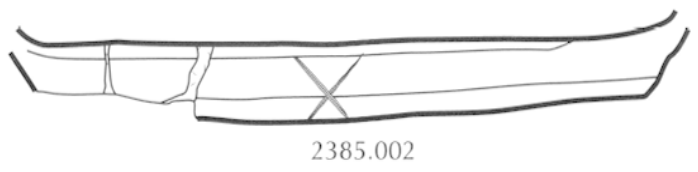

a

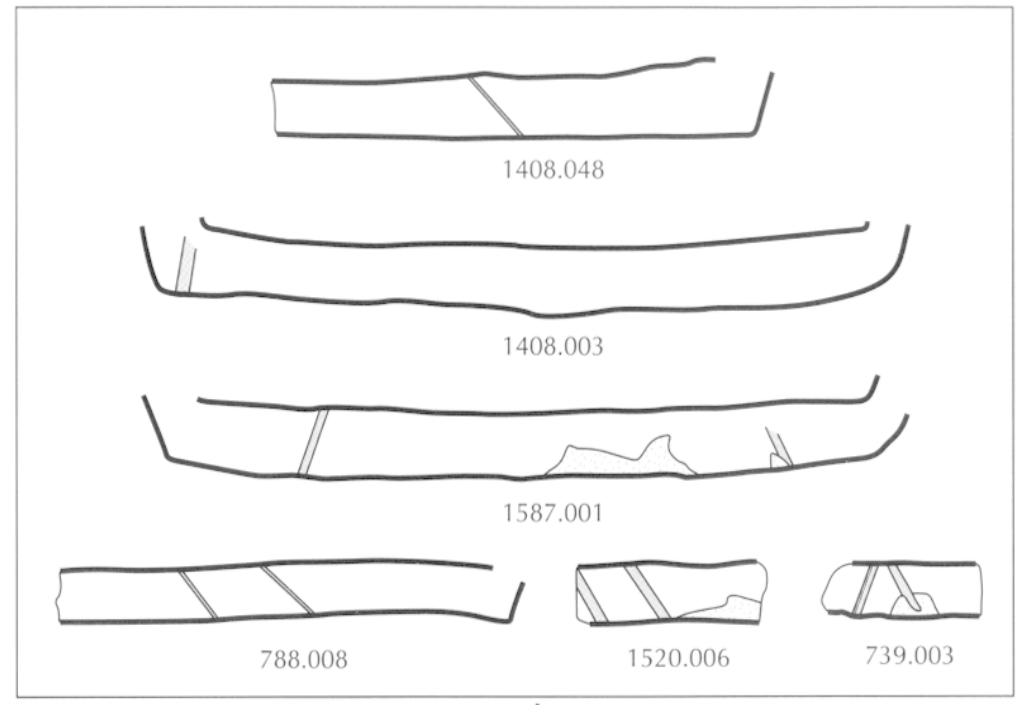

b
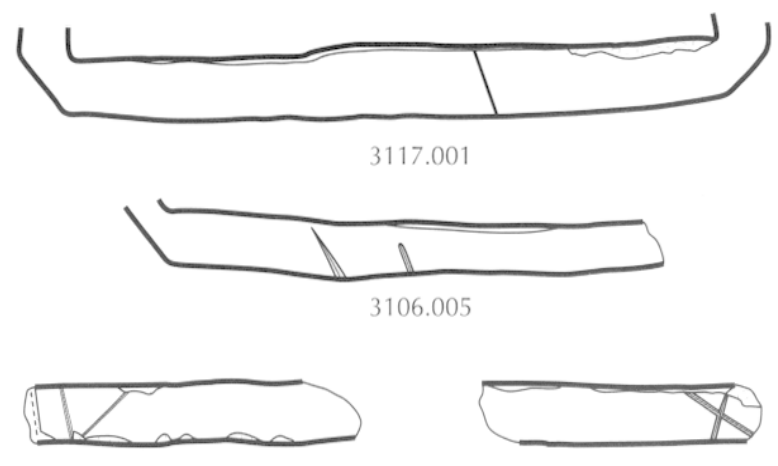

3056.002

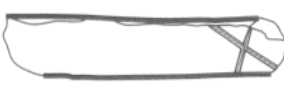

1033.005

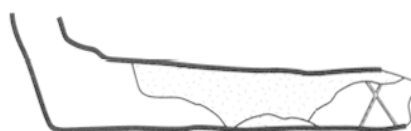

3032.005

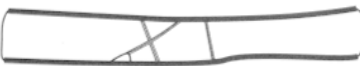

3052.001

Fig. 55 - Incisions de comptage sur la tranche avant de tegulae : a, la tuilerie à Moissey, Jura; b, lycée Condé à Besançon, Doubs; c, Freudenberg à Langres, Haute-Marne (dessin F. Charlier). Échelle : 1/4.

\section{PIÈCES DIVERSES}

\section{DOCUMENTS COMPTABLES}

Certains graffites sont composés d'une liste de noms suivis d'un nombre d'unc ou de quclques unités sculcment (CII., III, p. 962, n०3). Que ces graffites se rapportent au travail des tuiliers n'est qu'une hypothèse.

Le document découvert à Caerwent (Grande-Bretagne) se présente ainsi :

\begin{tabular}{l} 
]S[..]AS \\
VASFRONTO II \\
TIIRTIVS II \\
SIIMILICINVS I \\
SIINTIVS I \\
AGILIS I \\
FORTVNA[ \\
\multicolumn{1}{c}{ ]..II.[ }
\end{tabular}

M. Hassal et R. Tomlin supposent que ces six noms désignent des ouvriers et qu'ils sont suivis de la quantité de matériaux qu'ils ont fabriqués exprimée en nombre de lots. Ils restituent neuf sur la dernière ligne, qui serait le total des lots (Britannia, 24, 1993, p. 321-322, n”30 et pl. 16).

Le graffite de Montenach est plus explicite, il s'agit d'un compte de journées de travail concernant un ouvrier qui n'est pas nommé (57.1). Chacune des six lignes du texte mentionne un travail, avec plus ou moins de précision, et se termine par un nombre de journées ${ }^{126}$.

Il peut être comparé au graffite inscrit sur unc poteric sigillée découverte à La Graufescnque et qui est interprété comme un mémoire enregistrant les journées de travail effec-

126. On trouvera une analyse détaillée de ce graffite dans (harlier, 1999 , p. 173-176. 
tuées dans un atelier de potier par les esclaves d'une dénommée Atelia (Marichal, 1988, p. 226-228).

Le document de Montenach est probablement un mémoire du même typc. Il est probable que la forme juridique qui réglait les rapports de cet ouvrier et de son employeur était un contrat de louage, plus précisément une locatio operarum, ou une stipulation d'operae ${ }^{127}$.

\section{Autre DoCument}

Le graffite écrit sur une tegula découverte à Thorame-Haute est tout à fait singulier (04.5). Il présente un formulaire unique en son genre. La mention d'une cuisson suivie d'une date sur la première ligne avait conduit $R$. Marichal à en faire "un bordereau d'enfournement, incomplet d'ailleurs puisqu'il $\mathrm{y}$ manque les chiffres" (Marichal, 1988, p. 18). Je ne suis pas d'accord avec cette interprétation car il manque non seulement les chiffres mais aussi les noms. Il est évident que l'organisation d'une cuisson de tuiles dans un petit atelier était différente d'une cuisson de céramiques sigillées dans un centre de production comme l'était celui de La Graufesenque, mais à quoi peut bien servir un bordereau d'enfournement qui ne donne ni les noms des fabricants ni les quantités de matériaux. À moins d'invoquer la distraction du tuilier, il est difficile d'expliquer l'absence de ces données. Ce graffite présente aussi une autre particularité : il est le seul à préciser le jour de la semaine.

L'unicité et le sens de ce document me font douter qu'il ait joué un rôle quelconque dans la production.

\section{DOCUMENTS DE NATURE COMMERCIALE}

Quelques graffites semblent faire référence à des commandes de matériaux. Pour les exemplaires nos 1 et 2 du tableau IX, cela n'est qu'une hypothèse. Ils étaient peut-être destinés à rappeler aux tuiliers la nature et le nombre de matériaux qui leur avaient été commandés. D'après la nature des pièces indiquées dans le premier graffite, $\mathrm{R}$. Tomlin suppose qu'il s'agit de matériaux nécessaires à la construction des bains d'une villa (Tomlin, 1979, p. 233). Le deuxième graffite indique, semble-t-il, la partie d'un bâtiment à laquelle les briques étaient destinées, le troisième dallage (?). Ces deux documents s'apparentent, vu leur caractère succinct, à de simples aide-mémoire.

Les deux autres documents du tableau IX, les n's 3 et 4 , sont très différents des premiers dans leur forme et dans leur contenu. Un certain formalisme se manifeste en effet dans leur rédaction par la précision du lieu (le nom de la localité pour l'un, la formule uenit ad nos pour l'autre), par la mention de l'identité d'un certain nombre de personnes (les acheteurs des matériaux ${ }^{128}$ et dans un cas leurs destinataires) et, surtout, par

127. Ces notions juridiques sont introduites dans l'analyse du graffite de Sant'Angelo in Formis (voir p. 75-76).

128. Pour le graffite de Schuld, la lecture du nom de cet individu (mentionné à l'antépénultième ligne) est difficile. Schillinger-Häfele (1977) avance l'hypothèse de T(i)lus Augusti( $i$ ? seruus), reprise dans l'Année éptigraphique (1978, n569) ; Wegner (1990) préfère la lecture: T(i)tus Tusaucus T(iti) f(ilius). le fait qu'il s'agit non pas de simples énumérations mais de textes.

Les caractéristiques de ces documents font qu'ils ne peuvent pas être considérés comme des aide-mémoire, même s'ils pouvaient parfaitement être aussi utilisés ainsi par les tuiliers. Leur rédaction empreinte de formalisme évoque des actes juridiques, actes qu'il est facile de déterminer puisque le sens des textes et le vocabulaire employé font clairement référence à l'emptio/uenditio, au contrat de vente. Plus exactement ces deux textes ne font référence qu'à l'une des deux obligations que faisait naître la conclusion d'une vente : l'obligation pour le vendeur de délivrer les produits à l'acheteur. Les verbes cmployés sont différents mais aussi explicites : deferre et accipere à deux reprises. Le fait qu'aucune référence ne soit faite à l'autre obligation - celle pour l'acheteur de payer les matériaux - que le nom des vendeurs, les tuiliers, ne soit pas connu et qu'enfin aucune des deux parties n'ait souscrit les textes rend ces documents déficients comme moyen de preuve dans une procédure juridique. En outre, le grand nombre de ces « omissions » et leur parallélisme nous empêchent de croire que ces graffites constituent des instrumenta incomplets ou leurs brouillons. Ces documents attestent l'existence de contrats mais n'en sont pas les instrumenta. Ils le sont d'autant moins que nous savons que ces graffites sont restés entre les mains des tuiliersvendeurs et non des acheteurs, puisqu'ils ont été portés sur des matériaux crus qui ont ensuite été cuits. On comprend aisément qu'un tuilier détienne la preuve de l'engagement d'un acheteur, mais non qu'il conserve la trace écrite de ses propres obligations.

$\mathrm{Si}$ ces graffites n'avaient aucune valeur probatoire juridiquement parlant, il est probable qu'il en allait autrement du point de vue moral, et c'est là qu'il convient de chercher l'origine de ces documents.

Lors des ventes auxquelles font référence les deux graffites, il est probable que les acheteurs aient réglé aussitôt les tuiliers et que les deux parties se soient mises d'accord sur une date ultérieure de livraison des matériaux. Cette date dépendait de la convenance des acheteurs et de l'état des stocks de l'atelier ${ }^{12 \%}$. La délivrance des matériaux a ainsi été fixée neuf jours après la conclusion de la vente dans le cas du graffite de Schuld (tabl. IX, n'4). La livraison effective des matériaux reposait alors sur l'honnêteté et la bonne foi des tuiliers-vendeurs. Les deux graffites témoignent, me semble-t-il, de l'attitude, pour l'un de l'acheteur et pour l'autre du tuilier, dans cette situation. l. graffite de Rome est écrit à la troisième personne, mais il est aisć de comprendre que c'est l'acheteur, Lulio, qui l'a rédigé. On comprendrait mal, si ce n'était pas le cas, l'insistance contenue dans la formule verbale : indixit ut deferantur: Ce Lulio craignait-il que le tuilier ne respectât pas son obligation? Toujours est-il qu'il a cru bon de la lui rappeler par écrit avant

129. Il n’était pas nécessaire que l'objet soit présent pour conclure une vente, il suffisait que les deux parties estiment que l'objet existera. De ce point de vue, on distingue dans le droit romain l'emptio rei speralae (l'achat de la chose espérée) et l'emptio spei (l'achat de l'espérance). L'achat de briques ou de tuiles non encore fabriquées par le tuilier - ce que nous appelons communement une commande - appartient à la première catégorie. 
Tabl. IX - Graffites de nature commerciale: 1, Wiggonhold ; 2, Hummetroth ; 3, Rome; 4, Schuld.

\begin{tabular}{|c|c|c|c|}
\hline No & Lecture & Traduction & Référence \\
\hline 1 & $\begin{array}{l}\text { [--- ?] } \\
\text { pillares]. XX } \\
\text { cuniati IIII } \\
\text { tubi n(umero) DLX }\end{array}$ & $\begin{array}{l}\text { [--- ?] } \\
\text { briques bessales : } 20 \\
\text { briques voussoirs : } 4 \\
\text { tubulures, nombre : } 560\end{array}$ & RIB, II-5, no 2491.2 \\
\hline 2 & $\begin{array}{l}\text { stratura tertia } \\
\text { latercli } \cdot \text { capitlares } \\
\text { n(umero) CCCLXXV } \\
\end{array}$ & $\begin{array}{l}\text { Troisième dallage } \\
\text { briques capitalares } \\
\text { nombre : } 375 \\
\end{array}$ & Brambach, 1867, no 1397 \\
\hline 3 & $\begin{array}{l}\text { Benebento } \\
\text { tegulas indixit } \\
\text { Lulio } n \text { (umero) CCCCl ut defe } \\
\text { rantur at por(tus) Neapo }\end{array}$ & $\begin{array}{l}\text { À Beneventum } \\
\text { Lulio a notifié que } 401 \text { tegulae soient livrées } \\
\text { à l'entrepôt de Neapolis }\end{array}$ & CIL, XV, 6123 \\
\hline 4 & $\begin{array}{l}\text { Pulsator accip(i)et lamnas } L X X X \\
\text { imbrices murales n(umero) XX } \\
\text { qunios dodrantes n(umero) XX } \\
\text { sextum kalandas Augustas } \\
\text { lustius Optatus accip(i)et } \\
{[---]} \\
\text { sccundarias n(umcro)[ } \\
\text { lamnas } n(\text { umero) XII } \\
\text { imbrices n(umero) XXX } \\
\text { sur le côté, en bas à droite: } \\
\text { TTVSAVCVST! } \\
\text { uenit ad nos XV Kal(endas) } \\
\text { Augustas }\end{array}$ & $\begin{array}{l}\text { Pulsator recevra } 80 \text { dalles (?) } \\
\text { des imbrices murales au nombre de } 20 \\
\text { des quinos dodrantes au nombre de } 20 \\
\text { le } 6 \text { e jour avant les calendes d'août } \\
\text { lustius Optatus recevra } \\
{[---]} \\
\text { du second choix au nombre de... } \\
\text { des dalles (?) au nombre de } 12 \\
\text { des imbrices au nombre de } 30 \\
\text { TTVSAVCVSTI } \\
\text { est venu chez nous le } 15 \text { e jour avant les calendes } \\
\text { d'août }\end{array}$ & Schillinger-Häfele, 1977, p. 527-528, no 142 \\
\hline
\end{tabular}

de quitter la tuilerie. En revanche le graffite de Schuld a été rédigé par le tuilier, comme l'indique clairement la formule uenit ad nos. Faut-il croire, là aussi, que l'acheteur nourrissait quelques craintes? Il est sûr, en tout cas, qu'en portant par écrit la parole donnée, le tuilier cherchait à donner plus de poids à son engagement moral. Ce texte a évidemment été rédigé devant l'acheteur, juste après la conclusion de la vente : le tuilier tentait ainsi de le rassurer.

Ces textes constituaient une garantie purement symbolique de la parole donnée, de la bonne foi des tuiliers. Dépourvus de valeur juridique, ils n'en illustrent que mieux le caractère de bonne foi, bona fides, des contrats consensuels et notamment de la vente.

Comme pour tous les contrats consensuels, le droit romain n'exige aucun écrit particulier à la conclusion d'une vente, il suffisait que les parties soient définitivement d'accord sur la chose et sur le prix. Dans les ventes qui nous intéressent, acheteurs et tuiliers-vendeurs ont pu soit se contenter d'un accord oral, soit décider de porter leur accord par écrit. Dans ce dernier cas un instrumentum a probablement été rédigé sur une tablette de bois. Si les matériaux avaient été réglés immédiatement, un seul instrumentum destiné à l'acheteur était nécessaire, il devait mentionner le règlement et détailler les obligations du vendeur ${ }^{130}$. Quel que soit le choix des intéressés, avant de se

130. $\dot{A}$ titre de comparaison, on pourra consulter les tablettes Albertini (Courtois et al., 1952). Ces instrumenta, conformes au droit romain d'Occident malgré leur lieu de découverte (la frontière algérotunisienne) et leur date (la fin du $v^{*} \mathrm{~s}$.), rendent compte de ventes dans lesquelles ne subsistaient que les obligations du vendeur. L'objet de la séparer, l'un des deux a jugé préférable de rappeler sur un graffite l'obligation qui restait à exécuter. La volonté d'accentuer la valeur morale de ces graffites peut suffire à expliquer leur style relativement formel, mais il est tentant de tirer argument de ce formalisme pour en faire des copies plus ou moins serviles de certains passages de l'instrumentum du contrat auquel ils se rapportent.

Les deux premiers graffites (tabl. IX, $\mathrm{n}^{\text {os }} 1$ et 2) ne sont peut-être pas si différents des deux autres, leur absence de formalisme n'interdit pas qu'ils aient été écrits dans les mêmes conditions.

Outre leur intérêt juridique, ces documents ont le mérite de nous faire connaitre le nom de matériaux de construction en terre cuite, termes techniques rares dans la littérature latine. Il serait hors de propos et trop long d'énumérer et de commenter ici tous les noms des matériaux que les graffites nous livrent ${ }^{131}$. Je ne ferai que quelques remarques sur l'un des termes contenus dans le graffitc de Schuld dans la mesurc où il apportc un renseignement d'ordre commercial. Il s'agit de secundarias, en ligne 7 (tabl. IX, n4). On peut littéralement le traduire par " de taille inférieure ", ou " de qualité inférieure ". Il est probable que les matériaux auxquels ils étaient comparés étaient mentionnés dans la ligne précédente, ligne définiti-

vente était des parcelles de terre que les acheteurs avaient réglées immédiatement.

131. N. Gudea a établi une liste de noms de matériaux de construction en terre cuite livrés par des estampilles et des graffites (Gudea, 1996, p. 480-481). Cette liste non commentéc est particlle, l'auteur ne semble pas avoir comnaissance du graffite de Schuld. 
vement perdue par la détérioration de la brique. Si le terme secundarias porte sur la taille, on peut traduire par " (des matériaux) de taille inférieure ", et s'il concerne la qualité, l'expression "du second choix " convient parfaitement. Mais un " second choix " a-t-il un sens dans une tuileric romaine? Il me scmble que oui. Ces matériaux de qualité inférieure devaient être des pièces défectueuses, c'est-à-dire qu'elles étaient soit moins bien cuites ${ }^{132}$, soit déformées ${ }^{133}$, soit même en partie cassées ${ }^{134}$.

\section{RELATIONS ENTRE TUILIERS}

Quelques graffites se réfèrent explicitement à des travaux réalisés dans les tuileries ou mentionnent des individus impliqués dans la production. Ils ont donc été écrits par des tuiliers, qui sont soit des patrons (ou des contremaîtres), soit des ouvriers. Toutefois, contrairement aux documents précédents, ils ne jouent aucun rôle réel dans le déroulement du travail, ils sont totalement insignifiants de ce point de vue. Ils constituent, en revanche, une source précieuse pour comprendre la mentalité et la culture des artisans ainsi que pour apprécier l'ambiance qui régnait dans les ateliers.

On ne compte qu'une poignée de ces graffites dans le monde romain, et atucun en France.

\section{EXPRESSIONS DE PATRONS}

Deux graffites sont de la main de patrons qui s'adressent à l'un de leurs ouvriers.

I.'un, trouvé à Aquilée (Italic), est le suivant $(C H, \mathrm{~V}$, $8110.176)$ :

cave.malum.si.non.

raseris lateres $\cdot B C$

si.raseris. minus. malum. formidabis

Je le traduis littéralement ainsi : "Gare à la correction si tu n'as pas ébarbé 600 briques, si tu en as ébarbées moins, cette correction tu la redouteras ".

132. Un des chapitres du Manuel Roret de 1864 sur le travail des briquetiers et des tuiliers est consacré au "Défournement et triage des briques ". Il précise que les briques d'une même fournée n'étaient pas cuites d'une manière uniforme dans un four. Celles qui étaient placées sur la sole juste au-dessus de l'alandier vers le foyer étaient souvent surcuites, tandis que celles qui étaient voisines des parois et du sommet du laboratoire risquaient ne pas être suffisamment cuites. Un " triage" des matériaux selon leur degré de cuisson devait donc être opéré lors du défournement. l.es briques insuffisamment cuites pouvaient être vendues à bas prix pour être utilisées à l'intéricur de maçonneries (Malepeyre, 1864, p. 104-107). Rien n' interdit de croire que les artisans romains n'agissaient pas autrement.

133. I.e phénomène de retrait de laargile lors du séchage puis de la cuisson provoque des déformations plus ou moins importantes sur les matériaux, les pièces les plus voilées mais encore utilisables auraient pu constituer un second choix.

134. L'n passage de Caton (De l'agriculture, XVII, 14, 4) nous apprend que même les tuiles cassées pouvaient être utilisées sur un toit, du moins si la partie manquante n'excédait pas le quart de la tuile. Il est vai qu'il suffisait d'augmenter le recourrement des tuiles du toit pour en garantir l'étanchéité.
Cette inscription est une menace directe du responsable de la production à l'égard d'un ouvrier s'il n'effectue pas le travail réclamé.

Ce graffite a été souvent cité, mais je ne crois pas qu'il ait été entièrement compris avant la traduction que j'en ai donnéc (Charlier, 1999, p. 180-181). La difficulté était de traduire raseris, du verbe radere (rado, rasi, rasum, radere) qui signifie " raser ", " raboter ", " racler ". Les ćpigraphistes et les historiens n'ont pas compris l'expression "raser des briques " et ont considéré qu'il s'agissait pour l'ouvrier de les faire, c'est-à-dire de les mouler. Cette interprétation pourrait être confortée par l'un des sens du verbe raser en ancien français. "Raser " signifiait notamment " passer la rase " c'est-à-dire passer un bâton sur un boisseau de sel ou de blé pour en obtenir une mesure juste - on employait aussi dans ce sens la forme "rader", d'où " rade ", " radoire ", " radeur " - et par extension " remplir jusqu'à ras, jusqu'au bord " ${ }^{135}$. On pourrait croire que radere désignait l'action du mouleur qui, après avoir rempli son moule, faisait glisser une règle dessus pour en retirer l'excédent d'argile et que, par extension, cette action aurait désigné le moulage tout entier. Toutefois " raser » est employé avec le sens de " parer " dans le seul ouvrage technique qui contienne ce verbe, L'art du tuilier et du briquetier de Duhamel, Fourcroy et Gallon publié en $1763^{136}$. Parer, ou ćbarber, signific, pour des matériaux en terre, faire glisser une lame sur leurs côtés afin de les régulariser, d'ôter les bavures d'argile laissées par le moulage. Cétte action est réalisée alors que les matériaux sont disposés sur l'aire de séchage. En outre, un graffite trouvé à Taggia (Italie) atteste que radere désigne une autre action que le moulage (tabl. VIII, $\left.n^{\circ} 4\right)$. Sa formulation (CXX $\mid$ et rasi $\left.X X\right)$ indique qu'il enregistre le résultat de deux travaux différents. Le premier n'avait pas besoin d'être précisé et ne l'était jamais tant il allait de soi, c'était le moulage ; le second est introduit par le participe passé de radere. Le plus simple est de laisser à ce verbe son sens premier, c'est-à-dire raser, soit couper en effleurant ce qui correspond parfaitement à l'action de parer, d'ébarber des briques.

Le second graffite, inscrit sur un grand fragment de brique découvert à Malo Golubinje (Yougoslavie), se présente ainsi ( (.IL, III, 8277.3) :

\section{]I.ATERCIVS II \\ ]V RIANE \\ ]ALE DOR \\ ]S SI NVN FE. \\ CERIS}

Les éditeurs restituent le début des lignes de la manic̀re suivante :

[Fac] laterdus [CC: ?] [F]uriane: [m]ale dor[mie]s si nun feceris.

Je le traduis ainsi : "Fais 200 briques Furianus : tu vas passer une mauvaise nuit si tu ne les fais pas!"

135. "Raser" "dans le Dictionnaire de lancienme langue française el de tous ses dialectes (Paris, 1880-1902) de F. Codefroy; "rader " dans le Dictionnaire de la langue française (Paris, 1863-1872) de E.. Littre.

136. "Le premier mouvement du couteau le long des briques a rasé \& paré autant de briques du premier lang pour un bout, que le bras de l'homme en peut rencontrer dans l'attitude où il se met |...l. " (l)uhamel ot al., 1763, p. 32, $1^{\circ} 59$ ). 
Ce graffite se révele être très proche de celui d'Aquilée, une nouvelle fois un responsable menace un ourrier s'il ne réalise pas le travail qui lui est demandé. Dans le graffite de Malo Golubinje, ce travail consiste très probablement à mouler des briques dont la quantité est indiquée par " II ". On peut y voir le nombre de 200, comme les éditeurs le proposent, ou croire qu'il s'agit pour Furianus de mouler un nombre de briques équivalent à deux quotas journaliers (voir supra, p. 82).

Ces deux documents illustrent des rapports tendus entre responsables et ouvriers, où l'écriture est employée pour domner plus de poids encore à des ordres que l'on imagine avoir été prononcés le poing levé.

\section{EXPRESSIONS D'OUVRIERS}

Ecrits incontestablement par des mouleurs, deux textes constituent des témoignages tout à fait explicites de leur état d'humeur ${ }^{133}$.

Le plus long provient du site de Conimbriga (Portugal). Il a été porté sur une brique de colonne en quart-de-rond :

ex officin(a)
Maelonis.
diarias.
rogala
s. solui

Les éditeurs le traduiscnt ainsi : "Brique provenant de l'atelier de Maelo; les quantités requises de briques journalières, je m'en suis acquitté " (Étienne et al., 1976, p. 159-160, n'358a)

Un mouleur travaillant dans l'atelicr de Maelo manifeste clairement ici sa satisfaction d'avoir accompli son travail, ce qu'il exprime selon toute vraisemblance sur la dernière brique de la journéc. Ce document nous renseigne sur la nature du " contrat de travail" qui lie son auteur et le patron de la tuilerie, contrat qui porte ici sur un opus apprécié quotidiennement ${ }^{138}$. Cette mention claire d'un quota journalier de briques à mouler permet de conforter l'interprétation de certains graffites d'identification de production de mouleurs trouvés dans d'autres provinces.

C'est aussi sur la dernière brique d'une journée de travail qu'a certainement été inscrit un graffite trouvé à Silchester en Grande-Bretagne (RIB, II-5, n²491.159). Un scul mot en grands caractères s'étale sur toute la longueur de la brique: SATIS, soit "Assez! ". Je verrais cette fois dans ce document fort laconique moins la satisfaction du travail accompli qu'un fort sentiment de lassitude.

Nous savons que des personnes étrangères à la production ont pu réaliser des graffites (voir supra, p. 72). Si aucune allusion à la fabrication des matériaux n'est contenue dans un texte, il est difficile de pouvoir l'attribuer à un tuilier.

137. Des " expressions d'ourriers" d'époque républicaine sont commues en Italie. le premier document. qui est bilingue (osque et latin), figure sur une brique de Pietrabbondante dans le Samnium, le second sur une tegula urouvé à Pellara en Calabre (commentaire, bibliographie et reproductions dans Morel, 1991, p. 195-199).

138. (On trowera dans Étienne el al., 1976, p. 159 ; Marichal, 1988, p. 19 et Charlier. 1999, p. 182-184, des analyses comvergentes sur ce point.
Cependant, grâce à la richesse épigraphique des matériaux découverts à Conimbriga, on peut raisonnablement penser que les auteurs des deux graffites suivants sont des ourriers. Ces documents s'adressent en effet à des individus dont on sait, par d'autres graffites et des estampilles, qu'ils dirigeaient des tuileries.

Le premier est aussi court que respectueux. On lit sur une brique de colonne en quart-de-rond :

$$
\begin{aligned}
& \text { Aue } \\
& \text { Maelo }
\end{aligned}
$$

Soit : "Salut Maelo " (Étienne et al., 1976, p. 160, n”358b). Le second, écrit sur une dalle, révèle :

\section{Duatius \\ tacim \\ filiu(s). fe \\ lat te}

Les éditeurs le traduisent ainsi : " Duatius, il vaudrait mieux que je me taise: ton fils te suce. "(Étienne et al., 1976, p. $\left.158-159, \mathrm{n}^{\circ} 357 \mathrm{~b}\right)$.

La fréquence de ce type d'injure dans le monde romain, et notamment sur les murs de Pompéi, prouve que cet ouvrier anonyme, en proférant une injure de caractère sexucl à l'égard de son patron, respectait une «coutume " toute aussi romaine que la salutatio.

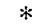

$$
\text { ** }
$$

Le rapprochement et le classement fonctionnel des différents graffites permettent d'apprécier leur originalité et de proposer quelques réflexions sur la pratique individuelle et collective de l'écriture dans les tuileries gallo-romaines.

On remarque que les graffites non relatifs au travail des tuiliers sont presque tous d'une grande banalité et ne se distinguent pas de ceux qui ont été inscrits sur les murs ou sur d'autres objets ${ }^{139}$. Le support ne change rien à la nature des inscriptions, citations poétiques, déclarations licencieuses, comptes ou noms, tous se retrouvent indifféremment sur l'argile d'une brique ou sur l'enduit d'un mur. I es graffites y sont toujours des messages individuels et spontanés. Parfois ils ont une utilité pratique, mais généralement ils sont anecdotiques et ne trouvent leur origine que dans le scul plaisir d'écrire de l'auteur. Il faut noter toutefois que quelques graffites sont d'une tout autre nature. Il s'agit de deux graffites trouvés à Châteaubleau (77.5 et 77.16), un à Villafranca de los Barros, Espagne, et un autre à Gornea, Roumanie (Gudea, 1983). Leur contenu est original par rapport aux autres documents et leurs auteurs les ont écrits non pour eux-mêmes mais pour des destinataires déterminés ${ }^{140}$. On imagine plus volontiers ces textes écrits sur des tablettes. La raison pour

139. On trowera dans Pietri, 1983, wne riche bibliographic sur les graffites, que l'on pourra compléter pour l'instrumentum arec les références citées dans les actes du colloque qui s'est tenu à Pécs en 1991 (Ormos, Visy dir., 1991).

140. Dans le cas de Gornea, ce destinataire était le fonctionnaire auquel était adressée cette requête, dans celui de Villafranca de los Barros (voir supra, n. 96, p. 74), et de même, peutêtre, dans ceux de (hâteaubleau (woir p. 72 et 74), il s'agissait d'un groupe de personnes. 
laquelle leurs auteurs les ont inscrits dans l'argile, alors qu'ils ne sont certainement pas des tuiliers, reste inconnue.

Ces observations peuvent être renouvelées au sujet des graffites relatifs au travail des tuiliers. Il est facile, à quelques spécificités professionnelles près, de leur trouver des parallèles dans le corpus des graffites écrits par d'autres artisans. Seuls quelques-uns sont atypiques. Les comparaisons s'établissent essentiellement avec les graffites de potiers et de carriers, puisque ce sont presque les seuls autres documents de ce type qui nous soient parvenus. Parmi eux, on trouve des dates, des chiffres, des noms, des comptes, ainsi que des consignes de travail. On comprend aisément que de telles inscriptions participaient au bon déroulement du travail ${ }^{1+1}$. Il s'agit de textes qui n'intéressaient que les artisans eux-mêmes, qui souvent ne pouvaient être compris que par leurs auteurs et qui perdaient toute valeur une fois passée la phase de travail à laquelle ils correspondaient. À ces graffites communs s'opposent quelques textes, eux aussi tracés dans l'argile molle d'une brique ou d'une tuile. L'instrumentum de louage d'ouvrage de Sant'Angelo in Formis et le compte de journées de travail de Montenach (57.1) sont ces graffites atypiques. Des textes de cette teneur sont en effet normalement portés sur des supports conçus pour l'écriture : tablette, papyrus... ${ }^{142}$.

141. Il n'est pas question pour autant d'interpréter systématiquement comme documents relatifs au travail des graffites composés d'éléments aussi communs qu'un nom ou une date. Certaines références bibliographiques citées ci-dessus fournissent de nombreux exemples de graffites de potiers, de même que les volumes consacrés aux inscriptions sur les poteries dans The Roman Inscriptions of Britain sous la direction de R. G. Collingwood et R. P. Wright. Je n'ajouterai que ces deux textes qui figurent sur les panses de deux amphores Dressel 20 trouvées à Genève : III K(alendas) octolm[e]s / Fortunatuls Le $3^{\text {e }}$ jour avant les calendes d'octobre, Fortunatus; Idibus Ianuarlils / Fortu[natus] - Le jour des ides de janvier, Fortunatus (Paunier, 1981 , p. 238 , p. 243 et p. 362, fig. 484-485). L.es carrières livrent de nombreux graffites semblables. On peut voir sur les parois des carrières militaires et civiles du Kriemhildenstuhl à Bad Dürkeim (Allemagne) les exemplaires suivant : IIII Idus Mai(as) - le 3 " jour avant les ides de mai ; Septimini VI ld(us) Augustas - De Septiminus, le $6^{\mathrm{e}}$ jour avant les ides d'août ; Ouadr(atorius ?) Mopesu/s] - I.c tailleur de pierre Mopesus (Bedon, 1984, p. 219-220). Dans la galerie de la mine de Pioch-Farrus à Cabrières (Hérault), deux graffites enregistrent la quantité de minerai extrait par tel et tel ouvrier: Gaius IIII et Aur(elianus) IIII (Bailly-Maître et al., 1984, p. 334-336). Des ordres, ou du moins des directives de travail, ont aussi été reconnus. Ainsi l'enduit d'un mur de Jublains (Mayenne) porte ce graffite de maçon écrit en latin vulgaire: Islimauit or ütunauito cïqsu - ce mur sera poli et jointoyé (Lambert, 2002, p. 363-365, *L-138). Sur un fragment de peau de chèvre trouvé à Vindonissa/Windisch (Suisse), on lit: TOTA, les éditeurs y voit un message adressé au tanneur: "Tanner toute la peau!" (Fellmann, 1992, p. 220, fig. 184).

142. La Graufesenque a certes livré sur des céramiques sigillées deux graffites comparables - le décompte des journées de travail des esclaves d'Atelia et un fragment d'un acte d'achat d'un esclave (Marichal, 1988, p. 226-228 et p. 243) -, mais cela fait bien peu comparé aux milliers de graffites connus. Le cas est différent pour les textes portés sur la tegula de Rome et sur la brique de Schuld qui se réfèrent sans conteste à une vente (voir p. 86-88). L.e contenu de ces graffites est inhabitucl, mais je ne crois pas que leurs auteurs auraient pu les écrire sur un autre support. La facilité avec laquelle on traçait des leures sur l'argile est à l'origine de ces documents, elle permettait de "mettre en scène " la bonne foi du tuilier-tendeur par le geste de l'écriture.
J'ai tenté, en établissant le classement des graffites relatifs au travail des tuiliers, de donner à chacun d'eux un sens et une place dans la chaîne opératoire, mais les interprétations proposées sont schématiques et ne rendent compte certainement que de façon partielle du rôle joué par ces écrits dans la production. Ce travail est en effet fondé sur le rapprochement de graffites issus de tuileries civiles et militaires dans tout l'Occident romain et durant tout l'Empire. L'établissement de telles séries ne permet évidemment que de dégager des « lois générales " qui sont certainement loin de correspondre à tous les cas de figure. Il est clair, vu leur contenu, que tous les graffites relatifs au travail, ou presque, ont été écrits soit par des patrons ou des contremaîtres, soit par des mouleurs. Ceux qui concernent les relations entre tuiliers illustrent parfaitement cette dichotomie. La fonction des autres documents permet en partie de déterminer leurs auteurs. Les $\mathrm{R}$ digités, les documents comptables et les documents de nature commerciale ont probablement été écrits par des responsables ${ }^{143}$. Quant aux graffites d'identification de production de mouleurs et aux incisions de comptage, savoir qui les a écrits est plus difficile. Il est tentant de faire des mouleurs les auteurs des graffites qui servaient à identifier leurs propres matériaux. Toutefois on pourrait tirer argument du fait que certains documents retrouvés en contexte militaire enregistrent la production de plusieurs mouleurs pour y voir l'œuvre de contremaîtres. Cette question ne peut être résolue puisque pour écrire ces graffites, il n'était pas nécessaire d'exercer une responsabilité quelconque dans l'atelier, il pouvait s'agir de responsables, de mouleurs ou de n'importe quel autre ouvrier tuilier. Leurs auteurs dépendaient de l'organisation du travail et surtout du degré d'alphabétisation des différents individus. Les mouleurs savaient-ils écrire? Si les documents de Conimbriga nous livrent une image relativement précise de la pratique scripturale dans des tuileries et attestent que les mouleurs lusitaniens savaient écrire - et ne s'en privaient pas! -, il est bien difficile d'être aussi affirmatif ailleurs. Il faut se contenter de quelques pièces isolées qui semblent avoir été écrites par des mouleurs: "Victorinus I ductor" de Aachen et "SATIS " de Silchester. Sur le territoire français, à l'exception des graffites inscrits dans les ateliers de la VIII' légion, à Mirebeau-sur-Bèze puis à Strasbourg, les graffites relatifs au travail sont très peu nombreux (si l'on excepte les incisions de comptage) et aucun ne nous renseigne sur son auteur. Le problème est identique pour les graffites non relatifs au travail. La plupart ont probablement été écrits par des personnes travaillant dans les tuileries, mais il n'est pas possible d'être plus précis ${ }^{1.44}$. L'analyse des graffites en termes de pratique indivi-

143. L.auteur du graffite de nature commerciale découvert à Rome devait être un acheteur de matériaux.

144. Il existait au xix"s. en Alsace une coutume qui voulait que chaque mouleur décore la derniere tuile de la journée. Sur ces tuiles de fin de journée, appelées Firozurziegel, les tuiliers écriaient toute sorte de choses, nom, date, texte..., qu'ils pouraient compléter par des symboles ou d'autres dessins (Klein, 1960, p. 164). Plusicurs graffites d’époque romaine semblent bien avoir été tracés sur un matériau de fin de journée, mais cela ne signifie nullement qu'une coutume analogue ait ćté en vigucur. 
duelle de l'écriture à l'intérieur des ateliers s'avère extrêmement difficile en l'état actuel du corpus.

Je terminerai par une approche plus globale de la question. L.inventaire des graffites découverts en France et leur répartition géographique révèlent que cette forme épigraphique était inconnue dans la plupart des tuileries gallo-romaines ${ }^{145}$. De plus, vu la rareté des graffites relatifs au travail, on peut affirmer que leur rôle était très ponctuel dans les tuileries civiles qui en faisaient usage ${ }^{146}$. Ils ne devaient constituer qu'un moyen parmi d'autres de faciliter le déroulement du travail. Mais aussi limité que soit le rôle de ces graffites, certaines tuileries les ont utilisés et d'autres non. Cette opposition peut-elle s'expliquer par des différences dans l'organisation du travail d'un atelier à l'autre ? On peut effectivement supposer que dans un atelier où plusieurs mouleurs étaient employés en même temps, on ait parfois eu recours à des graffites d'identification de production, alors que de tels documents n'étaient d'aucune utilité dans une petite tuilerie familiale où le moulage n'était assuré que par un seul individu. Toutcfois, si cette distinction est plausible à un niveau local, elle n'est plus valable à l'échelle de la Gaule. En effet, le pointage de tous les graffites sur la carte de France (fig. 50) montre que leur localisation obéit à des critères qui ne sont absolument pas spécifiques aux tuiliers. L'ancienneté de la romanisation, la présence de voies importantes et l'influence de l'armée romaine constituent des conditions favorables à la diffusion et au développement de l'écriture dans toutes les provinces romaines. L'usage de l'écriture par les tuiliers se confond avec celui de toute la société gallo-romaine. Leur graffites eux-mêmes, d'ailleurs, ne se distinguent pas des autres.

145. Je rappelle que les graffites répertoriés en France ont été découverts sur 49 communes. Un même site a pu être approvisionné par plusicurs tuileries, mais une seule d'entre elles a pu diffuser sa production sur différents sites. Dans l'état actuel des connaissances, je fixerai à une cinquantaine le nombre d'ateliers où l'on a écrit sur les matériaux avant leur cuisson.

146. En revanche, comme dans les autres tuileries légionnaires du limes rhénan, l'usage de graffites devait être important dans les tuileries de la VIII" légion à Mirebeau-sur-Bèze, puis à Strasbourg. Strasbourg est d'ailleurs le site qui a livré le plus de graffites relatifs au travail en France.
Les incisions de comptage semblent conforter ces observations. La réalisation de ces incisions était simple: il suffisait d'entailler la tranche des matériaux avec un couteau. Or, elles sont certes beaucoup plus nombreuses que tous les autres graffites, mais restent localisées dans les mêmes régions. La distinction entre les ateliers avec graffites et les ateliers sans graffites est donc essentiellement géographique. L'écriture dans les tuileries gallo-romaines dépendait moins des individus et de l'organisation du travail que d'un environnement plus ou moins favorable à cette pratique.

\section{Nota bene}

J'exprime ma reconnaissance aux membres du personnel des musées et aux archéologues professionnels et bénévoles qui ont accepté de répondre à mes sollicitations dans le cadre de cette recherche.

Pour l'aide qu'ils m'ont apportée lors du recensement et de l'étude des graffites, je voudrais remercier plus particulièrement J. Barbieux (Centre d'Histoire Locale, Tourcoing), F Berretrot (Musée de Bretagne, Rennes), E. Bernard (Service départemental d'archéologie de Vendée), J.-P. Bertaux (Grand), H. Chew (Musée des Antiquités nationales, SaintGermain-en-Laye), J.-L. Coudrot (Musée du Châtillonnais, Châtillon-sur-Seine), B. Counot (Musée de Liffol-le-Grand), F. Gateau (Musée de Lezoux), M. Gilles (Musée départemental d'art ancien et contemporain, Épinal), J. Guillaume (Service de l'Inventaire, DRAC Lorraine), A. Jacques (Service archéologique d'Arras), P.-Y. Lambert (CNRS, EPHE), M. Laprie (Centre de documentation du Patrimoine, SRA Aquitaine), J. Pellegrin-Gérard (Musée d'Évreux), J.-P. Mazimann (Belfort), N. Nin (Mission archéologie d'Aix-en-Provence), J. Richaud (Musée de Digne), J.-M. Salamito (Université Marc Bloch, Strasbourg), B. Schnitzler (Musée archéologique de Strasbourg), J.-M. Séguier (INRAP), M. Thauré (Musées du Mans), C. Thévenin (Musées de Sarreguemines), J.-L. Tilhard (Angoulême), N. Zapata-Aubé (Musée des Beaux-Arts de Bernay).

Enfin, il m'est particulièrement agréable de souligner que cette étude a bénéficié des nombreuses conversations que j'ai eues avec Christine Abt (professeure certifiée de lettres classiques) à toutes les étapes de la recherche. 


\section{ANNEXE \\ INVENTAIRE DES GRAFFITES ÉPIGRAPHIQUES RÉALISÉS AVANT CUISSON SUR LES MATÉRIAUX DE CONSTRUCTION EN TERRE CUITE GALLO-ROMAINS ET MÉROVINGIENS}

Cet inventaire ne compte que des graffites publiés et découverts en France, pour lesquels l'antériorité de l'écriture sur la cuisson est assurée.

Parmi coux-ci, seules les "incisions de comptage " sur la tranche des matériaux n'ont pas été retenues.

Les pièces sont présentées suivant l'ordre des numéros de départements, puis par ordre alphabétique de communes, en précisant ensuite leur lieu de découverte par un lieu-dit et/ou une indication topographique.

Le nombre de fragments d'un matériau n'est indiqué que lorsque ceux-ci ne permettent pas de le reconstituer entièrement.

Toutes les datations s'entendent après J.-C.

La bibliographie indique le premier signalement connu de la pièce et une ou deux publications complémentaires, en privilégiant les titres comportant une reproduction.

\section{4 - Alpes-De-Haute-Provence}

Référence bibliographique commune à plusieurs graffites : Bérard G., 1997 : Ies Alpes-de-Haute-Provence, 04, Paris, Académie des inscriptions et belles-lettres (coll. CAG), $567 \mathrm{p}$.

04.1. Beynes - Font Bonel

Fragment de tegula découvert lors de la fouille de sauvetage d'un four de tuilier effectuée en 1985 par R. Zérubia.

Graffite incomplet : ].VA[

Zérubia R., s.d. : Alpes-de-Haute-Provence : Beynes - Font Bonel, rapport de fouilles, fig. 13 (dessin).

Bérard, 1997, p. 106, n9.

04.2. Digne-les-Bains - Versant nord de la colline de SaintPancrace

Tegula entière, découverte probablement en 1930, qui proviendrait d'un groupe de sépultures (Antiquité tardive ?).

Graffite complet : $\quad$ EP

Gauthier M., 1985: "Informations archéologiques de Provence-Alpes-Côte d'Azur : Alpes-de-Haute-Provence, Digne ", Gallia, 43, 2, p. $516-517$ (dessin).

04.3. Lardiers - Le Chastelard

Cinq fragments d'une même tegula découverts lors des fouilles d'un vaste sanctuaire fouille par divers chercheurs depuis la $1^{\text {to }}$ moitié du xx" s., puis par J. et G. Barruol de 1961 à 1967. Graffite incomplet sur six lignes.

Bérard, 1997, p. 251, fig. 219 (photo).

04.4. Lardiers - Le Chastelard

Fragment d'une tegula découvert en 1963 lors de la fouille du portique du sanctuaire.

Graffite incomplet : Il TO[

\section{SALS·COII}

Lecture : J. Barruol, in Bérard, 1997.

Bérard, 1997, p. 251, fig. 218 (dessin).

04.5. Thorame-Haute - Église Saint-Julien

Tegula quasiment entière découverte en 1934 lors de travaux de terrassement qui mirent au jour des sépultures sous tuiles disposées perpendiculairement au mur nord de l'église.

Graffite complet : Supposuit furno III Idus Iulias

\section{die solis}

abuit tegulas

inbrices

"Il mit (le feu) sous le four le

$3^{r}$ jour avant les ides de juillet

[le 13 juillet]

le jour du Soleil [un dimanche]

il eut des tegulae

des imbrices "

Bailhache G., 1935 : "Compte de potier sur tuile romaine découverte à Thorame-Haute (Basses-Alpes) ", Revue archéologique, $6^{c}$ série, VI, juil.-déc., p. 102-104 (photo).

Bérard, 1997, p. 481, fig. 459 (photo).

\section{5 - Hautes-AlPeS}

05.1. Le Bersac - Serre-Muret

Fragment de tegula découvert en 1961 par F. Roumieu sur un site antique.

Graffite incomplet : ]AES

]AES

]RVATrVS

Blanc A., Desaye H., 1964 : "Inscriptions nouvelles de la Drôme, de l'Ardèche et des Hautes-Alpes ", Gallia, XXII, 2, p. $278-280, n^{\circ} 19$, fig. 10 (dessin).

\section{6 - ALPES-MARITIMES}

06.1. Nice (?) - Cimiez (?)

Fragment de tegula ou de brique.

Graffite complet : $\mathbf{R}$

Bourquelot F., 1850 : "Inscriptions antiques de Nice, de Cimic\% et de quelques lieux environnants ", Mémoires et dissertations sur les Antiquités nationales et étrangères publiés par la Société des Antiquaires de France, 10, p. 146, n"153 (dessin).

\section{1 - AUDE}

11.1. Sallèles-d'Aude - Clots de Reynaud

Imbrex (entière ?) découverte lors de la fouille de l'atelier de potiers et de tuiliers gallo-romain entreprise depuis 1976 sous la direction de F. Laubenheimer.

Graffite complet (?) : CXXIIII

Laubenheimer F., I.e Ny F. avec la collab. de Goury J., 1999 : "Les matériaux de construction en Narbonnaise ", in Bendala Gálán M., Rico C., Roldán Gómez L. (dir.), lil ladrillo y sus derizados en la época romana, Madrid, Casa de Velázquez, Universidad Autónoma de Madrid (coll. Monografías de Arquitectura Romana, 4), p. 21. 


\section{2 - AVEYRON}

12.1. Millau - La Graufesenque

Fragment d'un tuyau à eau découvert par A. Vernhet.

Graffite incomplet : ]DEF[

]MNO[

]TVXYZ[

\section{3 - BOUCHES-DU-RHÔNE}

13.1. Marseille (?)

Fragment (?) d'un matériau non précisć.

Graffite : AGGEVS

C.II, XII, 5681.2.

\section{5 - Cantal}

15.1. Le Monteil - Chastel-Marlhac (Respastit)

Fragment de tegula découvert lors de la fouille partielle d'une construction antique par J. Sirat en 1955.

Graffite incomplet: ]BEB[

Fournier P.-F., 1957 : " Informations archéologiques, VIII" circonscription, Cantal, Chastel-Marlhac ", Gallia, XV, 2, p. 233-234, fig. 3 (dessin).

\section{6 - Charente}

16.1. Saint-Médard - La Champagne de chez Roux Fragment de tegula trouvé en prospection avant 1992 par P. Briand et J.-L. Tilhard sur un habitat (?) du II"s. (?). Graffite incomplet: ]dessin $\mathbf{A B}[$

DẸF[

Tilhard J.-L., 1992 : " Inventaire des sites gallo-romains de la région de Barbezieux ", Bulletin annuel de la Sociélé archéologique, historique et littéraire de Barbezieux et du sud Charente, XXXV, p. 17 et 21, fig. 1.11 (dessin).

\section{1 - CôTe-D’OR}

21.1. Chenôve - La Noue

Fragment d'imbrex.

Graffite: BBB

\section{T.O.BLLOLL... \\ PI.T.T.ITE}

Lecture : Le Bohec, 1995.

Le Bohec Y., 1995 : “L'épigraphic de Mirebeau ", in Goguey R., Reddé M. (dir.), Le camp légionnaire de Mirebeau, Main\%, Römisch-Germanischen Zentralmuscums, Bonn, p. 315, n 11 et pl. $48, n^{\circ} 3$ (dessin).

21.2. Mirebeau-sur-Bèze - Thermes extra-muros du camp romain Demi-brique bessalis entière (coupée en deux en diagonale avant cuisson), découverte en 1970 lors des fouilles menées par R. Goguey sur les thermes extra-muros du camp de la VIII" légion Auguste. Cette pièce provient d'une couche de remblai comblant les vestiges des thermes. Le camp a été construit vers 70 par les légionnaires de la VIII légion pour être abandonné vers 90. Plusieurs états de construction observés dans les thermes laissent croire que leur utilisation a pu se poursuivre en partie après l'abandon du camp.

Graffite incomplet: Secundus СССХХИI

$$
\begin{aligned}
& \text { Arunti } \\
& \text { J..eus } \\
& \text { J.enus } \\
& \text { J.us } \\
& \text { Js }
\end{aligned}
$$

Goguey R., 1970-1971 : "Mirebeau : les fouilles de 1970 sur les thermes ", Mémoires de la Commission des Antiquités du département de la Côte-d'Or, XXVI, p. 16-17 (photo).

Le Bohec Y., 1995 : "L'épigraphie de Mirebeau ", in Goguey R., Reddé M. (dir.), Le camp légionnaire de Mirebeau, Mainz, Römisch-Germanischen Zentralmuscums, Bonn, p. 314-315, n"9 et pl. 48, n*1-2 (photo et dessin approximatif) [lecture : IVCVNDVS CCCXXVI | MVNTI I IIVVI I IVYVI I IIVI I II] .

21.3. Nuits-Saint-Georges - Les Bolards

Fragment d'imbrex provenant des fouilles anciemnes de l'agglomération antique des Bolards.

Graffite incomplet : ]VLELBVLO[

Habert T., 1893 : La poterie antique parlante, Paris, C. Reinwald, $\mathrm{n}^{\prime \prime} 614$.

Lambert P.-Y., 2002 : Recueil des inscriptions gauloises -II, 2- Textes gallo-latins sur instrumentum, Paris, CNRS Éditions (coll. Suppl. à Gallia, XLV), p. 231, *L-89 (photo).

\section{4 - DORDOGNE}

24.1. Petit-Bersac - L.c Camp

Quatre fragments d'une même legula découverts en 1967 par J. Pichardie lors des fouilles menées sur un atelier de tuilier gallo-romain.

Graffite incomplet : COL

VOI

ARLA[

[..] LLE[

Lecture : Gaillard, 1997.

Lc Ny F., 1992 : La production des matériaux de construction en terre cuite en Gaule romaine, thèse de $3^{c}$ cycle, univ. de Rennes I, vol. IA, p. 242, fig. 92C (photo d'un fragment).

Gaillard H., 1997 : La Dordogne, 24/1, Paris, Académie des inscriptions et belles-lettres (coll. CAG), p. 190.

\section{6 - Drôme}

26.1. Roussas - Treillas

Tegula quasiment entière, découverte en mai 1953 lors de travaux agricoles qui détruisirent une sépulture sous tuiles. Graffite daté de la fin du IN" ou du début du ${ }^{\text {N゙}}$ s. par F. Benoit (1952-1953). Graffite complet: dessin d'un

personnage assis fera com Era

sur un oiseau cornu

" avec la cruelle Héra"

Lecture et traduction : C. Perrat, in Benoit, 1952-1953.

Benoit F., 1952-1953 : "Séance du 16 décembre : un graffite récemment découvert dans la Drôme ", Bulletin de la Société nationale des Antiquaires de France, 1952-1953, p. 195-198 (dessin du texte uniquement).

Benoit F., 1954 : L.héroïsation équestre, Publication des Annales de 
la faculté des lettres d'Aix-en-Provence, éd. Ophrys, p. 27-29, pl. I.2 (photo).

Gagnière S., 1965 : "Les sépultures à inhumations du III" au XIII" s. de notre ère dans la basse vallée du Rhône : essai de chronologie typologique ", Cahiers rhodaniens, XII, p. 58 et 62 , fig. 8.1 (dessin).

\section{7 - EURE}

27.1. Arnières-sur-Iton - À la sortie du bourg vers Évreux, à droite de la voie ferrée

Fragment de tegula découvert en 1853 par T. Bonnin lors de la fouille partielle d'un édifice antique interprété à l'époque comme un théâtre.

Graffite : SOM・M

Lecture : Vipard, 1987.

Bonnin T., 1860 : Antiquités gallo-romaines des Éburoviques publiées d'après les recherches et les fouilles, Paris, Dumoulin, p. 21 et pl. III.13 d'Arnières (dessin approximatif).

Coutil L., 1921 : Archéologie gauloise, gallo-romaine, franque et carolingienne : département de l'Eure - 4 -Arrondissement d'Éreux, Évreux, Impr. de l'Eure, Paris, E. Leroux, E. Dumont, p. 121, fig. 59.XIII.

Vipard P., 1987 : Épigraphie gallo-romaine de la Lyonnaise seconde, mém. de maîtrise d'Histoire, univ. de Caen, vol. I, p. 441, $n^{\circ} 200,013$; vol. III, n²00,013 (photo).

27.2. Saint-Samson-de-la-Roque (anciennement Saint-Samsonsur-Risle) - Monastère de Pental

Brique rectangulaire entière découverte dans les ruines de l'église. Le monastère a été fondé vers le milieu du vi ${ }^{\circ} \mathrm{s}$. et sans doute détruit lors des invasions normandes au IX" s. ; seule l'église a été reconstruite, peut-être au X"s. Le graffite est une citation du Psaume I, verset 1 , suivic d'unc signaturc ; d'après la paléographie, il serait antérieur à la fin du vir's.

Graffite complet: Beatus uir qui

\section{non habiit}

in concilio impio

rum

Auitus scirpsit

ipse

"Heureux l'homme qui ne suit pas

les conseils des impies.

Avitus a écrit cela lui-même. "

Caumont M. de, 1858 : "Rapport verbal sur une excursion archéologique à Évreux ", Bulletin monumental, 24, p. 39-40 (dcssin).

Baylé M., 1985 : "Les monuments sculptés de la Normandie (VII'-IX" siècles) ", in Périn P., Feffer L.-C. (dir.), La Neustrie, Musées et monuments départementaux de Seine-Maritime, p. $216, n^{\circ} 72 . d$ (photo).

\section{1 - HaUte-GaronNe}

Référence bibliographique commune à tous les graffites : Aupert P., Monturet R., 2001 : Saint-Bertrand-de-Comminges -IILes thermes du forum, Bordeaux, Fédération Aquitania, $333 \mathrm{p}$. Tous les graffites découverts à Lugdunum/Saint-Bertrand-deComminges proviennent des thermes du forum, construits au début du $\mathrm{I}^{\mathrm{er}} \mathrm{s}$. et abandonné vers 400 . Les bâtiments ont été fouillés par B. Sapène dans les années 1920 et 1930, puis en 1953 et 1954 . Le site a fait l'objet de nouvelles investigations dirigées par P. Aupert dans les années 1980 et 1990.

31.1-31.12. Saint-Bertrand-de-Comminges - Les thermes du forum

1. Fragment de brique.

Graffite incomplet : ]VI[

Aupert, Monturet, 2001, p. 161, n²1 et p. 270, fig. 205.

2. Fragment de brique.

Graffite incomplet : ]XV[

Aupert, Monturet, 2001, p. 161, n²2 et p. 270, fig. 206.

3. Fragment de brique.

Graffite incomplet : ]XXX[ ou ]XXXV[

Aupert, Monturet, 2001, p. 161, n” 23 et p. 270, fig. 207.

4. Fragment de brique.

Graffite incomplet : MAX[

Aupert, Monturet, 2001, p. 161, n²4 et p. 270, fig. 208.

5. Fragment de brique.

Graffite incomplet : .V[

Aupert, Monturet, 2001, p. 161, no 25 et p. 270, fig. 209.

6. Fragment de brique.

Graffite incomplet : MAX[

Aupert, Monturet, 2001, p. 161, n²6 et p. 270, fig. 210.

7. Trois fragments d'une même brique.

Graffite incomplet : ]XXX[

Aupert, Monturet, 2001, p. 162, n'28 et p. 271, fig. 212.

8. Fragment d'une brique ou d'une tegula.

Graffite incomplet : ]. I[

Aupert, Monturet, 2001, p. 162, n²9 et p. 27l, fig. 213.

9. Fragment d'une brique.

Graffite incomplet : ]IIIII[

Aupert, Monturet, 2001, p. 162, n 30 et p. 271, fig. 214.

10. Fragment d'une brique.

Graffite complet (?) : X

Aupert, Monturet, 2001, p. 162, n`31 et p. 271, fig. 215.

11. Fragment d'une brique provenant du mur ouest du caldarium.

Graffite incomplet : ]AXVI[

Aupert, Monturet, 2001, p. 162, n 32 et p. 271, fig. 216.

12. Fragment d'une brique provenant du mur ouest du caldarium.

Graffite incomplet : ].S[

Aupert, Monturet, 2001, p. 162, n³3 et p. 272, fig. 217.

\section{4 - Hérault}

34.1. Vendémian - Propriété Chauvet (à l'époque de la découverte)

Tegula entière, découverte en 1832, qui faisait partic du coffre d'une sépulture. Cette tuile était placée verticalement à l'une des extrémités de la tombe, celle des pieds.

Graffite complet : $\quad$ Ego A

chillis

donaui

figulis an

fora uini

"Moi, Achille, j’ai donnć aux céramistes une amphore de vin. " 
Ricard A., 1835-1840 : Mémoire de la Société archéologique de Montpellier, I, p. 530-531 (lecture 1. 4 : sïgulis).

CIL, XII, 5681.1 (lecture 1. 4 : sigulis).

Bonnet É. [1905] : Géographie générale du département de l'Hérault Chapitre neuvième : Antiquités et monuments du département de l'Héraull, Société languedocienne de géographie, p. 451, n. 5 (lecture 1. 4 : sīgulis).

Reinach S., 1926 (2“ éd.) : Catalogue du musée des Antiquités nationales au château de Saint-Germain-en-Laye, t. I, Paris, Musées nationaux, p. 217-218, fig. 249 (photo) (lecture 1. 4 : figulis; dans la l're éd. en 1917, mêmes pages et même figure mais photo à l'envers ; indique dans les deux éditions que la tuile provient de Vichy).

Schneider L., Garcia D., 1998 : Le Lodévois, 34/1, Paris, Académie des inscriptions et belles-lettres (coll. CAG), p. 328 (lecture 1. 4 : singulis).

\section{5 - ILLE-ET-VILAINE}

35.1. Rennes - Provenance inconnue

Tegula entière donnée au musée par la Société archéologique d'Ille-et-Vilaine en 1854, la date, le contexte et les conditions de découverte sont inconnus.

Graffite complet de deux lignes, non lu.

Banéat P., 1909 (3c éd.) : Ville de Rennes, Catalogue du Musée archéologique et ethnographique, Rennes, Imprimerie Oberthur, p. $149, \mathrm{n}^{\circ} 1873$.

35.2. Rennes - Rue de Saint-Malo

Cinq tegulae ou briques (fragments ?), découvertes lors d'une fouille de sauvetage dirigée par F. Goupil en 1989, portent le même graffite.

Graffite complet : $\mathbf{R}$

Goulpeau L., Le Ny F., 1989 : « Les marques digitées apposées sur les matériaux de construction gallo-romains en argile cuite ", $R A O, 6$, p. 118 et 120, fig. 5a (dessin d'un seul exemplaire).

\section{8 - ISÈRE}

38.1. Saint-Barthélemy-de-Beaurepaire - Provenance inconnue Quatre fragments d'une même tegula découverts vers 1876.

Graffite incomplet : Jnumpit ami

$$
\begin{aligned}
& \multicolumn{1}{l}{\text { Jrtus du }} \\
& \text { fit puer Atti } \\
& \text { Att[ ] uxor fiat } \\
& \quad \text { Jet d du } \\
& \text { Att.l } \\
& \text { quid fl } \\
& \quad \text { ul }
\end{aligned}
$$

Lecture : $C I L$.

CII, XII, 5681.3 .

Mallon J., 1973 : "Briques et tuiles inscrites avant cuisson conservées au musée de Vienne (Isère) ", Bulletin de la Société nationale des Antiquaires de France, 1973, p. 38-40 et pl. Va-d (photos) [texte et photos republiés in Mallon J., 1986 : De l'ériture. Recueil d'études publiées de 1937 à 1981, Paris, éd. du CNRS, $\mathrm{n}^{\circ}$ XIVII].

38.2. Vienne - Mont du Coup-Garret

Fragment de brique découvert avant 1856 .
Graffite: Sestius Celisus

Cesor Maelo

Galicanus

Quadratus

Lecture : $C I I$.

Longpérier A. de, 1856 : "Note sur la forme de la lettre E dans les légendes de quelques médailles gauloises ", Revue numismatique, nouv. série, I, p. 81 .

CIL, XII, 5681.4.

Mallon J., 1973 : "Briques et tuiles inscrites avant cuisson conservées au musée de Vienne (Isère) ", Bulletin de la Société nationale des Antiquaires de France, 1973, p. 38-40, pl. Ve (photo) [texte et photo republiés in Mallon J., 1986 : De l'écriture. Recueil d'études publiées de 1937 à 1981, Paris, éd. du CNRS, $n^{\prime \prime}$ XLVII].

\section{6 - LoT}

Référence bibliographique commune à plusieurs graffites : Pauc R., 1982 : Les luiliers gallo-romains du Quercy, Cahors, Société des études du Lot, 324 p. et 23 pl.

46.1. Cajarc - Carrade

Fragment de tegula découvert en 1975 lors des fouilles menées par R. Pauc sur un atelier de potier et tuilier gallo-romain.

Graffite incomplet : Jmapo• cagiionl

Lecture : Lambert, 2002.

$$
\begin{aligned}
& \text { Jmagulo } \\
& \text { ]u } • \text { dọmul }
\end{aligned}
$$

Pauc, 1982, p. 153-154, fig. 22 (photo).

Lambert P.-Y., 2002 : Recueil des inscriptions gauloises -II, 2- Textes gallo-latins sur instrumentum, Paris, CNRS Éditions (coll. Suppl. à Gallia, XLV), p. 228-229, L-86, fig. 128 (photo).

46.2. Cajarc - Carrade

Fragment de tegula découvert par R. Pauc sur un atelier de potier et tuilier gallo-romain.

Graffite incomplet (?) : X[ ou ]X

Pauc, 1982, p. 153 et pl. XXIII, fig. 4 (photo).

46.3. Saint-Denis-Catus - Les Sagnes

Fragment (?) de tegula ramassé par $\mathrm{R}$. Pauc sur un atelier de potier et tuilier gallo-romain.

Graffite : $\mathbf{P}$

Pauc, 1982, pl. XXIII, fig. 7 (photo).

46.4. Saint-Denis-Catus - Les Sagnes

Fragment (?) de tegula ramassé par R. Pauc sur un atelier de potier et tuilier gallo-romain.

Graffite : $\mathbf{T}$

Pauc, 1982, pl. XXIII, fig. 5 (photo).

46.5. Saint-Paul-de-Loubressac - Saint-Gervais

Fragment de tegula ramassé par $\mathrm{M}^{\text {me }} \mathrm{C}$. Massip sur un site antique reconnu en 1969 par le Dr Carillon et identifié comme une tuilerie par R. Pauc en 1975.

Graffite incomplet : ]......

\section{l...tusas \\ Jcerutu \\ lu}

Lecture : Lambert, 2002.

Pauc, 1982, p. 153-156, fig. 23 (photo).

Lambert P.-Y., 2002 : Recueil des inscriptions gauloises -II, 2- Textes 
gallo-latins sur instrumentum, Paris, CNRS Éditions (coll. Suppl. à (Gallia, XIV), p. 229, *L-87, fig. 129 (photo).

\section{5 - MeuSe}

\subsection{Ancemont - Petite Sous}

Fragment de tegula trouvé en 1967 en prospection par A. Janot sur une villa gallo-romaine.

Graffite non lu.

Mourot F., 2002 : La Meuse, 55, Paris, Académie des inscriptions et belles-lettres (coll. $C A(B)$, p. 111, fig. 22a et p. 133.

55.2. Auzéville-en-Argonne (commune rattachéc à Clermonten-Argonne depuis 1973) - Sur le Moulin

Tegula entière découverte en 1929 dans une villa galloromaine lors de fouilles suivies par G. Chenet. Elle provient d'une série de tuiles qui, disposées en bâtière, formaient un canal. Ce canal appartient au premier état reconnu d'une pièce de la villa.

Graffite complet non lu.

Chenet G., 1930 : "Vestiges d'une villa gallo-romaine d'Argonne à Auzéville (Meuse) ", Revue des Musées : fouilles et découvertes archéologiques, 28, p. 107.

\section{7 - MOSELle}

57.1. Montenach - Leinstroff

Grand fragment de tegula découvert en 1922 par A. Théobald en labourant son champ.

Graffite quasi complet :

cum Anaillo dies I
cum Tertio dies I
inbricis dies III
inbricem baiolandam mortari VI dies III
tegule in campo Rassure dies I
latercli dies I

« avec Anaillus : ... journée(s)

avec Tertius : 1 journée

aux imbrices : 3 journées

à transporter les imbrices de 6 mortarii : 3 journées

aux tegulae dans le champ de Rassura : 1 journée aux briques : 1 journée "

Clément R., 1927 : “ Un compte d'un briquetier gallo-romain du pays de la Moselle ", RlEA, XXIX, p. $205-207$ (photo).

Charlier F., 1999 : "L.es conditions socio-juridiques du travail dans les tuileries d'après les marques sur les matériaux, en Gaule et dans les autres provinces occidentales romaines", in Annequin J., Geny $\hat{\mathrm{E}}$., Smadja $\hat{\mathrm{E}}$. (dir.), Le travail : recherches historiques, Acles de la table ronde internationale de Besanson, 14-15 nov. 1997, Besançon, Presses universitaires franccomtoises, p. 173-176, fig. 3 (photo).

\section{9 - NORD}

59.1. Marcq-en-Barœul - Ermitage du Quesne

Fragment de tegula ou de brique découvert par F. Mouton en 1970 lors du creusement de tranchées sur un habitat antique. Graffite incomplet : ].AE[

Barbieux J., Mouton F., 1996 : «Un établissement gallo-romain à Marcq-en-Barceul », Tourcoing et le Pays de Ferrain, 21, p. 3 et 5, fig. 4 (photo).

59.2. Sains-du-Nord - Rue du Moulin-à-Vent (lotissement des Hauts-de-Sains)

Fragment de brique rectangulaire découvert lors de fouilles menées en 1983 par A. Broëz dans un quartier artisanal de l'agglomération antique de Sains-du-Nord. La céramique recueillie est datée essentiellement du II"s.

Graffite incomplet : ralt]ionem $\cdot$ carnis[

$$
\begin{aligned}
& \text { cumprimum ueni[a } \\
& \text { abbo } \text { biarcillo.I } \\
& \text { item } ・ \text { cumprimum I } \\
& \text { item } ・ \text { torobol.I } \\
& \text { item cump .. mu I }
\end{aligned}
$$

Lecture : Lambert, 2001.

Broëz A., 1987 : "Essai de synthèse des fouilles menées sur le "vicus" de Sains-du-Nord ", Revue du Nord, I.XIX, 272, janv.mars, p. 53.

Lambert P.-Y., 2001 : " Une inscription provenant de Sains-duNord ", Revue du Nord, 343, p. 67-69 (photo et dessin).

\section{3 - PuY-DE-Dôme}

Référence bibliographique commume à plusieurs graffites : Bet P., Delage R., 1993 : “ Inscriptions gravées et graffites sur céramique à Lezoux (Puy-de-Dôme) durant la période romaine ", in Rivet L. (dir.), SFECAG, Actes du congrès de Versailles, p. 305-327.

63.1. Lezoux - Propriété Mathonnière (groupe d'atelicrs de Saint-Taurin)

Grand fragment de tegula découvert en 1933 dans la proprićté Mathomière lors de la fouille d'un four de potier de la période augustéenne.

\section{Graffite complet : Rufius Veneroni}

Lecture : Marichal, in Mathonnière-Plicque, Grenier, 1961.

Fabre C., 1935 : "I Les industries céramiques de Lczoux ", Revue archéologique, 6" série, V, janv.juin, p. 106-107, fig. 8 (photo). Mathonnière-Plicque A., Grenier A., 1961 : "Nouvelles fouilles à Lezoux (Puy-de-Dôme) ", Callia, XIX, 1, p. 57-58, fig. 5 (photos) [les auteurs considèrent à tort que le matćriau porteur est un morceau de ciment].

Provost M., Mennessier-Jouannet C., 1994 : Le Puy-de-l)ôme, 63/2, Paris, Académic des inscriptions et belles-lettres (coll. CAG), p. 141, n 70 et p. 154, n"160) (les auteurs n'ont pas compris que les deux références précédentes présentent la même fouille, ils distinguent donc faussement deux fours et deux graffites en les localisant à deux endroits différents).

63.2. Lezoux - Groupe d'ateliers de Saint-Taurin

Fragment d'antéfixe. Datation : Tibère/Claude - Flaviens/tou début du II"s.

Graffite incomplet: Jauo(t)

$$
\text { "a fait" }
$$

Bet, Delage, 1993, p. 319 et 321 , fig. 9.64 (dessin).

Lambert P.-Y., 2002 : Recueil des inscriptions gauloises -II, 2- Textes gallo-latins sur instrumentum, Paris, CNRS Éditions (coll. Suppl. à (sallia, XI.V), p. 50, L-20.78. 
63.3. Lezoux - Groupe d'ateliers de Saint-Taurin

Fragment d'imbrex. Datation : seconde moitié du II"-début du III"s.

Graffite incomplet: ]V

Bet, Delage, 1993, p. 317 et 321 , fig. 9.55 (dessin).

63.4. Lezoux - Groupe d'ateliers de Saint-Taurin

Tegula (entière ?) découverte hors stratigraphie. Datation : première moitié du II"-début du III" $s$.

Graffite complet : Atiliani

Bet, Delage, 1993, p. 317 et 321 , fig. 9.54 (dessin).

63.5. Lezoux - Cuvre Grancher, rue Pasteur (groupe d'ateliers de Saint-Taurin)

Tegula entic̀re faisant partie de l'aire dallée de préparation de largile F.117 fouillée par H. Vertet et P. Bet en 1979. Cette structure est datée de la seconde moitić du II"s.

Graffite incomplet : ATILL...

Vertet H., Bet P., 1980 : “Fouille du terrain de l'CFuvre Grancher à Lezoux (63) (1977-78-79). Les structures galloromaines du second siècle ", in Vertet H., Bet P., Corrocher J. (dir.), Recherches sur les ateliers de potiers gallo-romains de la Gaule centrale, hors-série $n^{\circ} 6$ de la Revue archéologique Sites, p. 63.

Bet, Delage, 1993, p. 317, n. 33.

\section{6 - Pyrénées-ORientales}

66.1. Perpignan - Château-Roussillon

Tuile ou brique (fragment?).

Graffite : R..S

Fédière G., 1980 : " Marques sur tuiles et sur briques d'époque romaine en Roussillon ", in Barruol G. (dir.), RVSCINO, Château-Roussillon, Perpignan (Pyrénées-Orientales) -I- État des travaux et recherches en 1975 (coll. Suppl. à la RAN, 7), p. 331.

\section{7 - BAS-RHIN}

Références bibliographiques communes à plusieurs graffites : Forrer R., 1913 : " Die Ziegel und Legionsstempel aus dem römischen Straßburg ", Anzeiger für Elsässische Altertumskunde, 17-18, p. 353-375.

Forrer R., 1919 : " Römische Mühlen-, Töpferei- und Handelsbetriebe, Metallwerkstätten und Waffenfunde in Straßburg ", Anzeiger für Llsässische Altertumskunde, 37-40, p. 988-1078.

Forrer R., 1927 : Strasbourg-Argentorate préhistorique, gallo-romain et mérovingien, Strasbourg, Librairie Istra, 2 vol.

Baudoux J., Flotté P., Fuchs M., Waton M.-D., 2002 : Strasbourg, 67/2, Paris, Académie des inscriptions el belles-lettres (coll. $C A(), 586 \mathrm{p}$.

67.1. Strasbourg - Kœnigshofen (selon Brambach), provenance incertaine ("vraisemblablement Strasbourg " selon Forrer). Fragment de tegula.

Graffite incomplet: ]T

\section{].VOLARE \\ ]VM \\ ]PLANE}

Brambach W., 1867 : Corpus Inscriptionum Rhenanarum, Elberfeldae, R. I. Friderichs, p. XXXII, n” 2075.

Forrer, 1913, p. 361, fig. 18 (dessin) (texte et dessin repris dans Forrer, 1927, p. 20, fig. 6).
67.2. Strasbourg - 8 rue du Dôme (anciennement Münstergasse)

Brique bessalis entière découverte en 1903 lors de travaux de canalisation. La brique était incluse dans une structure interprétée comme la plus ancienne chaussée antique du camp romain de Strasbourg. Le cantonnement de la $\mathrm{II}^{\mathrm{c}}$ légion à Strasbourg se place dans la première moitié du $\mathrm{I}^{\mathrm{cr}} \mathbf{s}$.

Graffite complet : $\quad$ LEC $\overline{\mathbf{I I}}$

$$
\text { "II" légion " }
$$

CIL, XIII, 12137

Forrer, 1913, p. 362, pl. I.1 (dessin) (texte et dessin repris dans Forrer, 1927, p. 21, pl. I.1).

Schnitzler B. (coord.), 1988 : - 12 : aux origines de Strasbourg, Strasbourg, Les musées de la ville de Strasbourg, Ancienne Boucherie, p. 139, n"68 (photo).

Baudoux et al., 2002, p. 299, fig. 254 (dessin).

67.3. Strasbourg - 8 rue du Dôme (anciennement Münstergasse)

Fragment de tuile estampillée au nom de la VIII" légion Auguste. Cette légion s'installa à Strasbourg vers 90 et $y$ demeura jusqu'au début du v"s.

Graffite incomplet: ]OLI

Forrer, 1919, p. 1051, fig. 128D (dessin) (texte et dessin repris dans Forrer, 1927, p. 519, fig. 386D).

67.4. Strasbourg - Rue du Dôme (anciennement Münstergasse) Brique bessalis entière, estampillée au nom de la VII' légion Auguste avec le surnom PFCC, soit pia fidelis constans Commoda, qui place cette brique sous le règne de Commode.

Graffite complet : $\quad C C X X X X$

$$
\text { " } 240 \text { (briques)" }
$$

Forrer, 1913, p. 365, pl. IV.65a (dessin) (texte et dessin repris dans Forrer, 1927, p. 27, pl. IV.65a).

67.5. Strasbourg - Place Saint-Pierre-le-Jeunc (anciennement Jung St. Peterplatz)

Fragment de tegula.

Graffite : $\quad \overline{\text { III }}$

$$
\text { "VIII" (légion)" }
$$

Forrer, 1913, p. 360-361, fig. 17 (dessin) (texte et dessin repris dans Forrer, 1927, p. 19-20, fig. 5).

67.6. Strasbourg - Rue des Serruriers (anciennement Schlossergasse - Ostende)

Brique sesquipedalis entière, estampillée au nom de la VIII' légion Auguste.

Graffite incomplet : VI Idus Sept

$N$ - -

" le 6 " jour avant les ides de septembre [le 8 septembre]

nombre : ..."

Forrer, 1919, p. 1004, fig. 93 (dessin) (texte et dessin repris dans Forrer, 1927, p. 469, fig. 344 ; lecture erronée de Forrer : Vlaus Sept ti... et lecture correcte proposée par Ritterling).

Baudoux et al., 2002, p. 172 (seulement lecture erronée de Forrer).

67.7. Strasbourg - Place du Marché-Gayot (anciennement Verbrannten Hof)

Fragment de tegula.

Graffite incomplet : ]ANDIOFE

$$
\text { "...andio a fait" }
$$


Forrer, 1919, p. 1004, fig. 94 (dessin) (texte et dessin repris dans Forrer, 1927, p. 469, fig. 345).

67.8. Strasbourg - Montagne Verte, canal de dérivation (entre les deux cours du Mühlbach)

Fragment de brique découvert dans les fouilles réalisées lors du creusement du canal de dérivation en 1938-1939 qui ont révélé un ancien lit de rivière. La brique, trouvée près de la berge nord du canal, est estampillée au nom de la VIII légion Auguste. Graffite complet (?) non lu.

Amiet P., 1952 : "Un port de rivière romain sur la Bruche à la Montagne Verte ", Cahiers d'archéologie et d'histoire d'Alsace, 132, p. 92 et 94 , pl. II. 22 et 5 (dessin).

67.9. Strasbourg - Ruelle Saint-Médard

Fragment de tegula découvert lors de fouilles menées en 19511952 par J.-J. Hatt. La pièce proviendrait d'une couche de destruction d'un grenier à blé détruit par un incendie, daté par J.-J. Hatt de 355 .

Graffite incomplet : VIIKA[

"le $7^{\mathrm{e}}$ jour avant les calendes de..."

Hatt J.-J., 1953 : «Les fouilles de la ruelle Saint-Médard à Strasbourg ", Gallia, XI, 2, p. 240 et p. 248, fig. 17.5 (photo). 67.10. Strasbourg - Rue des Capucins (au no90)

Fragment de tuile découvert dans un épandage de matériaux, datés de la fin du $\mathrm{I}^{\mathrm{er}}$ s.-début du $\mathrm{II}^{\mathrm{*}} \mathrm{s}$., lors la réalisation de sondages effectués par F. Schweitzer en 1993.

Graffite incomplet : VIL[

Baudoux et al., 2002, p. 422-423.

\section{0 - HaUte-SAÔNE}

Référence bibliographique commune aux deux graffites : Mazimann J.-P., 1997 : "Les graffites ", in Barbet G., Gandel P. (dir.), Chassey-lès-Montbozon (Haute-Saône) : un établissement rural gallo-romain, Paris, Les Belles Lettres (coll. Annales littéraires de l'université de Besançon, 627)

70.1. Chassey-lès-Montbozon - Pré Guillemin

Fragment de brique carrée découvert lors des fouilles d'un vaste établissement rural antique menées de 1991 à 1995 par

G. Barbet et P. Gandel.

Graffite : MAR

Mazimann J.-P., 1997, p. 271 et 274, fig. 1 (dessin).

70.2. Chassey-lès-Montbozon - Pré Guillemin

Fragment de tegula découvert lors des fouilles de l'établissement rural antique.

Graffite : VER

Mazimann J.-P., 1997, p. 271 ct p. 274, fig. 2 (dessin).

\section{1 - SAÔNE-ET-LoIRE}

71.1. Autun - «Partie basse de la ville, presque parallèlement aux remparts nord-ouest et au cours de l'Arroux"

Fragment d'imbrex découvert en 1866-1867 dans les travaux occasionnés par l'établissement du chemin de fer de Chagny à Nevers.

Graffite incomplet : ]VLIGANTRO

]TITIOTICLI

]ATALOMERCV.[

].A...
Fontenay H. de, 1874 : «Inscriptions céramiques galloromaines découvertes à Autun ", Mémoires de la Société éduenne des lettres, sciences et arts, III, p. 419 et pl. XXXI, n572.

Rebourg A., 1987 : "Graffites sur une tuile », in Autun/Augustodunum, capitale des Éduens, Catalogue d'exposition. Autun, ville d'Autun, musée Rolin, p. 274, n554 (photo). Lambert P.-Y., 2002 : Recueil des inscriptions gauloises -II, 2- Textes gallo-latins sur instrumentum, Paris, CNRS Éditions (coll. Suppl. à Gallia, XLV), p. 230, *L-88, fig. 130 (photo) (indique par erreur une brique; lecture 1.1 : uligatro).

\section{2 - SARTHE}

72.1. Le Mans - Rue du Bourg-d'Anguy (Percée Centrale) Fragment d'imbrex recueilli par M. Mémin en 1970 dans un contexte et des conditions de découverte inconnus.

Graffite incomplet : ]XX II[

Guillier G., Thauré M., 2003 : Les graffites antiques de la cité des Aulerques Cénomans, Montagnac, Monique Mergoil, p. 56, n²3, fig. 51 et 52 (dessin et photo).

\section{4 - HaUte-Savoie}

\section{1 et 74.2 Doussard - Bredannaz.}

Plusieurs tegulae $\left(\mathrm{n}^{\circ} 1\right)$ et briques ( $\mathrm{n}^{\circ}$ ) employées dans la maçonnerie d'un four de tuilier gallo-romain, fouillé par L. Revon avant 1870 , portent un graffite identique.

Graffite complet : $\mathbf{S}$

Revon L., 1870 : Inscriptions antiques de la Haute-Savoie : épigraphie gauloise, romaine et burgonde, Annecy, Imprimerie L. Thésio, p. $49, \mathrm{n}^{\circ} 187$.

CIL, XII, 5679.93 .

\section{7 - SEINE-ET-MARNE}

Références bibliographiques communes à plusieurs graffites : Lambert P.-Y., 1998-2000 : " Les autres tuiles inscrites de Châteaubleau (Seine-et-Marne) ", Études celtiques, XXXIV, p. 117-133.

Lambert P.-Y., 2002 : Recueil des inscriptions gauloises -II, 2- Texles gallo-latins surinstrumentum, Paris, CNRS Éditions (coll. Suppl. à Gallia, XLV), $431 \mathrm{p}$.

De nombreux graffites ont été mis au jour sur la commune de Châteaubleau en divers lieux-dits au cours de prospections et de fouilles depuis le XIX ${ }^{c}$ s. Dans l'Antiquité, Châteaubleau était une agglomération secondaire qui a connu une occupation du $\mathrm{I}^{\mathrm{er}}$ au IN"s.

À La Tannerie, un sanctuaire de source constitue la limite septentrionale de la bourgade antique. L'édifice daterait de l'époque d'Hadrien.

Aux lieux-dits L'Aumône et La Justice, un sanctuaire monumental regroupe plusieurs temples de tradition celtique et une vaste place. Cet ensemble est fréquenté de la seconde moitié du II" s. à l'époque constantinienne. À l'est de ce sanctuaire, au Bois de la Vigne, est accolé un théâtre construit au $\mathrm{II}^{\mathrm{e}} \mathrm{s}$.

Un quartier d'habitation se développe au lieu-dit Les Grands Jardins, il fut progressivement abandonné à la fin du III"s.

Entre 1961 et 1987, les fouilles du Groupe d'archéologie 
antique du Touring Club de France ont été dirigées par J.-P. Burin. Depuis 1990-1991, ces fouilles ont été reprises par l'association La Riobé sous la direction de F. Parthuisot.

77.1. Châteaubleau - Provenance inconnue

Fragment de tuile (d'après l'épaisseur) découvert avant 1862. Graffite : AL (et deux signes incomplets et incertains audessous)

Lecture : Lambert, 1998-2000.

Bourquelot F., 1862 : Bulletin de la Société impériale des Antiquaires de France, 1862 , p. 81.

Lambert, 1998-2000, p. 119.

77.2. Châteaubleau - La Tannerie

Fragment de tegula découvert avant 1858.

Graffite incomplet: SABIN[

Bourquelot F., 1858 : “Antiquités de Châteaubleau ", Bulletin de la Société impériale des Antiquaires de France, 1858, p. 163 (dessin). Lambert, 1998-2000, p. 118.

77.3. Châteaubleau - La Tannerie

Fragment de brique trouvé en prospection par Victor Burin vers 1850 .

Graffite incomplet : Juis filiu dodranti

\section{Jto cuincuages}

Jtauo saturni

Jșodago

Lecture : Lambert, 1998-2000.

Bourquelot F., 1858 : «Antiquités de Châteaubleau », Bulletin de la Société impériale des Antiquaires de France, 1858, p. 160-162 (dessin).

CIL, XIII.1, 3019.

Lambert, 1998-2000, p. 117-118, fig. 1 (dessin) (indique une tuile par erreur).

77.4. Châteaubleau - La Tannerie

Huit fragments d'une mème tegula découverts en 1966 dans l'angle nord-ouest de la galerie du sanctuaire. Cette tuile était réutilisée dans un foyer tardif, daté de la seconde moitié du IVtes.

Graffite complet : $\quad$ ABCDIIFGHIKLMNOPQR

\section{STVX}

ABCD

Burin J.-P., 1966 : « L'alphabet gravé sur tuile de Châteaubleau ", Bulletin du Groupement archéologique de Seine-etMarne, 7, p. 21-26 et pl. II.

Lambert, 1998-2000, p. 119-120, fig. 2 (photo).

Lambert, 2002, p. 232-233, fig. $131^{\text {bis }}$ (photo).

77.5. Châteaubleau - La Tannerie

Tegula quasiment entière découverte en 1969 par G. Harlay dans l'angle intérieur sud-ouest du sanctuaire, à la base de la couche d'effondrement de la toiture de la galerie.

Graffite quasi complet :

[[ba]] bidṣe uenerianum adebriureco.[

r............cum • suaueloslan/

slanossiietum • suagido • cọntil.ossil

íe sittem • mongnatixsouịm

"Ceci est le seuil du fanum de Vénus, à Ebriurecon

... qui a un bon vent (?)

qu'il me guérisse (?), qui a bon visage (?)

... ma fille (ou mon fils)"

Lecture et traduction : Lambert, 2002.
Burin J.-P., 1969 : " Les chantiers de Châteaubleau en 1969 ", Bulletin du Croupement archéologique de Seine-et-Marne, 10, p. $105 \mathrm{et}$ pl. X.3.

Lambert, 1998-2000, p. 120-123, fig. 4 (photo) et fig. 5 (dessin). Lambert, 2002, p. 233-235, fig. 132 (photo et dessin).

77.6. Châteaubleau - La Tannerie

Fragment d'imbrex trouvé en 1974, devant le portail principal du sanctuaire, au milieu d'autres débris de tuiles.

Graffite incomplet : Josiet[

\section{Jontiacatolol \\ J.nno sunl}

Lecture : Lambert 2002.

Burin J.-P., 1982 : "Vingt ans de recherches archéologiques à Châteaubleau (1961-1981) ", in Trois fouilles récentes en Îlede-France : Saint-Étienne de Paris, Saint-Germain-des-Prés, Châteaubleau-en-Brie, Mairie annexe du IV' arr., Rotonde de la Villette, Délégation à l'action artistique de la ville de Paris, Commission du Vieux-Paris, p. 28, C 117.

Lambert, 1998-2000, p. 124, fig. 6 (photo et dessin).

Lambert, 2002, p. 236, fig. 133 (photo et dessin).

77.7. Châteaubleau - La Tannerie

Fragment (?) de tuile ou de brique découvert lors des fouilles de 1976.

Graffite : sorte de K.

Rapport de fouille 1976 de Burin, cité par Lambert, 1998-2000. Lambert, 1998-2000, p. 125.

77.8. Châteaubleau - La Tannerie

Fragment d'imbrex découvert lors des fouilles de 1976.

Graffite incomplet : sorte de $\mathrm{G}$ avec barrette très longue.

Rapport de fouille 1976 de Burin, cité par Lambert, 1998-2000.

Lambert, 1998-2000, p. 125.

77.9. Châteaubleau - La Tannerie

Fragment de tegula découvert lors des fouilles de 1981.

Graffite incomplet : Jius

$$
\text { Jạpenull }
$$

Lecture : Lambert, 1998-2000.

Lambert, 1998-2000, p. 126-127, fig. 8 (photo et dessin).

77.10. Châteaubleau - L'Aumône

Fragment de tegula trouvé en prospection en 1975.

Graffite incomplet: Jmelis

$$
\text { jumelis }
$$

Lecture : Lambert, 1998-2000.

Burin J.-P., 1982 : «Vingt ans de recherches archéologiques à Châteaubleau (1961-1981) ", in Trois fouilles récentes en Îlede-France : Saint-Étienne de Paris, Saint-Germain-des-Prés, Châteaubleau-en-Brie, Mairie anncxc du IV"arr., Rotondc dc la Villette, Délégation à l'action artistique de la ville de Paris, Commission du Vieux-Paris, p. 25, C 90.

Lambert, 1998-2000, p. 124-125, fig. 7 (photo).

77.11. Châteaubleau - L'Aumône

Fragment de brique découvert en 1990.

Graffite incomplet : PJriscianus

Lambert, 1998-2000, p. 128-129, fig. 10 (photo et dessin).

77.12. Châteaubleau - L'Aumône

Fragment de tuile trouvé en prospection en 1998.

Graffite incomplet : $\quad l l . . . . . c l$

Jninus[

jia..I 
Lecture : I ambert, 1998-2000.

Lambert, 1998-2000, p. 131, fig. 13 (photo).

77.13. Châteaubleau - la Justice

Fragment de tegula découvert lors des fouilles du sanctuaire en 1994.

Graffite incomplet : Sabine

iu Satu

$$
\text { Jtua }
$$

Lecture : Lambert, 1998-2000.

Parthuisot F., 1995 : " Châteaubleau, La Justice », Bilan scientifique de la région Ille-de-France, 1994, Direction régionale des Affaires culturelles Île-de-France, Service régional de l'archéologie, p. 56-57 (dessin).

Lambert, 1998-2000, p. 129, fig. 11 (dessin).

77.14. Châteaubleau - Le Bois de la Vigne

Quatre fragments d'une même tegula provenant du théâtre.

Trois d'entre eux ont été trouvés en 1968 dans les remblais du vomitoire sud. Le quatrième fragment, découvert en 1974, était inclus dans la maçonnerie d'un pilier de soutènement intérieur de l'édifice.

Graffite incomplet :

$\begin{array}{lllll}\text { dessin } & \text { dessin } & \text { dessin } & \text { dessin } & \text { dessin } \\ \text { buste } & \text { buste } & \text { buste } & \text { buste } & \text { buste } \\ \text { masc. } & \text { masc. } & \text { fém. } & \text { fém. } & \text { ind. }\end{array}$

Apullus Siusilu Sorl

Lecture : Lambert, 1998-2000.

Burin J.-P., 1970 : « Gravures sur tuiles découvertes à Châteaubleau ", Forum, Revue du groupe archéologique antique, Suppl. au $n^{\circ} 821$ de la revue du Touring Club de France, 1, p. 76-77 (photo des 3 premiers fragments découverts).

Burin J.-P., 1974 : «Ce que nous apprennent les tuiles romaines de Châteaubleau ", Archéologia, 72, p. 60-61 (photo des 4 fragments).

L ambert, 1998-2000, p. 120-121, fig. 3 (photo).

77.15. Châteaubleau - Les Grands Jardins

Fragment de tegula découvert en 1995.

Graffite incomplet : ].[

\section{decan}

Lecture : Lambert, 1998-2000.

Lambert, 1998-2000, p. 130, fig. 12 (photo et dessin).

77.16. Châteaubleau - I es Grands Jardins

Tegula entière découverte en 1997 dans un puits public (F25) ouvert à la fin du II" s., ou au cours du III" s., et qui aurait été comblé dans la première moitié du $\mathrm{IV}^{*} \mathrm{~s}$. Certaines formes paléographiques paraissent caractéristiques du II"s. (l ambert, 2002).

Graffite complet :

Nemnaliumi beni $\cdot$ ueionna incorobouido neíanmanbe gniiou apenitemeuelle íexsetesi sueregeniatu o quprinnopetamebissi íteta • mií íegumi • suante ueiommi petamassi Papissone suirexetesi ígiiinna anmanbe ieguisini siaxsiou beiiassunebiti moi upiiummiateri $x$ si indore core $\cdot$ Nuana íegumisini $\bullet$ beíiassusete sue cluio u sedagisamo cele uiro ínoue iiobiie beíiassusete Rega iexstumisendi me • setingi Papissonebeíassusetemetingise tingibeiiassuseteregarịse iexstumisendi
"Je célèbre une femme qui est fiancée avec dot de bétail (ou : qui est menée [au mariage] à Coro Bouido) ..." Lecture et traduction : Lambert, 1998-2000 et 2002.

Melmoth F., 1998-1999 : "Inscription romano-gauloise ", L'Archéologue. Archéologie nouvelle, 39, déc.janv., p. 47-48.

Lambert P.-Y., 1998-2000 : "I a tuile gauloise de Châtcaubleau (Seine-et-Marne) ", Études celtiques, XXXIV, p. 57-115.

Schrijver P., 1998-2000 : "The Châteaubleau Tile as a Link between Latin and French and between Gaulish and Brittonic ", Études celtiques, XXXIV, p. 135-142.

Lambert, 2002, p. 238-241, fig. 135 (photo et dessin).

77.17. Châteaubleau - Les Grands Jardins

Fragment de tegula découvert en 1998 dans une fosse rectangulaire (F3), mêlé à des rejets osseux.

Graffite incomplet: ]BCD[

]VX[

Lambert, 1998-2000, p. 131.

77.18. Pécy - Les Orbies

Neuf fragments d'une même tegula découverts en 1987 par P. Geslin sur l'emplacement d'une villa gallo-romaine dans la tranchée de l'oléoduc de la société Esso à l'est de la route D 209. Un des fragments, celui qui porte le début des lignes, ne se raccorde pas aux autres.

Graffite incomplet : Jurninos • (f)ecit

t[ Jclam CCCX

crl Jron - merçașil

cagrl Jliat gạllategla

fec [

" ]urninos a fait

310 tegulae

$\cdots$

$\cdots$

a fait..."

Lecture : Lambert, 2002.

Geslin P., 1993 : Brie antique, Le Mée-sur-Seine, éd. Amattéis, p. 14 (photo des 8 fragments qui se raccordent).

Lambert, 1998-2000, p. 127-128, fig. 9 (photo des 8 fragments qui se raccordent).

Lambert, 2002, p. 237, fig. 134 (photo des 8 fragments et dessin du $\left.9^{*}\right)$.

\section{1 - TARN}

\subsection{Saint-Martin-Laguépie - Sommard}

Deux tegulae ou briques (fragments ?) porteuses du même graffite découvertes lors de la fouille d'un atelier de potier et de tuilier antique menée par J.-M. et J.-F. Blanc de 1974 à 1980. L'atelier a succédé à un habitat du II $^{\mathrm{c}} \mathrm{s}$. et aurait fonctionné jusqu'au iv's.

Graffite complet : R

Blanc J.-M., Blanc J.-F., 1984 : " Les fours de tuiliers et potiers gallo-romains de Sommard, Saint-Martin-Laguépie, Tarn ", Archéologie tarnaise, 1, p. 11-12, pl. 2 (dessin).

Goulpcau L., Le Ny F., 1989 : “ Les marques digitées apposées sur les matériaux de construction gallo-romains en argile cuite ", RAO, 6, p. 118 et 120, fig. 5a (dessin). 


\section{3 - VAR}

Référence bibliographique commune à plusicurs graffites : Brun J.-P. arec la collab. de Borréani M., 1999 : Le Var; 83, Paris, Académic des inscriptions et belles-lettres (coll. (AG), 2 vol. 83.1. Seillons-Source-d'Argens - La Passasse et Fontette Tegula (entic̀re ?) découvcrtc cn 1976 lors de la fouille menée par F. Carrazé de quatre tombes à incinération du Haut-Empire. Cette tuile constituait le fond du coffrage de la tombe $n^{\circ} 3$.

Graffite complet (?) : OVID

Goudineau C., 1977 : "Informations archéologiques, circonscription de Côte d'Azur : Var, Seillons-Source-d'Argens ", Gallia, 35,2 , p. 503.

Brun, Borréani, 1999, p. 717.

83.2. Toulon - À l'angle des rues H.-Duprat et É.-Dauphin (ex-impasse Saint-joseph)

Tegula entière qui faisait partie de la couverture en bâtière d'une des deux tombes de l'Antiquité tardive découvertes en 1897. Graffite complet : $\quad$ A ou $\mathbf{F}$

Lecture : Brun, Borréani, 1999.

Vidal R., 1897 : "Archéologie du Var. Toulon, chef-licu d'arrondissement : origines ", Bulletin de l'Académie du Var, XX, p. 194196.

Brun, Borréani, 1999, p. 825, fig. 1046 (dessin).

83.3. Toulon - Impasse Saint-Andricux

Tegula (entière ?) qui faisait partic de la couverture en tuile d'une des tombes localisées aux abords de l'ancienne chapelle Saint-Andrieux. Ces tombes ont été observées par J. Roustan lors de travaux effectués durant la guerre 1939-1945.

Graffite complet: TR ou RT ou TS

Benoit F., 1943 : "Sépultures en tuiles ", Gallia, I, p. 284 (lecture : TS).

Brun, Borréani, 1999, p. 805 (lecture: TS).

83.4. Toulon - Notre-Dame-d'Entrevignes

Grand fragment de tegula qui faisait partie de la couverture en tuile d'une des cinq ou six tombes mises au jour en 1892 lors du creusement d'une tranchée entre la boulangerie de la marine et la prison maritime. Cette tuile fut recueillie par M. Zürcher, directeur des travaux maritimes de Toulon.

Graffite complet (?) : Castella

\section{ne ernio \\ se posede \\ recum}

Lecture : Héron de Villefosse.

Héron de Villefosse, 1892-1893 : Bulletin de la Société d'études scientifiques et archéologiques de Draguignan, XIX, p. XCIII.

Brun, Borréani, 1999, p. 829, fig. 1053 (photo).

\section{5 - VENDÉE}

\subsection{Noirmoutier-en-l'Île - Saint-Hilaire}

Tegula entière provenant du coffre en tuile de la tombe n" 16 de la nécropole mérovingienne implantée sur une villa galloromaine. Cette tuile a été découverte en 1975, au cours des fouilles dirigées par J.-Y. Prampart.

Graffite complet: $\quad \mathbf{S C A}$

\section{ECELSIA}

" la sainte église »
Vincent J.,1984 : "Le site de Saint-Hilaire dans l’île de Noirmoutier", Annuarire de la Société d"émulation de la Vendée, 131, p. 37.

Provost M., Hiernard J., Pascal J., Bernard E., SimonHiernard D., 1996 : La Vendée, 85, Paris, Académie des inscriptions et belles-lettres (coll. $C A(i)$, p. 165.

\section{6 - VIENNE}

86.1. Poitiers - Rue de l'Industrie

Deux fragments d'une même brique trouvés par $\mathrm{F}$. Bonsergent en 1863 " à côté d'un petit groupe sculpté en pierre de Charente, représentant un homme et une femme assis l'un près de l'autre" (Espérandieu, 1888, p. 357).

Graffite complet: Ateuritus

\section{Heuticae salutem}

hoc illei in cunno dessin d'un phallus

"Ateuritus

à Heutica : salut

ça pour elle, dans le con "

Quicherat J., 1863 : Bulletin de la Société impériale des Antiquaires de France, 1863, p. 137-138.

Mowat R., 1873 : "Un graffite conservé à Poitiers ", Bulletin de la Société nationale des Antiquaires de France, 1873, p. 82-91 (dessin).

Espérandieu É., 1888 : Épigraphie romaine du Poitou et de la Saintonge, Melle, Édouard Lacuve, p. 357-362 (dessin) (ne fait que citer Mowat, 1873).

86.2. Sanxay - Hameau de Herbord

Fragment de brique découvert lors des fouilles du sanctuaire de Sanxay par le R. P. Camille de La Croix entre 1881 à 1883.

Graffite incomplet : ]LLIVS ou ]ILLVS

Héron de Villefosse, 1884 : "Les inscriptions recueillies par le R. P. de La Croix dans les fouilles d'Herbord, dites de Sanxay ", Bulletin de la Société nationale des Antiquaires de France, 1884, p. 124.

Eygun F., 1944 : " Liste des objets recueillis à Sanxay par le R. P. de La Croix ", (callia, II, p. 117-118, n"92, fig. 26 (photo).

\section{7 - Haute-Vienne}

87.1. Limoges - Brachaud

Brique de colonnc en quart-de-rond trouvée lors des fouilles d'une villa gallo-romaine menées par J.-P. Loustaud de 1974 à 1987.

Graffite : XIII R ou X IIII R

Lecture : I.oustaud, 2000.

Loustaud J.-P., 2000 : Limoges antique, Suppl. n'5 aux Travaux d'archéologie limousine, p. 275.

\section{8 - VOSGES}

88.1. Grand - Terrain de Colin Coroy (à l'époque de la découverte)

Fragment de brique acheté par le muscé d'Épinal en 1869 à "Colin Coroy demeurant à Grand rue des Roises".

Graffite incomplet: nolite o iuuenes|

\section{Martiuillal}

nolite o i I 
« Gardez-vous, ô jeunes gens...

Martivilla...

Gardez-vous, ô jeunes gens... "

Thédenat, 1883 : "Inscription inédite, provenant de Grand (Vosges) ", Bulletin de la Société nationale des Antiquaires de France, 1883, p. 139-142 (dessin).

88.2. Grand - Fossé de l'enceinte au pied de la tour 21

Fragment de tegula découvert en 1968 par J. Guillaume et J.-P. Bertaux lors de la fouille d'une portion du fossé de l'enceinte du sanctuaire de Grand.

Graffite complet : $\mathbf{R}$

Le Ny F., 1992 : La production des matériaux de construction en terre cuite en Gaule romaine, thèse de $3^{r}$ cycle, univ. de Rennes I, vol. III, p. 493.
88.3. Liffol-le-Grand - Le chemin de la Goulotte

Nombreuses tegulae (entières et fragments), porteuses du même graffite, découvertes dans une tuilerie et un bâtiment gallo-romain fouillés durant quelques années à partir de 1954 par P. et J. Roussel et B. Counot. Ceux-ci datent la tuilerie de la première moitié du III $^{\mathrm{c}} \mathrm{s}$.

Graffite complet : $\mathbf{R}$

Le Ny F., 1988 : Les fours de tuiliers gallo-romains : méthodologie, étude technologique, typologique et statistique, chronologie, Paris, éd. de la Maison des sciences de l'homme (coll. DAF, 12), p. 89, $\mathrm{n}^{\circ} 117$.

Goulpeau L., Le Ny F., 1989 : « Les marques digitées apposées sur les matériaux de construction gallo-romains en argile cuite ", $R A O, 6$, p. 110, fig. 3d (photo) et p. 118 et 120, fig. 5a (dessin de deux exemplaires). 